UNIVERSIDADE DE SÃO PAULO

ESCOLA DE ENFERMAGEM

RITA DE CÁSSIA ALMEIDA VIEIRA

RECUPERAÇÃO DAS VÍTIMAS DE LESÃO AXONIAL DIFUSA E FATORES ASSOCIADOS

SÃo PAULO

2015 


\section{RECUPERAÇÃO DAS VÍTIMAS DE LESÃO AXONIAL DIFUSA E FATORES ASSOCIADOS}

Tese apresentada ao Programa de PósGraduação em Enfermagem na Saúde do Adulto da Escola de Enfermagem da Universidade de São Paulo para obtenção do título de Doutor em Ciências

Área de concentração: Enfermagem na Saúde do Adulto

Orientadora: $\operatorname{Prof}^{\mathrm{a}} . \quad \operatorname{Dr}^{\mathrm{a}} . \quad$ Regina Márcia Cardoso de Sousa 
AUTORIZO A REPRODUÇÃO TOTAL OU PARCIAL DESTE TRABALHO, POR QUALQUER MEIO CONVENCIONAL OU ELETRÔNICO, PARA FINS DE ESTUDO E PESQUISA, DESDE QUE CITADA A FONTE.

Assinatura: Data

Vieira, Rita de Cássia Almeida

Recuperação das vítimas de lesão axonial difusa e fatores associados / Rita de Cássia Almeida Vieira. São Paulo, 2015. $161 \mathrm{p}$.

Tese (Doutorado) - Escola de Enfermagem da Universidade de São Paulo.

Orientadora: Prof. ${ }^{a}$ Dr. ${ }^{a}$ Regina Márcia Cardoso de Sousa Área de concentração: Enfermagem na Saúde do Adulto

1. Ferimentos e lesões. 2. Índice de gravidade da doença. 3. Enfermagem. I. Título. 


\section{Nome: Rita de Cássia Almeida Vieira}

Título: Recuperação das vítimas de lesão axonial difusa e fatores associados.

Tese apresentada ao Programa de Pós-Graduação em Enfermagem na Saúde do Adulto PROESA da Escola de Enfermagem da Universidade de São Paulo para obtenção do título de Doutora em Ciências.

\section{Aprovada em:}

\section{Banca examinadora}

Nome:

Instituição:

Julgamento:

Assinatura:

Nome:

Instituição:

Julgamento:

Assinatura:

Nome:

Instituição:

Julgamento:

Assinatura:

Nome:

Instituição:

Julgamento:

Assinatura:

Nome:

Instituição:

Julgamento:

Assinatura: 


\section{DEDICATÓRIA}

Ao meu tesouro, minha vida, minha fonte de inspiração $e$ sabedoria... Daniel Filho! Para você e por você dedico esta conquista. Que Deus te ilumine sempre!

Ao meu alicerce, meu melhor amigo, meu conselheiro, meu companheiro, meu amante, meu cúmplice, ao grande amor da minha vida... Daniel Vieira! Obrigada por sempre estar ao meu lado, me incentivando e apoiando. Te amo muito!

Aos meus pais Júlio Vieira e Nélia Vieira, por semearem em mim o respeito ao próximo, pelo incentivo, pela ajuda no momento mais dificil e decisivo de minha vida! Sem sua ajuda, Pai, não teria conseguido. Obrigada por cuidarem do meu tesouro! 


\section{AGRADECIMENTOS}

A professora Doutora Regina Márcia Cardoso de Sousa, pela oportunidade de concretizar um sonho. Serei eternamente grata por todos os conselhos, ensinamentos, orientações e paciência. Foi uma honra trabalhar ao lado de alguém tão especial, competente e serena.

À Coordenação de Aperfeiçoamento de Pessoal de Nível Superior (CAPES) do Ministério da Educação (MEC), pela concessão da bolsa de doutorado para a realização desta pesquisa.

Aos Professores Doutores Wellingson Paiva e Almir Ferreira, por todo apoio, orientação, sugestão no Exame de Qualificação e auxílio no período de coleta de dados.

A Professora Doutora Ana Cristina Mancussi, pelas sugestões no Exame de Qualificação.

Aos Doutores Robson Amorim e Vinícius Guirado e aos residentes de neurocirurgia do HCFMUSP por toda disponibilidade e ajuda.

Aos meus avós Edildécio Vieira e Maria de Lourdes (in memoriam), pelo exemplo de força e pelo incentivo.

Às minhas irmãs Anne Vieira e Nair Vieira, aos meus tios Cantídio Vieira e Tereza Vieira e à minha irmã de coração Isabel Cavalcante, pela força, compreensão, incentivo, apoio e pela capacidade de acreditar em mim.

À minha amiga/irmã que o doutorado me presenteou, Karla Albuquerque. Obrigada por ser minha amiga, confidente, ouvinte, conselheira por todos esses anos. Nossa amizade cruzará fronteiras! 
Às amigas e doutoras Elaine Machado, Mariana Alvina, Mariana Cabral, Rafaela Andolhe, Karina Suzuki, Soraia Buchhorn, Tábatta Renata, Daniella Pires, Érika Guedes, Alda Graciele, Andréa Cascaes, Camila Quartim, Cassiane da Fonseca, em especial a Rafaela Queiroga, obrigada pelas risadas, pelos conselhos e pelos momentos especiais que vivemos nesses 4 anos.

Às Doutoras Cristina Setterval, Cristiane Domingues e à Professora Doutora Lilia Nogueira, por me receberem de braços abertos no grupo e permitirem que essa parceria e amizade fosse um sucesso. Obrigada pela disponibilidade, auxílio, ensinamentos e companhia ao longo dessa trajetória.

Aos amigos Eduesley Santana Santos $e$ Marco Corso Neto, por todo apoio, disponibilidade e carinho. Vocês são verdadeiros irmãos!

Às enfermeiras Roberta de Oliveira, Nencis dos Santos, Caroline Aguiar, Vívian Yagi e Verena Neumann e à futura enfermeira Gabriela Rodriguez pelo auxílio, empenho e dedicação especial na etapa de coleta de dados.

Às amigas do ambulatório Fabrícia Biudes e Flávia Verdugo, pelo aprendizado, apoio e companheirismo.

À coordenação de enfermagem do Hospital das Clínicas pela autorização na coleta. Estendo esses agradecimentos a todos enfermeiros $e$ à equipe de enfermagem do Hospital das Clínicas e do Ambulatório do Trauma, pela colaboração e acolhimento durante a coleta de dados.

À equipe da UTI do Trauma, UTI Clínica do $4^{o}$ andar $e 6^{\circ}$ andar, UCI, UAC, Sala de Trauma, Enfermaria do PS $5^{\circ}$ andar e $3^{\circ}$ andar, Enfermaria da Cirurgia Plástica do Hospital das Clínicas, pela colaboração, paciência e acolhimento durante a fase de coleta de dados. 
À Equipe do Ambulatório do Trauma do Hospital das Clínicas, pelo acolhimento, ajuda e colaboração durante a fase de coleta de dados.

Aos pacientes e familiares, por acreditarem neste trabalho $e$ por permitirem a participação na pesquisa em um momento de grande dor e sofrimento. Sem a participação de vocês isso não seria possível.

Ao Queni Winters, pela presteza na revisão de português; ao Bernardo dos Santos, pelo auxílio na estatística; e à Patrícia Ramos, pelo excelente trabalho de formatação.

Aos funcionários da Secretaria da PósGraduação, pelo apoio administrativo.

A todos os meus amigos, que sempre estiveram ao meu lado, me apoiando nesta trajetória.

A todos aqueles que, direta ou indiretamente, colaboraram para a concretização deste sonho. 
Vieira RCA. Recuperação das vítimas de lesão axonial difusa e fatores associados. São Paulo: Escola de Enfermagem, Universidade de São Paulo; 2015.

\section{RESUMO}

Introdução: A lesão axonial difusa (LAD) se destaca entre os ferimentos traumáticos pela gravidade de suas consequências. Entretanto, são poucas as pesquisas que descrevem a recuperação das vítimas e os fatores associados às consequências dessa lesão. Ampliar o conhecimento nessa área é relevante para introduzir novas técnicas na assistência prestada, planejar tratamentos e monitorar a evolução das vítimas. Objetivo: Descrever a recuperação das vítimas com diagnóstico principal de LAD até 6 meses após trauma e identificar fatores sociodemográficos e clínicos associados a óbito e dependência aos 6 meses após a lesão. Método: Estudo do tipo coorte prospectivo, com dados coletados na internação, alta hospitalar, 3 e 6 meses após a LAD. Fizeram parte do estudo vítimas de LAD com idade $\geq 18$ anos e $\leq 60$ anos, admitidas no Hospital das Clínicas da Faculdade de Medicina da Universidade de São Paulo no período de julho de 2013 a fevereiro de 2014, com escore na escala de coma de Glasgow (ECGl) $\leq 8$. A recuperação das vítimas de LAD foi analisada pelas diferenças dos resultados da aplicação da escala de Katz e escala de resultados de Glasgow ampliada (ERGA) em 3 períodos de avaliação (alta, 3 e 6 meses após LAD). Foram testadas associações entre variáveis de interesse e óbito, além de dependência até avaliação final. A regressão logística múltipla foi utilizada para identificar modelos para esses desfechos. Resultados: A casuística compôs-se de 78 vítimas com idade média de 32 anos $(\mathrm{dp}=11,9), 83,3 \%$ envolvida em acidentes de transporte e $89,7 \%$ do sexo masculino. A média do Injury Severity Score foi de 35,0 $(\mathrm{dp}=11,9)$ e do New Injury Severity Score (NISS), 46,2 (dp=15,9). Para a Maximum Abbreviated Injury Scale/cabeça, a média foi de 4,6 (dp=0,5). LAD leve foi observada em $44,9 \%$ das vítimas e a grave em 35,9\%. Até 6 meses, 30,8\% das vítimas foram a óbito e a pontuação média na ERGA dos sobreviventes evoluiu de 3,8 $(\mathrm{dp}=1,2)$ na alta para $2,1(\mathrm{dp}=1,6)$ aos 3 meses e 1,2 $(\mathrm{dp}=1,6)$ na avaliação final. Para a escala de Katz, as médias foram de $8,5(d p=5,5)$ na alta, de $3,2(d p=5,5)$ aos 3 meses e $1,8(d p=4,5)$ aos 6 
meses. Diferenças estatisticamente significativas foram observadas na comparação dos resultados de todos os tempos. Apresentaram significância estatística no modelo de regressão logística para óbito as variáveis de gravidade da LAD com hipóxia pela $\mathrm{SpO}_{2}$ e hipotensão com NISS; para dependência, a gravidade da LAD e tempo de internação hospitalar permaneceram no modelo isoladamente. Conclusões: Foi elevada a mortalidade; entretanto, a grande maioria dos sobreviventes alcançou condições condizentes com vida independente aos 6 meses. Nesse período, a recuperação das vítimas foi expressiva, ainda que mais acentuada nos 3 primeiros meses. A LAD grave destacou-se como fator de risco para óbito e dependência. A quase totalidade das vítimas com essa lesão morreu ou estava dependente aos 6 meses após trauma. Como fatores de risco para óbito, também foram identificados o NISS, a hipóxia pela $\mathrm{SpO}_{2}$ e a hipotensão e, para dependência, o tempo de internação hospitalar.

PALAVRAS-CHAVE: Lesão axonal difusa. Escala de resultado de Glasgow. Ferimentos e lesões. Índices de gravidade do trauma. 
Vieira RCA. Outcome of diffuse axonal injury victims and associated factors. São Paulo: Escola de Enfermagem, Universidade de São Paulo; 2015 .

\section{ABSTRACT}

Introduction: Diffuse axonal injury (DAI) stands out from other traumatic injuries because of the severity of its consequences. However, few studies describe outcome and the factors associated to outcome of this type of injury. Enhance knowledge in this area is important to introduce new techniques in the delivery of care, treatment planning and to monitor the recovery of DAI. Objective: Describe outcome of victims with primary diagnosis of DAI 6 months after trauma and identify sociodemographic and clinical factors associated to mortality and dependence 6 months after injury. Method: Prospective cohort study with data from admission, discharge, 3 and 6 months after DAI. Participants were DAI victims aged $\geq 18$ years and $\leq 60$ years old, admitted to the Hospital das Clínicas da Universidade de São Paulo from July 2013 to February 2014, with a Glasgow Coma Scale (GCS) $\leq 8$. The outcome of victims was analyzed by the differences found between the results of the Katz scale and the Extended Glasgow Outcome scale (GOS-E) in three different periods (discharge, 3 and 6 months after DAI). Associations between variables of interest and mortality, and dependence to final evaluation were tested. Multiple logistic regression was applied to identify models of these outcomes. Results: The sample consisted of 78 victims with an average age of 32 years $(\mathrm{SD}=11.9)$, $83.3 \%$ involved in traffic accidents, and $89.7 \%$ were male. The mean Injury Severity Score was $35.0(\mathrm{SD}=11.9)$ and the New Injury Severity Score (NISS) was $46.2(\mathrm{SD}=15.9)$. For the Maximum Abbreviated Injury Scale/head, the average was $4.6(\mathrm{SD}=0.5)$. Mild DAI was observed in $44.9 \%$ of the victims and severe DAI was observed in $35.9 \%$. Up to 6 months, $30.8 \%$ of the victims died and the average score in GOS-E survivors increased from $3.8(\mathrm{SD}=1.2)$ at discharge to $2.1(\mathrm{SD}=1.6)$ at 3 months and $1.2(\mathrm{SD}=1.6)$ at the final evaluation. According to Katz scale, the average was $8.5(\mathrm{SD}=5.5)$ at discharge, $3.2(\mathrm{SD}=5.5)$ at 3 months and $1.8(\mathrm{SD}=4.5)$ at 6 months. Statistically significant differences were observed comparing the results from all periods. In the regression model for mortality 
the variables of DAI severity with hypoxia by $\mathrm{SpO}_{2}$ and hypotension with NISS were statistically relevant; for dependence, the DAI severity and the hospitalization period remained in the model alone. Conclusions: Besides the high mortality, the vast majority of survivors reached conditions consistent with independent living at 6 months after injury. During this period, the recovery of victims was increased, although more pronounced in the first 3 months. Severe DAI stood out as a risk factor for mortality and dependence. Almost all the victims died or were dependent six months after trauma. NISS, hypoxia by $\mathrm{SpO}_{2}$ and hypotension were also identified as risk factors related to mortality; the length of hospitalization was identified as a risk factor related to dependence on outcome.

KEY-WORDS: Diffuse axonal injury. Glasgow Outcome Scale. Injuries and lesions. Trauma severity scores. 


\section{LISTA DE ILUSTRAÇÕES}

Figura 1 - Vítimas de LAD segundo gravidade do trauma estimada pelo ISS. HCFMUSP, 2013-2014. 63

Figura 2 - Vítimas de LAD segundo gravidade do trauma estimada pelo NISS. HCFMUSP, 2013-2014. 63

Figura 3 - Vítimas de LAD segundo gravidade do TCE estimada pelo MAIS/cabeça. HCFMUSP, 2013-2014

Figura 4 - Vítimas de LAD segundo gravidade dessa lesão. HCFMUSP, 2013-2014. 64

Figura 5 - Vítimas de LAD segundo escores na RASS 24 horas antes da retirada da sedação. HCFMUSP, 2013-2014. 68

Figura 6 - Evolução do escore médio da ECGl das vítimas de LAD. HCFMUSP, 2013-2014. 69

Figura 7 - Vítimas de LAD segundo o número de eventos de hipotensão, hipotermia e hipoglicemia durante internação hospitalar. HCFMUSP, 20132014

Figura 8 - Vítimas de LAD segundo o número de eventos de hipertensão, hipertermia e hiperglicemia durante internação hospitalar. HCFMUSP, 2013-2014.

Figura 9 - Vítimas de LAD segundo realização de tratamentos em especialidades da aérea de saúde entre a alta do IC/HCFMUSP e seis meses após o trauma. HCFMUSP, 2013-2014. 71

Figura 10 - Médias das pontuações nas escalas de Katz e ERGA entre a alta do IC/HCFMUSP e seis meses após LAD. HCFMUSP, 2013-2014 .72

Figura 11 - Médias das pontuações nos itens da escala de Katz entre a alta do IC/HCFMUSP e 6 meses após LAD. HCFMUSP, 2013-2014 .74

Figura 12 - Vítimas de LAD aos 6 meses após trauma segundo capacidade funcional pela ERGA. HCFMUSP, 2013-2014. 
Figura 13 - Vítimas de LAD segundo categorias da escala de Katz aos 6 meses após o trauma por itens da escala. HCFMUSP, 2013-2014 .............. 82 


\section{LISTA DE TABELAS}

Tabela 1 - Ensaio clínico com uso de progesterona - revisão bibliográfica sobre recuperação de vítimas de LAD. São Paulo, 2014. 34

Tabela 2 - Recuperação de vítimas de LAD aos 6 meses - revisão bibliográfica. São Paulo, 2014. 36

Tabela 3 - Recuperação de vítimas de LAD após um ano - revisão bibliográfica. São Paulo, 2014. 37

Tabela 4 - Descrição de estudos publicados sobre recuperação das vítimas de LAD avaliadas após o seguimento. São Paulo, 2014. 38

Tabela 5 - Vítimas de LAD segundo características sociodemográficas na época do trauma. HCFMUSP, 2013-2014. 60

Tabela 6 - Vítimas de LAD segundo características relacionadas ao trauma e APH. HCFMUSP, 2013-2014.....

Tabela 7 - Vítimas de LAD segundo características clínicas na admissão hospitalar. HCFMUSP, 2013-2014.

Tabela 8 - Vítimas de LAD segundo características clínicas na internação hospitalar. HCFMUSP, 2013-2014.

Tabela 9 - Vítimas de LAD segundo mortalidade e destino após alta do IC/HCFMUSP. HCFMUSP, 2013-2014. .71

Tabela 10 - Vítimas de LAD segundo categorias da ERGA nos períodos de avaliação. HCFMUSP, 2013-2014. .72

Tabela 11 - Comparações múltiplas dos resultados da ERGA entre a alta do IC/HCFMUSP e seis meses após LAD. HCFMUSP, 2013-2014. .73

Tabela 12 - Estatísticas descritivas e comparação das pontuações na escala de Katz entre a alta do IC/HCFMUSP e seis meses após LAD. HCFMUSP, 2013-2014. .73

Tabela 13 - Comparações múltiplas dos resultados da escala de Katz entre a alta do IC/HCFMUSP e seis meses após LAD. HCFMUSP, 2013-2014....73

Tabela 14 - Vítimas de LAD segundo categorias do item "tomar banho" da escala de Katz nos períodos de avaliação. HCFMUSP, 2013-2014. ...........75

Tabela 15 - Comparações múltiplas das médias do item "tomar banho" da escala de Katz entre a alta do IC/HCFMUSP e 6 meses após LAD. HCFMUSP, 2013-2014. .75

Tabela 16 - Vítimas de LAD segundo categorias do item "vestir-se" da Katz nos períodos de avaliação. HCFMUSP, 2013-2014. .75

Tabela 17 - Comparações múltiplas das médias do item "vestir-se" da escala de Katz entre a alta do IC/HCFMUSP e 6 meses após LAD. HCFMUSP, 2013-2014. .76

Tabela 18 - Vítimas de LAD segundo categorias do item "cuidado pessoal" da escala de Katz nos períodos de avaliação. HCFMUSP, 2013-2014........76 
Tabela 19 - Comparações múltiplas das médias do item "cuidado pessoal" da escala de Katz entre a alta do IC/HCFMUSP e 6 meses após LAD. HCFMUSP, 2013-2014.

Tabela 20 - Vítimas de LAD segundo categorias do item "realizar transferência" da Katz nos períodos de avaliação. HCFMUSP, 2013-2014.

Tabela 21 - Comparações múltiplas das médias do item "realizar transferência" da escala de Katz entre a alta do IC/HCFMUSP e 6 meses após LAD. HCFMUSP, 2013-2014. .77

Tabela 22 - Vítimas de LAD segundo categorias do item "necessidades urinárias" da escala de Katz nos períodos de avaliação. HCFMUSP, 20132014 .78

Tabela 23 - Comparações múltiplas das médias do item "necessidades urinárias" da escala de Katz entre a alta do IC/HCFMUSP e 6 meses após LAD. HCFMUSP, 2013-2014. .78

Tabela 24 - Vítimas de LAD segundo categorias do item "alimentar-se" da escala de Katz nos períodos de avaliação. HCFMUSP, 2013-2014. ...........78

Tabela 25 - Comparações múltiplas das médias do item "alimentar-se" da escala de Katz entre a alta do IC/HCFMUSP e 6 meses após LAD. HCFMUSP, 2013-2014. .79

Tabela 26 - Vítimas de LAD segundo a evolução pela ERGA após o trauma. HCFMUSP, 2013-2014. .79

Tabela 27 - Vítimas de LAD que não alcançaram pontuação máxima na escala de Katz até alta do IC/HCFMUSP $(n=45)$ segundo evolução após o trauma. HCFMUSP, 2013-2014. 80

Tabela 28 - Estatísticas descritivas e comparações entre mortos e vivos aos 6 meses após LAD em relação a idade, anos de escolaridade e renda per capita familiar (R\$) na época do trauma. HCFMUSP, 2013-2014. 83

Tabela 29 - Comparações entre mortos e vivos aos 6 meses após LAD em relação a gênero, raça, vínculo conjugal e situação ocupacional na época do trauma. HCFMUSP, 2013-2014.

Tabela 30 - Comparações entre mortos e vivos aos 6 meses após LAD em relação a características relacionadas ao trauma e APH. HCFMUSP, 20132014.

Tabela 31 - Estatísticas descritivas e comparações entre mortos e vivos aos 6 meses após LAD em relação a gravidade do trauma (ISS, NISS) e TCE (MAIS/cabeça). HCFMUSP, 2013-2014.

Tabela 32 - Comparação entre mortos e vivos aos 6 meses após trauma em relação à gravidade da LAD. HCFMUSP, 2013-2014. 85

Tabela 33 - Comparações entre mortos e vivos aos 6 meses após LAD em relação às características na admissão hospitalar. HCFMUSP, 2013-2014. 85 
Tabela 34 - Estatísticas descritivas e comparação entre mortos e vivos aos 6 meses após LAD em relação a ECGl na admissão. HCFMUSP, 2013-2014.

Tabela 35 - Comparações entre mortos e vivos aos 6 meses após LAD em relação às características relacionadas à internação hospitalar. HCFMUSP, 2013-2014.

Tabela 36 - Estatísticas descritivas e comparações entre mortos e vivos aos 6 meses após LAD em relação a características relacionadas à internação hospitalar. HCFMUSP, 2013-2014. 89

Tabela 37 - Modelo de regressão logística dos fatores de risco para óbito até seis meses após LAD. HCFMUSP, 2013-2014. 90

Tabela 38 - Modelo de regressão logística dos fatores de risco para óbito até 6 meses após LAD excluindo a gravidade dessa lesão. HCFMUSP, 20132014. 91

Tabela 39 - Estatísticas descritivas e comparações entre independentes e dependentes aos 6 meses após LAD em relação a idade, anos de escolaridade e renda per capita familiar ( $R \$$ ) na época do trauma. HCFMUSP, 2013-2014. .92

Tabela 40 - Comparações entre independentes e dependentes aos 6 meses após LAD em relação a gênero, raça, vínculo conjugal e situação ocupacional na época do trauma. HCFMUSP, 2013-2014. .92

Tabela 41 - Comparações entre independentes e dependentes aos 6 meses após LAD em relação a características relacionadas ao trauma e APH. HCFMUSP, 2013-2014. .93

Tabela 42 - Estatísticas descritivas e comparações entre dependentes e independentes aos 6 meses após LAD em relação a gravidade do trauma (ISS, NISS) e TCE (MAIS/cabeça). HCFMUSP, 2013-2014 93

Tabela 43 - Comparação entre independentes e dependentes aos 6 meses após trauma em relação à gravidade da LAD. HCFMUSP, 2013-2014 .....94

Tabela 44 - Comparações entre independentes e dependentes aos 6 meses após LAD em relação às características na admissão hospitalar. HCFMUSP, 2013-2014.

Tabela 45 - Estatísticas descritivas e comparação entre independentes e dependentes aos 6 meses após LAD em relação a ECGl na admissão. HCFMUSP, 2013-2014. .95

Tabela 46 - Comparações entre independentes e dependentes aos 6 meses após LAD em relação às características relacionadas à internação hospitalar. HCFMUSP, 2013-2014. 96

Tabela 47 - Estatísticas descritivas e comparação entre dependentes e independentes aos 6 meses após LAD em relação a características relacionadas à internação. HCFMUSP, 2013-2014.

Tabela 48 - Modelo de regressão logística dos fatores de risco para dependência aos 6 meses após LAD. HCFMUSP, 2013-2014. 
Tabela 49 - Modelo de regressão logística dos fatores de risco para dependência aos 6 meses após LAD excluindo a gravidade dessa lesão.

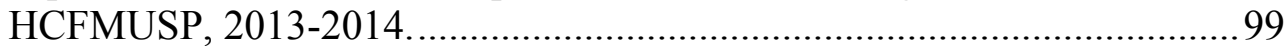




\section{LISTA DE ABREVIATURAS}

AIS

ANOVA

$\mathrm{APH}$

AVD

BPM

DP

DRS

ECGl

ERG

ERGA

FC

FR

HCFMUSP

HIC

IC

IC/HCFMUSP

IOT

IRPM

ISS

LAD

MAIS

MRM

NISS

OR

PAS

PIC

$\mathrm{PO}_{2}$

RASS

RGHC

$\mathrm{RM}$

$\mathrm{SNC}$

$\mathrm{SpO}_{2}$

SPSS

TC

TCE

TCLE

UTI
Abbreviated Injury Scale

Análise de Variância

Atendimento Pré-Hospitalar

Atividades da Vida Diária

Batimentos por Minuto

Desvio Padrão

Disability Rating Scale

Escala de Coma de Glasgow

Escala de Resultados de Glasgow

Escala de Resultados de Glasgow Ampliada

Frequência Cardíaca

Frequência Respiratória

Hospital das Clínicas da Faculdade de Medicina da Universidade de São Paulo

Hipertensão Intracraniana

Intervalo de Confiança

Instituto Central do Hospital das Clínicas da

Faculdade de Medicina da Universidade de São

Paulo

Intubação Orotraqueal

Incursões Respiratórias por Minuto

Injury Severity Score

Lesão Axonial Difusa

Maximum Abbreviated Injury Scale

Melhor Resposta Motora

New Injury Severity Score

Odds Ratio

Pressão Arterial Sistólica

Pressão Intracraniana

Pressão Parcial de Oxigênio

Richmond Agitation and Sedation Scale

Número de Registro do Hospital das Clínicas

Ressonância Magnética

Sistema Nervoso Central

Saturação Periférica de Oxigênio

Software Statistical Package for the Social

Sciences

Tomografia Computadorizada

Trauma Cranioencefálico

Termo de Consentimento Livre Esclarecido

Unidade de Terapia Intensiva 


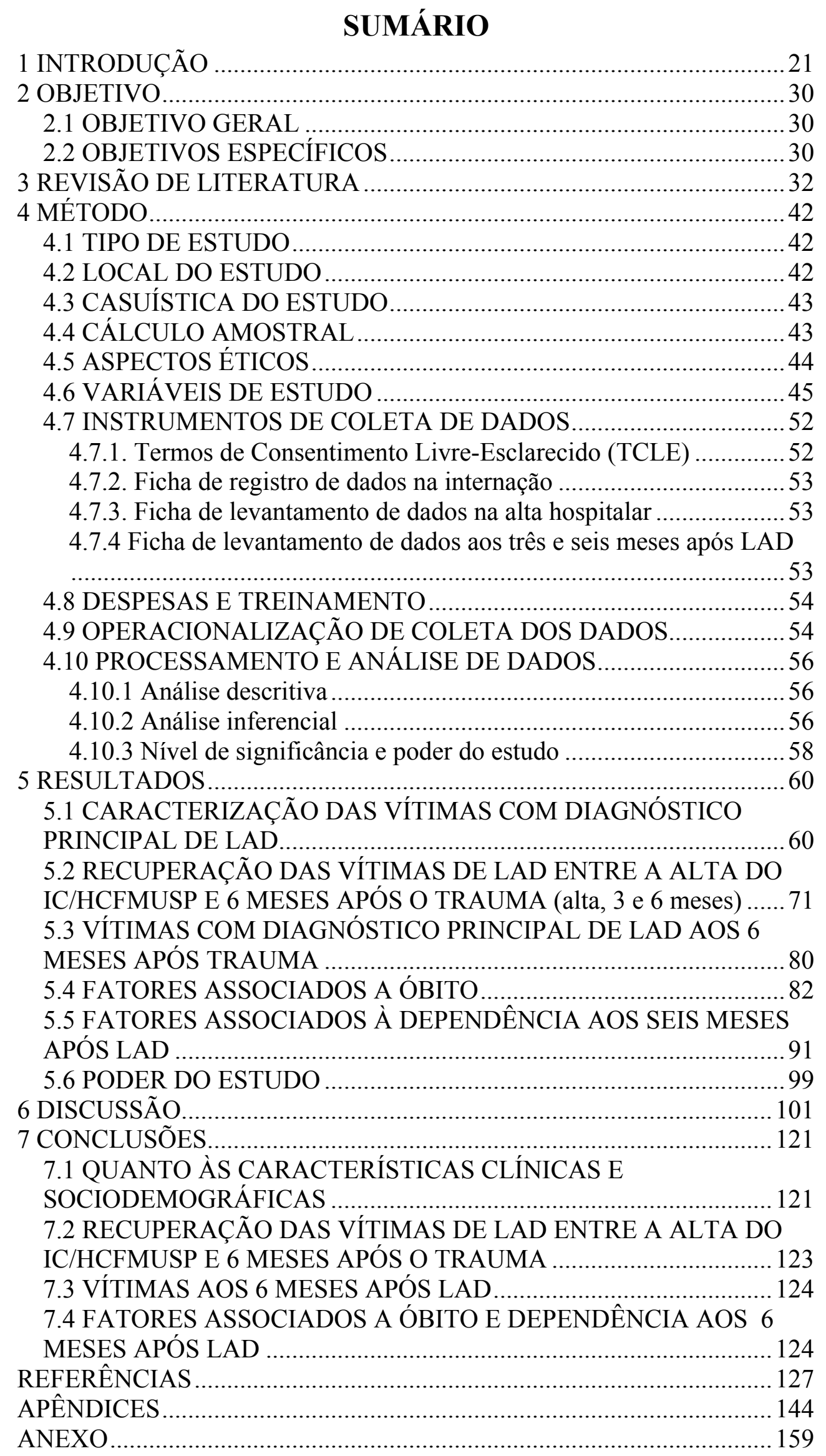




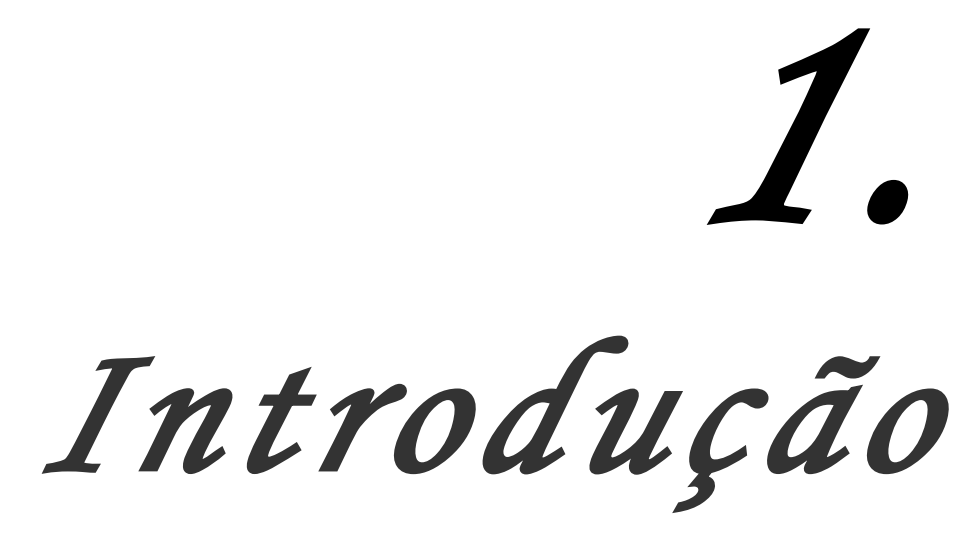




\section{INTRODUÇÃO}

A lesão axonial difusa (LAD) é uma lesão microscópica dos axônios nos tratos dos hemisférios cerebrais, corpo caloso e tronco encefálico, associada com importante mortalidade e morbidade. As consequências dessa lesão são causadas pelo rompimento do axônio do corpo celular e interrupção do impulso da célula nervosa. A LAD é uma lesão cerebral traumática resultante da rotação do encéfalo e deslocamento diferente das substâncias cinzenta e branca. Consequentemente, a presença de LAD depende do mecanismo do trauma, sendo mais frequente no trauma de maior energia, especialmente em acidentes de trânsito ${ }^{(1-3)}$.

A LAD é definida clinicamente por coma com duração de seis horas ou mais após trauma cranioencefálico (TCE), excluindo-se os casos de lesões encefálicas expansivas ou isquêmicas ${ }^{(1-2)}$. O coma é reconhecido no paciente pelo estado de inconsciência no qual o indivíduo apresenta incapacidade de realizar abertura ocular, pronunciar palavras e obedecer comandos simples ${ }^{(4)}$.

Gennarelli (1987, 1993) propôs que as lesões difusas sejam classificadas em concussão leve ou clássica e LAD leve, moderada ou grave $^{(1-2)}$. A concussão leve engloba os casos com distúrbios neurológicos reversíveis sem perda de consciência. A concussão clássica é definida como perda de consciência com duração de até seis horas e é associada com amnésia pós-traumática. Na LAD leve, o coma tem duração de 6 a 24 horas. $\mathrm{Na}$ LAD moderada, o coma possui duração superior a 24 horas, porém não é acompanhado de postura patológica. Nos casos graves de LAD, a duração do coma é superior a 24 horas e também se observam sinais de comprometimento do tronco encefálico, como descerebração, decorticação, hipertensão arterial, hipertermia e hiper-hidrose ${ }^{(1-2)}$.

Para determinar o grau de comprometimento encefálico das vítimas, a avaliação inicial inclui a aplicação da Escala de Coma de Glasgow (ECGl) e a busca de sinais de comprometimento do tronco encefálico. Esses parâmetros são usados como medida clínica e objetiva 
para avaliar a gravidade tanto do TCE como da LAD e são utilizados como um guia na seleção dos exames diagnósticos nos casos de lesões neurológicas ${ }^{(5)}$.

A tomografia computadorizada (TC) é o exame de eleição para avaliação precoce e classificação de gravidade das vítimas de TCE. Apesar de ser bastante utilizado na sala de emergência, este exame possui baixa sensibilidade no diagnóstico de $\operatorname{LAD}^{(6-8)}$ e, atualmente, a ressonância magnética (RM) é o método não invasivo mais indicado para o esclarecimento desse diagnóstico ${ }^{(7-8)}$. Entretanto, a RM não é amplamente utilizada na sala de emergência devido à condição instável do paciente, longa duração do exame, necessidade de cooperação do doente em relação à imobilidade durante sua realização e alto custo.

A realização da TC crânio na sala de emergência pode resultar na observação de alguma imagem sugestiva de LAD ou indicação de nenhuma alteração cerebral, mesmo na presença desse tipo de lesão. Atualmente, a RM é utilizada após a fase inicial do tratamento do trauma nas vítimas com quadro clínico sugestivo de LAD para confirmar o diagnóstico, quando a TC não evidencia nenhuma lesão cerebral e para avaliar o grau de atrofia cerebral $^{(7)}$.

Em estudo ${ }^{(8-9)}$ com 55 vítimas de TCE contuso, que não necessitaram de neurocirurgia imediata, porém apresentaram alteração de consciência e ou déficit focal, detectou-se LAD pela TC em apenas um paciente $(1,8 \%)$ ante $28(50,9 \%)$ pela RM. Nessa investigação, no período de até 5 dias após TCE, os participantes foram submetidos a TC e RM; portanto, foi frequente encontrar, nos primeiros dias após o trauma, exames tomográficos normais e imagens sugestivas da LAD na RM. Em pesquisa realizada com 124 casos de $\mathrm{LAD}^{(10)}$, a TC foi suficiente para diagnosticar precocemente essa lesão em 31 pacientes (25,0\%); nas demais vítimas, a RM foi necessária para definir esse diagnóstico. Conclui-se, desta forma, que, embora a TC de crânio permaneça como o principal exame diagnóstico nas vítimas de TCE, a RM pode contribuir para a elucidação de déficits neurológicos não explicados pela TC. 
A LAD é considerada o fator mais importante para a determinação da morbimortalidade nas vítimas de TCE, além de ser a causa mais comum de coma pós-traumático, de incapacidades e de estado neurovegetativo persistente $^{(1-2)}$. Essas consequências da lesão permanecem além da fase aguda do tratamento, estendendo-se e modificando-se por um longo período após o evento traumático, visto que o tecido cerebral pode estar funcionalmente prejudicado, mas não destruído, podendo gradualmente retomar a função normal, conforme ocorre a estabilização do estado clínico e a remodelagem das conexões neurais em razão da plasticidade encefálica $^{(11-12)}$.

Por conseguinte, o tempo após TCE relaciona-se com as consequências pós-traumáticas e a recuperação do trauma é um processo dinâmico, dependente do tempo, com evolução relativamente prolongada. Observações clínicas em vítimas de TCE têm sugerido melhora durante o primeiro ano, sobretudo durante os primeiros seis meses, havendo após esse período a estabilização do processo de recuperação ${ }^{(13-14)}$.

Conhecer o padrão de recuperação após uma lesão encefálica auxilia a suprir lacunas do conhecimento do processo fisiopatológico no transcorrer da recuperação cerebral e identificar precocemente vítimas que não apresentam a recuperação esperada. É também relevante para avaliação do resultado de novas técnicas e tratamentos a fim de minimizar a intensidade das incapacidades, visto que a introdução dessas intervenções deve trazer melhor recuperação do que é regularmente observado. Além disso, conhecer o padrão de recuperação possibilita prever recursos para assistência integral a esses pacientes, avaliar o cuidado prestado e contribuir para o desenvolvimento de uma assistência sistematizada voltada à reabilitação das vítimas ${ }^{(15-20)}$.

Em vista disso, a fisiopatologia das deficiências após TCE e os mecanismos envolvidos na recuperação são objetos de investigações que oferecem a base para direcionar os programas de reabilitação e orientar o desenvolvimento de terapia individualizada após esse tipo de trauma ${ }^{(21)}$.

A comparação dos resultados de exames de $\mathrm{RM}$ realizados em vítimas de LAD, no período de até 7 dias, 3 e 12 meses após o trauma, 
evidenciou que muitas imagens de lesões encefálicas desaparecem no primeiro ano após a $\mathrm{LAD}$; entretanto, não foi verificada associação entre esta melhora e o processo de recuperação clínica, após ajuste dos dados para outros fatores prognósticos. Os autores concluíram que somente achados precoces na RM auxiliam a predizer resultados clínicos e que esse exame realizado tardiamente depois do TCE pode falhar nesse propósito ${ }^{(22)}$. Portanto, a avaliação clínica das consequências pós-traumáticas parece soberana no estudo da recuperação após LAD, mesmo que relações entre imagens da RM e incapacidades sejam observadas no período inicial póstrauma ${ }^{(22-24)}$.

Com o intuito de identificar a funcionalidade das vítimas de lesão cerebral e caracterizar sua recuperação, alguns instrumentos são aplicados. Os mais utilizados para essas finalidades são a Escala de Resultados de Glasgow (ERG) e a Disability Rating Scale (DRS). Na aplicação destas escalas, a DRS tem se mostrado mais sensível que a ERG original para avaliar vítimas de TCE grave e mais sequeladas; entretanto, na literatura científica, a ERG é mais utilizada que a DRS para avaliar a recuperação das vítimas de $\operatorname{LAD}^{(23,25-29)}$.

Além disso, a ERG apresenta uma versão ampliada que permite equiparar seus resultados com os da versão original. A Escala de Resultados de Glasgow Ampliada (ERGA) oferece, portanto, a possibilidade de comparar seus resultados com investigações que utilizam a escala original e, concomitantemente, é mais sensível para evidenciar mudanças nas vítimas, visto que divide as categorias boa recuperação, incapacidade moderada e grave da ERG original em duas subcategorias. Sendo assim, a ERGA tem oito categorias perante as cinco de sua versão original. Em relação à DRS, a ERGA apresenta maior sensibilidade para detectar mudanças na condição das vítimas com leves consequências pós-traumáticas ${ }^{(26)}$.

Algumas pesquisas que analisam vítimas de $\mathrm{LAD}$ vêm utilizando a ERG com o objetivo de caracterizar as consequências dessa lesão em diferentes condições clínicas ${ }^{(23,27-28)}$. Estudo ${ }^{(27)}$ que avaliou a funcionalidade por meio da ERG em 65 casos de LAD, após 6 meses do trauma (entre 185 e 445 dias), mostrou que as vítimas sem hipopituitarismo apresentaram 
melhores resultados funcionais quando comparadas às que adquiriram essa insuficiência com o TCE $(\mathrm{p}=0,043)$. Utilizando a ERG como escala numérica e não categórica, o valor médio da pontuação no total de participantes desta pesquisa foi de 3,17. Nos grupos com e sem hipopituitarismo, esse valor foi de 2,86 e 3,37, respectivamente. Apesar dessa diferença, houve ausência de indivíduos que apresentaram boa recuperação nos dois grupos (ERG variou de 1 a 4) e os escores médios indicaram, em geral, quadros clínicos de grave incapacidade.

Chelly et al. (2011) estudaram retrospectivamente dados demográficos, clínicos, biológicos e radiológicos de 124 casos de LAD admitidos em Unidade de Terapia Intensiva (UTI) e acompanharam essas vítimas por um tempo médio de 12,3 meses, variando de 3 a 51 meses $^{(10)}$. A consequência global do trauma para cada paciente foi avaliada pela ERG e os resultados mostraram desfechos desfavoráveis em 64 pacientes: 53 morreram, 3 permaneceram em estado vegetativo persistente e 8 tiveram grave incapacidade. No entanto, os demais apresentaram boa recuperação.

Pesquisa $^{(28)}$ que investigou 32 pacientes com lesões não hemorrágicas detectadas em RM mostrou que 15 pacientes apresentaram escore inicial na ECGl $\leq 7$ em decorrência do TCE e 17 tiveram escore de 8 a 15. Os resultados da ERG indicaram 15 pacientes com boa recuperação, 4 com incapacidade moderada, 8 com incapacidade grave e 5 em estado neurovegetativo persistente.

Os resultados dessas pesquisas que aplicaram a ERG mostram piores consequências da LAD para suas vítimas, quando comparados com os apresentados em investigações com vítimas de TCE grave em geral ${ }^{(30-32)}$. Para avaliar consequências do trauma, além de escalas de funcionalidade, alguns estudos analisam o desempenho para realizar as atividades da vida diária (AVD). No campo do estudo da recuperação da lesão cerebral traumática, pesquisadores têm argumentado que descrever o perfil de capacidade nas AVD é relevante para documentar a independência das vítimas e os déficits para realização de funções executivas em tarefas $\operatorname{cotidianas}^{(33-34)}$. 
Entre as escalas que avaliam as AVD, destaca-se a Escala de $\mathrm{Katz}^{(35-36)}$. Esta escala avalia seis funções das AVD: tomar banho, vestir-se, cuidado pessoal, realizar transferência, necessidades urinárias e alimentar$\mathrm{se}^{(35-36)}$. O somatório dos escores dos domínios da escala alcança, no máximo, 18 pontos e o valor total zero indica independência total para as AVD.

Bottari et al. (2011), comparando um grupo de vítimas de TCE moderado e grave, a maioria com diagnóstico de lesões frontais e/ou LAD, ante um grupo controle, mostraram que as vítimas com TCE eram mais propensas a ter dificuldades no planejamento e execução das atividades programadas do que o conjunto de indivíduos controle ${ }^{(37)}$.

A avaliação da independência para AVD de 65 vítimas de LAD, após seis meses da lesão, mostrou escore médio de 80,6 e variação de 23 a 100 pontos no Índice de Barthel ${ }^{(27)}$. Ainda que não se observe consenso em relação ao ponto de corte apropriado para definir resultados favoráveis nesse índice, os autores reconhecem que valores $<75$ usualmente correspondem à condição na qual os pacientes relatam necessidade de ajuda para realizar suas $\mathrm{AVD}^{(38)}$.

Análises da evolução das vítimas de LAD em relação à independência para AVD não foram observadas na literatura científica, apesar de sua importância no estudo das repercussões desse tipo de lesão.

A LAD, assim como o TCE, frequentemente resulta em deficiências físicas, cognitivas e comportamentais que podem ser temporárias ou permanentes. As pesquisas de recuperação funcional após TCE, que utilizam as escalas de funcionalidade e de desempenho nas AVD, retratam as consequências individuais e sociais das alterações físicas e cognitivas apresentadas pelas vítimas após TCE.

Diferentes variáveis têm sido relacionadas com desfechos indesejáveis e funcionalidade das vítimas de TCE, sendo esse também um aspecto de interesse na pesquisa sobre a recuperação da LAD.

Jeong et al. (2010) identificaram, em vítimas de LAD, que a duração da inconsciência, a classificação tomográfica de Marshall, o hipopituitarismo e a intensidade de sinal anormal na RM em linha média ou 
estruturas profundas do cérebro estão associados a capacidade funcional após seis meses da lesão ${ }^{(27)}$.

Chelly et al. (2011) analisaram as características epidemiológicas, clínicas e radiológicas pós-traumáticas de vítimas de LAD internadas em UTI quanto a mortalidade e resultados da ERG entre 3 e 51 meses após o trauma. Identificaram como fatores associados com elevada mortalidade a disautonomia $(\mathrm{p}=0,018 ;$ odds ratio $-\mathrm{OR}=4,17)$ e a hiperglicemia $\geq 8 \mathrm{mmol} / \mathrm{L}$ ( $\mathrm{p}=0,001 ; \mathrm{OR}=3,84$ ) na admissão na UTI, além do diagnóstico de hematoma subdural $(\mathrm{p}=0,031$; OR $=3,99)$. Os fatores associados aos piores resultados na escala de funcionalidade foram ECGl $<8$ ( $p=0,032$; $\mathrm{OR}=3,55)$, número de lesões secundárias $\geq 3(\mathrm{p}=0,034 ; \mathrm{OR}=2,83)$, hiperglicemia $\geq 8 \mathrm{mmol} / \mathrm{L}(\mathrm{p}=0,002 ; \mathrm{OR}=5,55)$ e número de lesões $\geq 6$ ( $\mathrm{p}=$ $0,035 ; \mathrm{OR}=3,33)^{(10)}$.

Em outras investigações, a recuperação das vítimas após LAD também tem sido associada com o número de lesões identificadas em exame de imagem. Estudo longitudinal, que analisou a evolução de lesões axonais traumáticas em imagens de RM de 58 vítimas de TCE moderado ou grave, mostrou que, quanto maior o número de lesões identificadas na fase inicial após trauma, maior o comprometimento da funcionalidade após 12 meses ${ }^{(22)}$. Estudo realizado com 26 vítimas de $\operatorname{LAD}^{(24)}$ apontou uma forte correlação entre o volume e o número de lesões identificadas na RM realizada até 48 horas após a admissão hospitalar e o nível de deficiência observado no momento da alta hospitalar.

A avaliação de 24 vítimas de LAD em relação a resultados da RM e a funcionalidade após 6 meses do trauma mensurada pela ERGA ${ }^{(23)}$ também evidenciou que, quanto maior a região acometida pela $\mathrm{LAD}$, piores os resultados funcionais observados.

Poucos estudos sobre vítimas de LAD têm destacado os fatores clínicos e sociodemográficos associados à recuperação, descrito o processo após trauma de reaquisição da funcionalidade e da independência nas AVD das vítimas. Diante desta constatação, esta pesquisa pretende contribuir para responder os seguintes questionamentos: qual o padrão de recuperação das 
vítimas de LAD? Que características clínicas e sociodemográficas estão relacionadas às consequências da LAD?

Esses questionamentos foram desencadeados pela expectativa de contribuir para fundamentar uma melhor prática clínica e assistência às vítimas de LAD e pela necessidade constante de garantir a reintegração das vítimas de trauma na sociedade. 


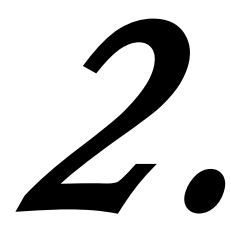

Objetivo 


\section{OBJETIVO}

\subsection{OBJETIVO GERAL}

- Descrever a recuperação das vítimas com diagnóstico principal de LAD até seis meses após trauma e identificar fatores clínicos e sociodemográficos associados ao óbito e capacidade funcional aos seis meses após ocorrer essa lesão.

\subsection{OBJETIVOS ESPECÍFICOS}

- Caracterizar as vítimas com diagnóstico principal de LAD atendidas no Instituto Central do Hospital das Clínicas da Faculdade de Medicina da Universidade de São Paulo (IC/HCFMUSP), segundo dados clínicos e sociodemográficos.

- Evidenciar a evolução das vítimas de LAD até seis meses póstrauma por meio da comparação dos escores da ERGA e escala de Katz de três períodos: alta hospitalar, após três e seis meses do trauma.

- Descrever, seis meses após o trauma, a capacidade funcional pela ERGA e a independência em AVD por meio da escala de Katz.

- Identificar os fatores clínicos e sociodemográficos associados ao risco de morte e dependência, após seis meses do trauma. 


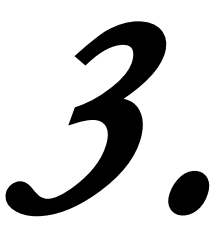

Revisão de
Literatura 


\section{REVISÃO DE LITERATURA}

Considerando os objetivos deste estudo, foi realizada revisão de literatura tendo como propósito localizar as pesquisas que descreveram as consequências do trauma em grupos de indivíduos adultos vítimas de LAD, incluindo ou não análises de fatores associados à sua recuperação.

Foram realizadas várias buscas bibliográficas online no período de agosto de 2011 a outubro de 2014, nas bases de dados PubMed, Medline, Lilacs e Scielo, utilizando as palavras "diffuse axonal injury" sem limites temporais. Os critérios de inclusão foram pesquisas realizadas com seres humanos, idade $\geq 15$ anos, cujos resumos estão disponíveis nos idiomas português, inglês e espanhol.

Foram localizados resumos de 816 publicações para leitura. Desses estudos, 75 não se referiam a trauma, 81 eram post-mortem, 30 foram realizados em animais, 210 abordavam complicações do TCE, 41 focavam as alterações neuropsicológicas e cognitivas, 2 diziam respeito a lesão em nervo óptico, 81 discutiram a LAD na fase aguda de tratamento, 95 examinaram a atividade cerebral em exames de imagem, 154 eram sobre biomarcadores na $\mathrm{LAD}$, porém não abordavam a recuperação, 12 eram estudos de casos, 15 relatavam recuperação da LAD em grupos que incluíam predominantemente crianças e 2 não foram obtidos na íntegra.

Restaram 18 referências que atenderam o propósito desta revisão e foram localizadas utilizando a estratégia de busca estabelecida ${ }^{(18,23,27,31-32,39-}$ $51)$

As escalas mais utilizadas foram de funcionalidade: a ERG $(61,1 \%)$, a ERGA $(33,4 \%)$ e a DRS. Entretanto, um dos estudos ${ }^{(27)}$ utilizou a ERG e o Índice de Barthel modificado concomitantemente, medida da capacidade de realizar as AVD.

Os estudos foram desenvolvidos predominantemente nos Estados Unidos (38,8\%) e Irã $(27,8 \%)$. A maioria das pesquisas incluiu vítimas com indícios ou diagnóstico de LAD, ECGl $\leq 12$ e envolvidas em ocorrências nas 
quais o mecanismo do trauma resultou em aceleração e desaceleração compatível com LAD.

O tamanho das amostras variou de 8 a 85 indivíduos. Muitos estudos (50,0\%) apresentaram relação entre achados clínicos e exames de imagem e cerca de $66,0 \%$ analisaram fatores associados.

Dos 18 estudos, 4 eram ensaios clínicos que testaram tratamentos e analisaram seu impacto no processo de recuperação. Ainda que seus resultados retratem as consequências da LAD com essas intervenções, essas publicações foram incluídas nesta revisão considerando essa ressalva.

A avaliação da recuperação apenas no momento da alta hospitalar foi observada em uma pesquisa realizada no Irã com 20 vítimas de LAD. Este estudo avaliou o nível de mediadores anti-inflamatórios e fatores do crescimento (TGF $\beta 1$, Interleucina 8 e Óxido Nítrico) e sua associação com gravidade e consequências do trauma ${ }^{(39)}$. Nos resultados, a pontuação média na ERG foi de 4,6 (desvio padrão - $d p=0,68$ ), compatível com boa recuperação e incapacidade moderada, e o escore da escala apresentou associação com a Interleucina 8 . Na pesquisa, os autores ${ }^{(39)}$ utilizaram a ERG atribuindo pontuação 1 aos casos de morte e 5 às vítimas com boa recuperação. Sendo assim, quanto maior a pontuação obtida, melhor a recuperação observada.

A Tabela 1 reúne as informações de um ensaio clínico que analisou o efeito da progesterona no prognóstico da LAD, considerando as condições das vítimas de LAD 3 meses após a alta hospitalar. Na investigação ${ }^{(40)}$, o grupo caso incluiu 38 indivíduos que receberam progesterona por 5 dias e o grupo controle incluiu 38 pacientes que não foram submetidos a intervenção. Após 3 meses da alta hospitalar, as vítimas foram avaliadas pela ERG. Observou-se que 50,0\% dos indivíduos que usaram a progesterona apresentaram boa recuperação ou incapacidade moderada e menor frequência foi constatada no grupo controle $(29,0 \%)$. Os autores concluíram que o uso da progesterona melhora significativamente o prognóstico após a lesão e proporciona benefícios para o tratamento na fase aguda, especialmente nas vítimas com $\mathrm{ECGl} \geq 5 \mathrm{e} \leq 8^{(40)}$. 
Tabela 1 - Ensaio clínico com uso de progesterona - revisão bibliográfica sobre recuperação de vítimas de LAD. São Paulo, 2014.

\begin{tabular}{|c|c|c|}
\hline & \multicolumn{2}{|c|}{ Shakeria et al. ${ }^{(40)}$} \\
\hline Local do estudo & \multicolumn{2}{|c|}{ Irã } \\
\hline Ano de publicação & \multicolumn{2}{|c|}{2013} \\
\hline Critérios de inclusão & \multicolumn{2}{|c|}{$\begin{array}{c}\text { ECGl } \leq 8, \text { LAD, admitido até } 6 \\
\text { horas após o TCE, sexo } \\
\text { masculino e sem antecedente de } \\
\text { uso hormônios }\end{array}$} \\
\hline $\begin{array}{l}\text { Número de } \\
\text { participantes }\end{array}$ & \multicolumn{2}{|c|}{76} \\
\hline Escala utilizada & \multicolumn{2}{|c|}{ ERG } \\
\hline $\begin{array}{l}\text { Tempo de } \\
\text { seguimento }\end{array}$ & \multicolumn{2}{|c|}{3 meses após alta hospitalar } \\
\hline Resultados na ERG & Caso & Controle \\
\hline 5- Boa recuperação & $26,3 \%$ & $15,8 \%$ \\
\hline $\begin{array}{l}\text { 4- Incapacidade } \\
\text { moderada }\end{array}$ & $23,7 \%$ & $13,2 \%$ \\
\hline $\begin{array}{l}\text { 3- Incapacidade } \\
\text { grave }\end{array}$ & $2,6 \%$ & $15,8 \%$ \\
\hline $\begin{array}{l}\text { 2- Estado vegetativo } \\
\text { persistente }\end{array}$ & $15,8 \%$ & $10,5 \%$ \\
\hline 1- Morte & $31,6 \%$ & $44,7 \%$ \\
\hline
\end{tabular}

No Texas, pesquisadores estudaram a relação dos marcadores de LAD na RM e volume cerebral com resultados cognitivos de 24 vítimas após 3 meses do trauma. Nesse período, os autores também avaliaram a capacidade funcional com a ERGA e verificaram que metade das vítimas de LAD tiveram boa recuperação, valor médio na escala de $6,4(\mathrm{dp}=1,9)$ e mediana de 7. A pontuação atribuída pelos autores às categorias da ERGA foi de 1 a 8 , sendo os maiores valores designados às vítimas que alcançaram melhor condição funcional ${ }^{(41)}$.

Resultados das publicações que descreveram a recuperação aos 6 meses após $\mathrm{LAD}$, discriminando a frequência de vítimas em categorias das 
escalas $^{(18,23,31,42-43)}$, estão apresentados na Tabela 2. Entre esses estudos, a mortalidade foi incluída em duas pesquisas, sendo esse valor apresentado isolado em uma delas - $19,6 \%{ }^{(42)}$ e juntamente com casos de estado vegetativo em outra $-13,6 \%{ }^{(23)}$. A frequência de participantes que apresentaram boa recuperação variou de $12,5 \%$ a $60,0 \%$; indivíduos incapazes aos 6 meses eram entre 40,0\% e 87,5\% e dependentes entre $20,0 \%$ e $41,3 \%^{(18,23,31,42-43)}$. Conclui-se dessas observações que houve grande variabilidade na condição dos grupos de vítimas aos 6 meses após a LAD e que características específicas dos grupos estabeleceram diferentes resultados.

Duas investigações que aplicaram a ERGA aos 6 meses apresentaram valores médios de 4,4 $(\mathrm{dp}=2,2)^{(44)}$ e $5,97(\mathrm{dp}=1,97)^{(45)}$, porém não descreveram a distribuição das vítimas nas categorias da escala. Considerando as pontuações utilizadas pelos autores - 1 a 8 , sendo o maior valor relativo à total recuperação - os resultados foram compatíveis com incapacidade grave e incapacidade moderada acentuada no estudo com menor média de pontuação ${ }^{(44)}$ e incapacidade moderada no que apresentou maior escore médio ${ }^{(45)}$. Dessas pesquisas, somente uma analisou fatores associados à recuperação e verificou que a pontuação da ERGA apresentou correlação com gravidade da LAD, contagem e volume das fibras nervosas identificada na tractografia com base na RM de tensor de difusão(44), concluindo que esse exame poderá servir de biomarcador para LAD e ajudar na previsão das consequências da lesão a longo prazo ${ }^{(44)}$.

Com avaliações realizadas com a ERG e o Índice de Barthel modificado, autores coreanos estudaram o efeito do hipopituitarismo após LAD na capacidade funcional das vítimas. Verificaram que o escore médio na ERG, após 6 meses, foi de 2,86 entre os 21 pacientes com hipopituitarismo e de 3,37 nos 44 indivíduos sem essa alteração. A média no Índice de Barthel modificado foi de 64,7 e 88,5, respectivamente nesses grupos. Duração da inconsciência, classificação de Marshall na TC, hipopituitarismo, intensidade de sinal anormal na imagem da RM em linha média ou em estruturas profundas do encéfalo foram associados a desfechos desfavoráveis ${ }^{(27)}$. 
Tabela 2 - Recuperação de vítimas de LAD aos 6 meses - revisão bibliográfica. São Paulo, 2014.

\begin{tabular}{|c|c|c|c|c|c|}
\hline & $\begin{array}{c}\text { Warner et } \\
\text { al. }^{(31)}\end{array}$ & $\begin{array}{c}\text { Ljungqvist J } \\
\text { et al. }{ }^{(43)} \\
\end{array}$ & $\begin{array}{l}\text { Marquez de la } \\
\text { Plata et al. }^{(23)}\end{array}$ & $\begin{array}{c}\text { Paterakis } \\
\text { et al. }{ }^{(18)} \\
\end{array}$ & $\begin{array}{c}\text { Mannion et } \\
\text { al. }^{\left({ }^{(42)}\right.} \\
\end{array}$ \\
\hline Local do estudo & Texas & Suécia & Texas & Grécia & Reino Unido \\
\hline $\begin{array}{l}\text { Ano de } \\
\text { publicação }\end{array}$ & 2010 & 2011 & 2007 & 2000 & 2007 \\
\hline $\begin{array}{l}\text { Critérios de } \\
\text { inclusão }\end{array}$ & $\begin{array}{l}\text { Idade de } 16-65 \\
\text { anos, TCE } \\
\text { contuso, } \\
\text { mecanismo do } \\
\text { trauma } \\
\text { compatível com } \\
\text { LAD, estável } \\
\text { hemodinâmica- } \\
\text { mente, } \\
\text { classificação de } \\
\text { Marshall grau II } \\
\text { ou TC normal } \\
\text { com ECGl<13 }\end{array}$ & $\begin{array}{c}\text { TCE com } \\
\text { indícios de } \\
\text { LAD ou TC } \\
\text { normal com } \\
\text { perda de } \\
\text { consciência }\end{array}$ & $\begin{array}{c}\text { ECGl } \leq 12, \text { LAD, } \\
\text { sem antecedente } \\
\text { de patologia } \\
\text { crônica que } \\
\text { causa alterações } \\
\text { na RM }\end{array}$ & $\begin{array}{l}\text { TCE fechado, } \\
\text { ECGl } \leq 12 \mathrm{e} \\
\text { discrepância } \\
\text { entre achados } \\
\text { radiológicos e } \\
\text { estado } \\
\text { neurológico } \\
\text { nas primeiras } \\
48 \text { horas após } \\
\text { lesão }\end{array}$ & $\begin{array}{c}\text { ECGl } \leq 8, \\
\text { TCE com IOT } \\
\text { e VM por } \\
\text { mais de } 24 \\
\text { horas e } \\
\text { presença de } \\
\text { lesão em } \\
\text { tronco } \\
\text { cerebral }\end{array}$ \\
\hline $\begin{array}{l}\text { Número de } \\
\text { participantes }\end{array}$ & 25 & 8 & 24 & 24 & 46 \\
\hline Escala utilizada & ERGA & ERGA & ERGA & ERG & ERG \\
\hline $\begin{array}{l}\text { Resultados da } \\
\text { escala }\end{array}$ & & & & & \\
\hline - Boa recuperação & $-\left[\begin{array}{l}40,0 \% \\
20,0 \%\end{array}\right.$ & $\begin{array}{c}12,5 \% \\
-\end{array}$ & $27,2 \%$ & $54,2 \%$ & 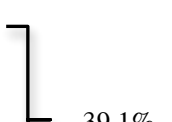 \\
\hline $\begin{array}{l}\text { - Incapacidade } \\
\text { moderada }\end{array}$ & $-\left[\begin{array}{l}12,0 \% \\
8,0 \%\end{array}\right.$ & $-\left[\begin{array}{l}37,5 \% \\
12,5 \%\end{array}\right.$ & $22,7 \%$ & $25,0 \%$ & 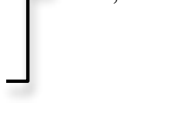 \\
\hline $\begin{array}{l}\text { - Incapacidade } \\
\text { grave }\end{array}$ & $-\left[\begin{array}{l}4,0 \% \\
16,0 \%\end{array}\right.$ & $-\left[\begin{array}{l}25,0 \% \\
12,5 \%\end{array}\right.$ & $36,3 \%$ & $16,7 \%$ & $41,3 \%$ \\
\hline $\begin{array}{l}\text { - Estado } \\
\text { vegetativo } \\
\text { persistente }\end{array}$ & - & - & $13,6 \%$ & $4,1 \%$ & $19,6 \%$ \\
\hline - Morte & - & - & & & \\
\hline $\begin{array}{l}\text { Variáveis } \\
\text { estudadas }\end{array}$ & Taxa de atrofia & - & $\begin{array}{c}\text { Volumes } \\
\text { encefálicos na } \\
\text { RM }\end{array}$ & $\begin{array}{c}\text { LAD } \\
\text { hemorrágica } \\
\text { e } \\
\text { não } \\
\text { hemorrágica }\end{array}$ & $\begin{array}{c}\text { Lesão em } \\
\text { tronco } \\
\text { encefálico, } \\
\text { mesencéfalo e } \\
\text { ponte na RM }\end{array}$ \\
\hline $\begin{array}{l}\text { Fatores } \\
\text { associados }\end{array}$ & $\begin{array}{c}\text { A perda de } \\
\text { volume e atrofia } \\
\text { cerebrais } \\
\text { regionais } \\
\text { específicas } \\
\text { foram } \\
\text { preditivos para } \\
\text { incapacidade a } \\
\text { longo prazo }\end{array}$ & - & - & $\begin{array}{c}\text { LAD } \\
\text { hemorrágica } \\
\text { foi associada } \\
\text { com } \\
\text { prognóstico } \\
\text { desfavorável }\end{array}$ & $\begin{array}{l}\text { Lesões no } \\
\text { mesencéfalo, } \\
\text { ponte e tronco } \\
\text { encefálico } \\
\text { foram } \\
\text { associados } \\
\text { com } \\
\text { prognóstico } \\
\text { desfavorável }\end{array}$ \\
\hline
\end{tabular}


A Tabela 3 apresenta dados dos estudos que investigaram a recuperação das vítimas de LAD após um ano do trauma ${ }^{(32,46)}$. Em ambas as pesquisas, a maioria das vítimas alcançou boa recuperação nesse período de avaliação. Indivíduos incapazes foram $25,0 \%{ }^{(32)}$ e $45,0 \%{ }^{(46)}$ das amostras analisadas e os dependentes foram identificados somente em um dos estudos com frequência de $20,0 \%{ }^{(46)}$.

Tabela 3 - Recuperação de vítimas de LAD após um ano - revisão bibliográfica. São Paulo, 2014.

\begin{tabular}{|c|c|c|}
\hline & Urakami $^{(32)}$ & Matsukawa et al. ${ }^{(46)}$ \\
\hline Local do estudo & Japão & Japão \\
\hline Ano de publicação & 2011 & 2011 \\
\hline Critérios de inclusão & $\begin{array}{c}\text { Presença de atividade } \\
\text { espontânea durante o estágio } 2 \\
\text { do sono }\end{array}$ & $\begin{array}{l}\text { TCE, lesão única da LAD, } \\
\text { LAD confirmada por RM, sem } \\
\text { patologia crônica e uso de } \\
\text { anticoagulantes }\end{array}$ \\
\hline Número de participantes & 8 & 69 \\
\hline Escala utilizada & ERG & ERG \\
\hline \multicolumn{3}{|l|}{ Resultados na ERG } \\
\hline 5- Boa recuperação & $75,0 \%$ & $55,0 \%$ \\
\hline 4- Incapacidade moderada & $25,0 \%$ & $25,0 \%$ \\
\hline 3- Incapacidade severa & - & $14,0 \%$ \\
\hline 2- Estado vegetativo persistente & - & $6,0 \%$ \\
\hline 1- Morte & - & - \\
\hline Variáveis estudadas & - & $\begin{array}{c}\text { Idade, sexo, ECGl, ISS, } \\
\text { anormalidades pupilares, } \\
\text { hematoma subcutâneo, dose } \\
\text { de etanol no sangue, } \\
\text { localização da lesão na } \\
\text { cabeça, mecanismo do trauma } \\
\text { e achados nos exames }\end{array}$ \\
\hline Fatores associados & - & $\begin{array}{l}\text { Lesão em corpo caloso e } \\
\text { contusão cerebral em exames } \\
\text { de imagem foram } \\
\text { independentemente associados } \\
\text { a prognóstico desfavorável }\end{array}$ \\
\hline
\end{tabular}

Nos ensaios clínicos com drogas ${ }^{(49-50)}$, a eficácia da utilização da Boswellia Serrata ${ }^{(50)}$ e Amantadina ${ }^{(49)}$ foi avaliada tendo em vista a recuperação funcional das vítimas até 3 meses após a LAD. Os grupos controles desses estudos, além dos submetidos à intervenção, apresentaram melhora funcional consistente no período de seguimento; entretanto, as 
diferenças na evolução dos grupos caso e controle nos estudos evidenciaram que a Boswellia Serrata ${ }^{(50)}$ não afetou a recuperação e que a Amantadina ${ }^{(49)}$ proporcionou tendência de melhora funcional mais rápida, independentemente do início de seu uso nas primeiras 12 semanas após LAD.

Tabela 4 - Descrição de estudos publicados sobre recuperação das vítimas de LAD avaliadas após o seguimento. São Paulo, 2014.

\begin{tabular}{|c|c|c|c|c|c|}
\hline & \multicolumn{3}{|c|}{ Liew et al. ${ }^{(48)}$} & \multicolumn{2}{|c|}{ Chabok et al..$^{(47)}$} \\
\hline Local do estudo & \multicolumn{3}{|c|}{ Malásia } & \multicolumn{2}{|c|}{ Irã } \\
\hline Ano de publicação & \multicolumn{3}{|c|}{2009} & \multicolumn{2}{|c|}{2012} \\
\hline Critérios de inclusão & \multicolumn{3}{|c|}{$\mathrm{ECGl} \leq 8$ e $\mathrm{LAD}$} & \multicolumn{2}{|c|}{$\begin{array}{c}\text { Idade } \geq 16 \text { anos, TCE, ECGl } \leq 8 \\
\text { admissão até } 3 \text { horas após a } \\
\text { lesão e ausência de hematoma } \\
\text { na TC }\end{array}$} \\
\hline $\begin{array}{l}\text { Número de } \\
\text { participantes }\end{array}$ & \multicolumn{3}{|c|}{72} & \multicolumn{2}{|c|}{28} \\
\hline Escala utilizada & \multicolumn{3}{|c|}{ ERG } & \multicolumn{2}{|c|}{ ERG } \\
\hline Tempo de seguimento & \multicolumn{3}{|c|}{ Alta, 3 e 6 meses } & \multicolumn{2}{|c|}{3 meses e 2 anos } \\
\hline Resultados na ERG & Alta & 3 meses & 6 meses & 3 meses & 2 anos \\
\hline - Boa recuperação & 7 & $79.6 \%$ & $978 \%$ & $10,7 \%$ & $35,7 \%$ \\
\hline - Incapacidade moderada & 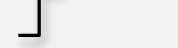 & & & $21,4 \%$ & $25,0 \%$ \\
\hline - Incapacidade severa & $44,4 \%$ & $14,3 \%$ & $2,2 \%$ & $42,9 \%$ & $14,3 \%$ \\
\hline $\begin{array}{l}\text { - Estado vegetativo } \\
\text { persistente }\end{array}$ & & & & $17,9 \%$ & $10,7 \%$ \\
\hline - Morte & $15,3 \%$ & $6,1 \%$ & - & $7,1 \%$ & $14,3 \%$ \\
\hline Variáveis testadas & $\begin{array}{l}\text { Idade, gra } \\
\text { classificação } \\
\text { pressã }\end{array}$ & $\begin{array}{l}\text { idade da } \\
\text { de Marsh } \\
\text { arterial r }\end{array}$ & $\begin{array}{l}\text { D pela } \\
\text { na TC e } \\
\text { dia }\end{array}$ & $\begin{array}{r}\text { Proteína } \\
\text { horas, } 24 \text { h } \\
\text { horas) e EC } \\
24 \text { horas, } 4\end{array}$ & $\begin{array}{l}\text { (Pico, } 6 \\
\text { horas e } 72 \\
\text { ial, } 6 \text { horas, } \\
\text { e } 72 \text { horas) }\end{array}$ \\
\hline Fatores associados & $\begin{array}{r}\text { Gravida } \\
\text { classificação } \\
\text { pressão a } \\
\text { independente } \\
\text { a sc }\end{array}$ & $\begin{array}{l}\text { de da LA } \\
\text { de Marsh } \\
\text { terial méc } \\
\text { nente ass } \\
\text { brevivên }\end{array}$ & $\begin{array}{l}\text { pela } \\
\text { l na TC e } \\
\text { estão } \\
\text { iados com }\end{array}$ & $\begin{array}{r}\text { Proteína S10 } \\
24 \text { horas, } 4 \\
\text { foi associ } \\
\text { desfavorá } \\
\text { proteína S10 } \\
48 \text { hora } \\
\text { associad } \\
\text { desfavorá } \\
\text { ECGl avalia } \\
\text { horas, } 48 \\
\text { associa } \\
\text { desfavor }\end{array}$ & $\begin{array}{l}\text { período de } \\
\text { e } 72 \text { horas } \\
\text { resultado } \\
3 \text { meses; a } \\
\text { período de } \\
\text { oras foi } \\
\text { esultado } \\
2 \text { anos e a } \\
\text { eríodo de } 24 \\
2 \text { horsa foi } \\
\text { ultado } \\
3 \text { meses }\end{array}$ \\
\hline
\end{tabular}


Ensaio clínico realizado no Irã avaliou a eficácia e os efeitos secundários da Ciclosporina-A na recuperação da consciência e função cognitiva no período entre 3 e 6 meses após LAD. A frequência de desfecho favorável aos 3 meses no grupo controle foi de 64,0\% e aos 6 meses, 56,0\%. No grupo intervenção, aos 3 meses, 54,0\% dos indivíduos tinham desfecho favorável e, aos 6 meses, esse valor diminuiu para 42,0\%. Não houve diferença significativa entre o grupo caso e controle nos escores da ERGA entre 3 e 6 meses e a Ciclosporina-A não se mostrou eficaz para melhora da função cognitiva e de consciência após a $\operatorname{LAD}^{(51)}$.

Além dos ensaios clínicos, dois estudos apresentaram a recuperação das vítimas por um período após LAD: um deles, entre alta hospitalar e 6 meses; outro, entre 3 meses e 2 anos. A análise da evolução das vítimas entre alta e 6 meses mostrou resultados favoráveis (total recuperação, boa recuperação ou incapacidade moderada e moderada acentuada) em 40,3\%, $79,6 \%$ e $97,8 \%$ dos pacientes na alta, 3 e 6 meses, respectivamente ${ }^{(48)}$. Na investigação entre 3 meses e 2 anos, desfechos favoráveis foram observados em 32,1\% dos participantes aos 3 meses e em 60,7\% aos 2 anos. Nos resultados de ambas as investigações, a frequência de indivíduos com resultados desfavoráveis (estado vegetativo persistente, incapacidade grave e grave acentuada) diminuiu com o tempo decorrido, enquanto aumentavam os que apresentaram resultados favoráveis ${ }^{(47)}$.

Poucos foram os estudos que analisaram a recuperação das vítimas, e entre eles foram maioria os ensaios clínicos com drogas, dificultando assim identificar a recuperação sem essas intervenções. Segundo resultados de estudos clínicos, o uso da Progesterona ${ }^{(40)}$ e da Amantadina ${ }^{(49)}$ pode ser benéfico para recuperação das vítimas de LAD. Os estudos também evidenciaram prováveis biomarcadores que podem auxiliar nas estimativas de prognósticos e fatores relacionados com prognósticos desfavoráveis.

As amostras das publicações analisadas apresentaram diferentes níveis de funcionalidade mesmo quando as avaliações foram realizadas no mesmo período após LAD. O fundamento dessas diferenças está provavelmente na frequência de fatores de risco para piores prognósticos nas vítimas das amostras analisadas. Os resultados dos estudos que 
apresentaram períodos de recuperação sugerem importante melhora das vítimas entre alta e 6 meses e também entre o período de 3 meses e 2 anos. Portanto, análises complementares ainda deverão ser realizadas para identificar o período de estabilidade da recuperação das vítimas de LAD. 


$$
\begin{array}{r}
4 . \\
\text { Método }
\end{array}
$$




\section{MÉTODO}

\subsection{TIPO DE ESTUDO}

Trata-se de um estudo do tipo coorte prospectivo, com dados coletados na internação, alta hospitalar, três e seis meses após a LAD. Inicialmente foram coletados dados sociodemográficos, relacionados ao trauma, ao atendimento pré-hospitalar, admissão e internação hospitalar. As vítimas foram acompanhadas diariamente até a alta, quando a escala de Katz e a ERGA foram aplicadas. Aos três e seis meses após LAD, avaliações com essas escalas foram efetuadas e informações quanto a tratamentos realizados foram coletadas.

\subsection{LOCAL DO ESTUDO}

O estudo foi realizado no IC/HCFMUSP, hospital especializado tipo II, referência no tratamento a vítimas de trauma, localizado na região centro-oeste do município de São Paulo.

O IC/HCFMUSP é uma autarquia do Governo do Estado de São Paulo, vinculada à Secretaria de Estado da Saúde para fins de coordenação administrativa e associada à Faculdade de Medicina da Universidade de São Paulo para fins de ensino, pesquisa e prestação de ações e serviços de saúde destinados à comunidade.

O pronto-socorro do IC/HCFMUSP é uma Unidade de Emergência Referenciada, que presta atendimento aos casos de alta complexidade. Esta unidade é referência em tratamento de neurocirurgia, responsável pelo atendimento das vítimas de TCE da região e redondezas. No ano de 2013, o serviço de neurocirurgia realizou 2.340 atendimentos, dos quais 1.837 (78,5\%) resultaram em internações. Aproximadamente 22,0\% dos 
internados ocuparam leitos de UTI, com média de permanência de 4,7 dias e mortalidade de $16,5 \%$ na unidade ${ }^{1}$.

Este pronto-socorro é o local de atendimento inicial às vítimas de trauma na fase hospitalar. Após a alta hospitalar, as vítimas são acompanhadas no ambulatório do mesmo complexo hospitalar, localizado em prédio anexo ao IC/HCFMUSP.

A coleta de dados do período de internação e na alta hospitalar foi realizada nas dependências do IC/HCFMUSP. As demais abordagens dos pacientes foram realizadas no ambulatório de Neurocirurgia e Trauma, no hospital de retaguarda de Suzano e na residência, quando a vítima estava incapaz de locomoção no período de três meses após o trauma.

\subsection{CASUÍSTICA DO ESTUDO}

Fizeram parte do estudo pacientes com diagnóstico de LAD, internados no IC/HCFMUSP no período de julho de 2013 a fevereiro de 2014, com ECGl $\leq 8$ na admissão hospitalar, idade $\geq 18$ anos e $\leq 60$ anos. Foram excluídas as vítimas atendidas nesse hospital após seis horas do evento traumático, transferidas de outros hospitais, com diagnóstico anterior de TCE, distúrbios psiquiátricos e com outras lesões na região da cabeça e medula espinhal de gravidade $\geq 3$, segundo Abbreviated Injury Scale (AIS) ${ }^{(52)}$. Vítimas com lesões AIS $\geq 3$, nas regiões corpóreas especificadas, podem apresentar deficiências e incapacidades por longo período póstrauma ${ }^{(53)}$, o que dificulta a distinção das consequências da LAD no processo de recuperação.

\subsection{CÁLCULO AMOSTRAL}

O cálculo do tamanho da amostra foi realizado priorizando-se o objetivo de identificar a recuperação das vítimas de LAD até seis meses

\footnotetext{
${ }^{1}$ São Paulo. Hospital das Clínicas da Faculdade de Medicina da Universidade de São Paulo. Secção de estatística. Anuário de atendimentos do pronto-socorro: 2013. São Paulo, 2014.
} 
após trauma. A amostragem foi não aleatória e a amostra incluiu todos os pacientes admitidos no local do estudo no período de coleta de dados que atendessem aos critérios de elegibilidade desta investigação.

Para estabelecer o tamanho dessa amostra, considerou-se o efeito de Cohen ${ }^{(54)}$, uma medida relativa das diferenças das médias (inicial e final), que é ponderada pelo desvio dessa diferença: quanto maior o desvio, maior deve ser a diferença observada. Dessa forma, o efeito é calculado pelo desvio das diferenças das médias (inicial e final) de todos os resultados esperados na recuperação dividido pela raiz quadrada da variância dos desvios dessa diferença ${ }^{(54)}$.

Em uma amostra de 35 a 40 pacientes, identificou-se um efeito de 0,49 a 0,46 , com $80,0 \%$ de poder e nível de significância de $5 \%$. Cohen ${ }^{(54)}$ define que um efeito de aproximadamente 0,5 é um efeito grande, ou seja, o tamanho amostral de 35 a 40 pacientes é suficiente para identificar as medidas de recuperação que se modificaram significativamente aos seis meses.

Optou-se por coletar aproximadamente o dobro de casos do tamanho estimado da amostra tendo em vista possíveis perdas e óbitos durante o seguimento dos pacientes. Para isso, novos casos foram incluídos neste estudo durante 7 meses, de julho de 2013 a fevereiro de 2014; entretanto a coleta de dados estendeu-se até o início de setembro desse ano, a fim de completar o período de 6 meses de seguimento.

\subsection{ASPECTOS ÉTICOS}

O presente estudo foi aprovado pelo Comitê de Ética em Pesquisa da Escola de Enfermagem da Universidade de São Paulo sob número de processo 016159/2013 em 11/06/2013 e pelo Comitê de Ética em Pesquisa do Hospital das Clínicas da Faculdade de Medicina da Universidade de São Paulo (HCFMUSP) com número de protocolo 311.774 em 03/07/2013 e Certificado de Apresentação para Apreciação Ética número 14115513.1.3001.0068 (Anexo A). 
O Termo de Consentimento Livre e Esclarecido (TCLE) foi aplicado a fim de obter autorização para inclusão da vítima neste estudo de seguimento. Preferencialmente, a autorização foi obtida junto ao paciente; no entanto, nos casos em que as condições clínicas da vítima não indicaram esse procedimento, a solicitação para participação na pesquisa e para assinatura do TCLE foi realizada junto a familiares responsáveis pelo paciente.

\subsection{VARIÁVEIS DE ESTUDO}

\section{Variáveis relacionadas à gravidade e consequências da LAD}

- Gravidade da LAD - variável que foi mensurada a nível ordinal utilizando-se a classificação de Gennarelli( ${ }^{(1)}$ apresentada na seção de introdução deste estudo. Nas análises de associação, pacientes que tiveram indicação de LAD de gravidade leve e moderada foram reunidos em uma única categoria.

- Maximum Abbreviated Injury Scale (MAIS)/cabeça - com este indicador foi descrita com um único digito a gravidade da lesão mais séria das vítimas de trauma na região da cabeça. O MAIS/cabeça corresponde ao mais alto escore da AIS na região da cabeça, independentemente do número de lesões ${ }^{(52)}$. A AIS é uma escala utilizada para descrever as lesões decorrentes de um trauma e identificar sua gravidade. A lista de lesões é apresentada no manual AIS, que fornece para cada descrição de lesão um identificador composto por sete números, sendo o sétimo dígito o valor referente ao escore de gravidade da AIS. Nesta escala de gravidade, escore um é atribuído para lesões leves, dois para moderadas, três para sérias, quatro para graves, cinco para críticas e seis para lesões de gravidade máxima. Nesse estudo, as lesões foram codificadas segundo a última versão do manual: AIS 2005 - update $2008^{(52)}$. O MAIS, assim como a AIS, varia de um a seis pontos. As regiões corpóreas consideradas para cálculo do MAIS foram as seis utilizadas para cálculo do Injury Severity Score (ISS). 
- ISS - variável numérica que indica a gravidade global do trauma de uma vítima, calculada a partir da análise de todas as lesões decorrentes do trauma. O ISS é um índice anatômico, calculado com base no escore de gravidade das lesões segundo a AIS e considera seis regiões corpóreas: cabeça ou pescoço, face, tórax, abdome ou conteúdo pélvico, extremidades ou cintura pélvica e superfície externa. Segundo o ISS, a gravidade global do trauma é calculada pela soma do quadrado do escore mais alto de três regiões do corpo diferentes. Seu valor varia de 1 a 75; quanto maior o valor do escore, maior a gravidade do trauma e, consequentemente, maior a probabilidade de morte ${ }^{(53)}$.

- New Injury Severity Score (NISS) - variável numérica que, assim como o ISS, estima a gravidade global do trauma. O NISS é uma modificação do ISS que objetiva sanar falhas apontadas no ISS em vítimas com múltiplas lesões localizadas na mesma região corpórea. A pontuação do NISS também pode variar de 1 a 75 e é representada pela soma do quadrado do escore das três lesões mais graves de uma vítima; portanto, seu cálculo não requer a separação das lesões conforme as regiões corpóreas, o que simplifica a estimativa do índice em relação ao $\operatorname{ISS}^{(55)}$.

- Capacidade funcional - a funcionalidade foi avaliada pela ERGA, que tem como finalidade quantificar a capacidade funcional das vítimas de forma global $^{(26)}$. A pontuação da ERGA apresenta oito categorias, variando de total recuperação a morte ${ }^{(26)}$. No presente estudo, a escala foi aplicada somente em vítimas sobreviventes à internação hospitalar e a análise de mortalidade foi realizada separadamente. Para categorização da ERGA, seguiu-se os seguintes critérios de categorização:

(0) Total recuperação: indivíduos que assumiram vida normal, sem nenhuma alteração ou queixa consequente ao trauma.

(1) Boa recuperação: indivíduos que reassumiram vida normal, com presença de leves dificuldades em atividades físicas ou mentais.

$\checkmark$ (2) Incapacidade moderada: “independentes, mas incapazes" podem ter vida independente com algumas dificuldades e restrições. $\mathrm{O}$ ponto básico de diferenciação para categoria boa recuperação é que os 
indivíduos nela incluídos não conseguem retornar a todas as atividades realizadas anteriormente ao trauma.

$\checkmark$ (3) Incapacidade moderada acentuada: "independentes, mas incapazes" - podem ter vida independente com auxílio de artefatos ou em meio ambiente adaptado para possibilitar realizar atividades essenciais para independência.

$\checkmark$ (4) Incapacidade grave: “conscientes, mas dependentes" necessitam de ajuda de outrem para atividades de autocuidado, assim como para carregar objetos e produtos necessários à subsistência, deslocar-se dentro e fora da residência, preparar refeições, fazer compras, manejar dinheiro, entre outras. Precisam viver com a ajuda de outra pessoa.

$\checkmark$ (5) Incapacidade grave acentuada: "conscientes, mas dependentes" necessitam de ajuda de outrem para atividades de autocuidado e não podem permanecer sozinhos por períodos de oito horas em sua residência.

(6) Estado vegetativo persistente: não demostram evidência de capacidade de elaboração de resposta significativa. Não obedecem a comandos simples nem pronunciam qualquer palavra.

- Capacidade para realizar AVD - o desempenho nas AVD foi avaliado pela escala de Katz, que mede a independência para realizar essas atividades por meio de seis domínios: tomar banho, vestir-se, cuidado pessoal, realizar transferência, necessidades urinárias e alimentar-se ${ }^{(36)}$. Em cada um desses domínios os indivíduos são classificados como independentes, independentes com necessidade de ajuda por meio de adaptações ou artefatos, necessidade de ajuda humana e dependência total. A pontuação em cada domínio varia de 0 a 3 e o escore total da escala de Katz, de 0 a 18. Nessa escala, quanto menor a pontuação, maior a independência para realizar as $\mathrm{AVD}^{(36)}$.

- Recuperação funcional - medida pela diferença na categorização das escalas ERGA e Katz entre alta, três e seis meses após LAD.

- Dependência aos seis meses após trauma - variável dependente nas análises de associação. Para essas análises, as categorias da ERGA foram 
reunidas de forma dicotômica e os pacientes agrupados em dependentes e independentes. Segundo critérios estabelecidos nessa escala, são pessoas independentes aquelas incluídas nas categorias de total recuperação, boa recuperação e incapacidade moderada ou moderada acentuada. Indivíduos dependentes são os sobreviventes com incapacidade grave ou grave acentuada e em estado vegetativo persistente ${ }^{(56-57)}$.

- Tratamento em especialidades da aérea de saúde entre a alta e seis meses após o trauma - variável que identificou a realização ou não de tratamento nesse período com especialistas das aéreas de Fisioterapia, Terapia Ocupacional, Psicologia e Fonoaudiologia.

- Estado vital aos seis meses após trauma - variável dependente nas análises de associação que agrupou os casos de óbito e sobrevida nesse período.

- Tempo de sobrevivência antes do óbito - tempo, em dias, que os participantes que morreram até seis meses após LAD sobreviveram a essa lesão.

\section{Variáveis sociodemográficas}

- Gênero - variável categórica (feminino e masculino).

- Idade - variável numérica considerada em anos e referente à data do trauma.

- Escolaridade - variável numérica que considerou os anos de estudo, conforme nível de escolaridade alcançado na época do trauma.

- Vínculo conjugal na época do trauma - variável categórica que descreveu as vítimas como solteiras, casadas ou separadas.

- Raça - para categorização dos participantes da pesquisa, segundo esta variável, foi utilizada a informação do paciente ou familiar responsável, não se considerando a observação do entrevistador.

- Situação ocupacional no período do trauma - variável categórica que agrupou as vítimas em inseridas no mercado de trabalho (empregados ou autônomos) e sem inserção (auxílio-doença, desempregado ou não trabalha). 
- Renda per capita familiar na época do trauma - variável numérica baseada na informação do paciente ou responsável quanto à renda familiar mensal e número de dependentes desse valor. Foi calculada em reais e salários mínimos. O salário mínimo utilizado como referência foi de $\mathrm{R} \$ 724,00$ em vigência no ano de $2014^{2}$.

\section{Variáveis clínicas relacionadas ao trauma e Atendimento Pré-hospitalar} (APH)

- Causa externa - variável categórica que foi descrita de acordo com os grupos de causas do capítulo XX (causas externas de morbidade e de mortalidade) da Classificação Estatística Internacional de Doenças e Problemas Relacionados com a Saúde-10 (CID-10) ${ }^{(58)}$.

- Relato de ingestão de álcool - variável dicotômica que identificou os casos em que houve registro em prontuário de sinais de consumo de álcool ou relato por familiares ou paciente de uso dessa droga no período próximo ao evento traumático.

- Tipo de APH - variável categórica que diferenciou vítimas atendidas por serviços aéreos e terrestres.

- ECGl na cena - valor desta escala no local do evento traumático informada pela equipe de APH. Variável numérica que definiu o nível de consciência das vítimas por meio da avaliação de três parâmetros: abertura ocular, melhor resposta verbal e melhor resposta motora (MRM). Os escores da ECG1 variam de 3 a 15; quanto maior a pontuação obtida, melhor o nível de consciência.

- Intubação orotraqueal (IOT) na cena - variável dicotômica que indica a realização ou não desse procedimento na vítima pela equipe de APH.

\section{Variáveis clínicas na admissão e internação hospitalar}

- IOT na admissão hospitalar - variável dicotômica que indica a realização ou não desse procedimento na admissão hospitalar.

- Sedação - variável dicotômica que indica o uso de sedativos na admissão hospitalar.

\footnotetext{
2 http://www.brasil.gov.br/economia-e-emprego/2013/12/valor-do-salario-minimo-vaipara-r-724-em-2014
} 
- Frequência respiratória (FR) na admissão hospitalar - atribuída à vítima com respiração espontânea ou em assistência ventilatória. Nas análises de associação, as vítimas foram agrupadas segundo FR normal (10 a 29 incursões respiratórias por minuto - irpm) e FR alterada $(<10$ ou $>29$ irpm) $)^{(59)}$.

- Saturação periférica de oxigênio $\left(\mathrm{SpO}_{2}\right)$ - variável numérica medida por oxímetro de pulso que identificou indivíduos em hipóxia, quando $\mathrm{SpO}_{2}$ $<90 \%{ }^{(60)}$.

- Pressão parcial de oxigênio $\left(\mathrm{PO}_{2}\right)$ na admissão hospitalar - variável numérica obtida em resultado de gasometria arterial. Nas análises de associação, este parâmetro também foi utilizado para identificar hipóxia, sendo $\mathrm{PO}_{2}<60 \%$ considerada indicação de presença dessa alteração ${ }^{(60)}$.

- Pressão arterial sistólica (PAS) na admissão hospitalar - variável numérica atribuída à vítima após a aferição da pressão arterial. Nas análises de associação, PAS $<90 \mathrm{mmHg}$ foi indicativo de hipotensão ${ }^{(60)}$. Os maiores e menores valores diários dessa variável foram registrados permitindo estabelecer a frequência de episódios de hipotensão e hipertensão durante a internação hospitalar. Episódios de hipertensão foram identificados por $\mathrm{PAS} \geq 160 \mathrm{mmHg}^{(61)}$.

- Frequência cardíaca (FC) na admissão hospitalar - variável numérica que, nas análises de associação, foi utilizada para analisar a presença de dois tipos de alteração: a bradicardia ( $\mathrm{FC}<50$ batimentos por minuto - bpm) e a taquicardia $(\mathrm{FC}>100 \mathrm{bpm})^{(62)}$.

- Glicemia na admissão hospitalar - variável numérica que permitiu reunir indivíduos com e sem hipoglicemia e com e sem hiperglicemia nas análises de associação. Valores de glicemia capilar $<70 \mathrm{mg} / \mathrm{dl}$ foram indicativos de hipoglicemia e $>160 \mathrm{mg} / \mathrm{dl}$, indicativos de hiperglicemia ${ }^{(61,63)}$. Valores diários dessa variável foram registrados, permitindo estabelecer a frequência de episódios de hipoglicemia e hiperglicemia durante a internação hospitalar e, também, identificar as vítimas que apresentaram essas alterações nos primeiros cinco dias de internação. 
- Temperatura corporal - variável numérica que permitiu reunir indivíduos com e sem hipotermia e com e sem hipertermia nas análises de associação. Temperatura axilar $\leq 35^{\circ} \mathrm{C}$ foi indicação de hipotermia ${ }^{(60)} \mathrm{e}$ $\geq 38^{\circ} \mathrm{C}$, de hipertermia ${ }^{(64,65)}$. Valores diários dessa variável foram registrados, permitindo estabelecer a frequência de episódios dessas alterações durante a internação hospitalar.

- ECGl na internação hospitalar - durante a internação hospitalar, a ECGl foi aplicada diariamente, permitindo identificar seu valor não só na admissão hospitalar, mas também 24 e 48 horas após retirada da sedação. O tempo em dias para alcançar pontuação 6 no parâmetro MRM da ECGl após LAD também pode ser identificado com base nessa avaliação diária.

- Alterações pupilares - variável dicotômica em que a presença de anormalidade foi registrada em casos de alterações de forma, tamanho e reflexo fotomotor.

- Internação na UTI - variável dicotômica que descreveu se as vítimas foram ou não admitidas nesse tipo de unidade durante sua internação no IC/HCFMUSP.

- Tempo de internação na UTI - variável numérica considerada em dias.

- Uso de sedação contínua - variável dicotômica que indicou a presença de sedação contínua durante a internação hospitalar.

- Tempo de sedação contínua - variável numérica considerada em dias.

- Escala de agitação e sedação de Richmond (The Richmond Agitation and Sedation Scale - RASS) - aplicada para aferir tanto a sedação quanto o nível de agitação ${ }^{(66)}$. Os escores da escala variam de +4 a -5 ; quanto menor a pontuação, maior o nível de sedação do paciente ${ }^{(66)}$. Durante a sedação contínua, a RASS foi aplicada diariamente, permitindo identificar seu valor 24 horas antes da retirada da sedação.

- Outros tratamentos com drogas que atuam no sistema nervoso central (SNC) - variável dicotômica que reuniu os participantes que utilizaram drogas que atuam no SNC, sem finalidade de sedação.

- Tratamento cirúrgico - variável dicotômica que descreveu se os pacientes foram ou não submetidos a tratamento cirúrgico durante a internação hospitalar. 
- Reabordagem cirúrgica: variável dicotômica que reuniu os pacientes que necessitaram de reabordagem cirúrgica durante a internação hospitalar.

- Infecção durante internação - variável dicotômica que indicou diagnóstico de infecção confirmado por exames laboratoriais, durante a internação hospitalar.

- Outras complicações - variável dicotômica que indicou a presença ou não de complicações clínicas, exceto infecção, durante a internação hospitalar.

- Sinais de LAD precoces na TC de crânio: variável dicotômica que considerou os resultados das TC de crânio nas primeiras 72 horas de atendimento hospitalar e reuniu indivíduos que tiveram presença de hemorragia intraventricular, hemorragia subaracnoide, gliding contusion, inchaço difuso com apagamentos das cisternas basilar ou sulcos; sinais indiretos da lesão ${ }^{(67-71)}$.

- Monitorização da pressão intracraniana (PIC) - variável dicotômica que indicou a presença ou não dessa monitorização durante a internação.

- Hipertensão intracraniana (HIC) - variável dicotômica que reuniu pacientes que tiveram esse diagnostico durante a internação com auxílio de resultados de TC de crânio e Doppler Transcraniano ${ }^{(72)}$.

- Tempo de internação hospitalar: variável numérica considerada em dias.

- Destino após alta do IC/HCFMUSP: variável categórica que descreveu o local para onde os sobreviventes foram encaminhados após alta do IC/HCFMUSP.

\subsection{INSTRUMENTOS DE COLETA DE DADOS}

\subsubsection{Termos de Consentimento Livre-Esclarecido (TCLE)}

Instrumento aprovado pelo Comitê de Ética e Pesquisa que foi utilizado para manifestação do paciente ou responsável sobre sua anuência para participar do estudo (Apêndice A). 


\subsubsection{Ficha de registro de dados na internação}

Nesta ficha, foram registrados os dados coletados durante a internação hospitalar e obtidos no prontuário do paciente, em registros eletrônicos e em entrevistas com familiares ou pacientes.

Os campos contemplados nessa ficha direcionaram a coleta de informações referentes às variáveis clínicas e sociodemográficas relacionadas ao APH, admissão e internação hospitalar (Apêndice B).

O registro das descrições das lesões, conforme região corpórea acometida, foi realizado durante a internação hospitalar e incluiu as lesões decorrentes do trauma registradas em anotações de prontuário e confirmadas em inspeção corpórea, laudo de exames ou em fichas cirúrgicas. Após a identificação das lesões, foi identificada a gravidade de todas elas isoladamente, segundo o Manual AIS 2005 ${ }^{(52)}$, update 2008, e estabelecido o valor do MAIS/cabeça, além de realizado o cálculo dos índices ISS e NISS.

\subsubsection{Ficha de levantamento de dados na alta hospitalar (Apêndice C)}

Os campos contemplados nessa ficha direcionaram a coleta de informações do paciente no que se refere a data de alta hospitalar, destino após alta do IC/HCFMUSP, ERGA e AVD pela escala de Katz. Nesta fase, foram asseguradas as informações que permitiram contatos posteriores com o paciente ou responsável.

\subsubsection{Ficha de levantamento de dados aos três e seis meses após LAD} (Apêndice D)

Instrumento para a coleta de dados do paciente durante o acompanhamento após alta hospitalar. Nesse período, em entrevistas com pacientes ou familiares responsáveis, a Katz e a ERGA foram aplicadas e informações relacionadas a tratamentos realizados coletadas. 


\subsection{DESPESAS E TREINAMENTO}

A pesquisa recebeu financiamento da Fundação de Amparo à Pesquisa do Estado de São Paulo, que custeou despesas referentes a materiais de consumo, material permanente, serviços de terceiros especializados e despesas de transporte. As despesas referentes a pagamento dos auxiliares de coleta foi custeada pela pesquisadora.

Para colaborar com a coleta de dados desta investigação, foram selecionadas três enfermeiras e uma aluna do $2^{\circ}$ ano do curso graduação da Escola de Enfermagem da Universidade de São Paulo. Durante duas semanas, foram realizados encontros para apresentação dos instrumentos e esclarecimentos sobre sua aplicação, conhecimento dos instrumentos, técnica de abordagem de pacientes e/ou família, além de formas de acesso às fontes de dados. O treinamento in loco iniciou-se apenas após a aprovação do Comitê de Ética. Nesta fase, todos os envolvidos coletavam dados dos pacientes simultaneamente e, depois, confrontavam os resultados. Divergências, dificuldades e dúvidas foram sanadas no momento da coleta pela pesquisadora, que acompanhava todo o treinamento. Esta segunda etapa do treinamento teve duração de dois meses e foi finalizada quando a equipe apresentou segurança no resgate de dados, aplicação dos instrumentos e na abordagem do paciente e/ou família.

\subsection{OPERACIONALIZAÇÃO DE COLETA DOS DADOS}

Após a aprovação da pesquisa pelo Comitê de Ética e Pesquisa e treinamento dos auxiliares de coleta, iniciou-se a coleta de informações em julho de 2013 no IC/HCFMUSP.

A pesquisadora realizou, diariamente, o rastreamento das vítimas internadas e acompanhadas pela equipe de neurocirurgia por meio do censo eletrônico do pronto-socorro, atualizado diariamente pelos residentes de medicina da neurocirurgia do hospital. Esse censo informava nome, idade, data da ocorrência traumática, número de registro do Hospital das Clínicas (RGHC), localização no hospital, quadro clínico, laudos de exames 
realizados e diagnóstico de todos os doentes admitidos e internados no pronto-socorro e atendidos por essa equipe.

Nesse censo eletrônico, foram selecionados os pacientes admitidos nas últimas 24 horas, com idade $\geq 18$ anos e $\leq 60$ anos. Após essa seleção, os pacientes foram rastreados no pronto-socorro e seus prontuários foram analisados para identificar os indivíduos atendidos no hospital até 6 horas após o trauma, que vieram direto da cena da ocorrência, vítimas de TCE contuso, com ECGl $\leq 8$ na admissão hospitalar.

Depois de diagnosticadas as lesões, foram excluídas do estudo as vítimas que não tiveram confirmação de LAD e também aquelas que, embora tivessem esse diagnóstico, apresentaram lesão com AIS $\geq 3$ na região cabeça ou medula espinhal. Portadores de patologia crônica psiquiátrica ou indivíduos com diagnóstico anterior de TCE foram excluídos à medida que esta informação foi obtida com pacientes ou familiares. Nesta fase, a confirmação da LAD foi realizada por sinais da lesão em TC ou RM, identificados por neurocirurgiões especialistas no atendimento nesse tipo de lesão. Casos de ECG1 menor ou igual a 8, sem RM e TC normal, também receberam diagnóstico dessa lesão ${ }^{(67-71)}$.

A participação voluntária na pesquisa foi confirmada após a assinatura do TCLE pelas vítimas ou familiar responsável. Cada participante recebeu uma cópia do TCLE e foi informado sobre a possibilidade de retirada do consentimento em qualquer momento da pesquisa, sem prejuízo ou perda de qualquer benefício adquirido com sua participação.

Durante o período de internação no IC/HCFMUSP, as vítimas de LAD selecionadas receberam visita diária da equipe de pesquisa, que coletou informações com pacientes, familiares, profissionais de saúde e prontuário. Cada auxiliar de coleta tinha dias fixos para comparecer ao hospital e coletar os dados, sempre supervisionada a distância ou in loco pela pesquisadora.

Quando definida a alta hospitalar, a ficha de levantamento de dados relacionada a esse período foi preenchida. Nos casos de alta para residência, após o término da entrevista, os pacientes e familiares receberam orientação para seguimento ambulatorial 3 e 6 meses após o trauma. Os participantes 
deste estudo encaminhados para outras instituições tiveram seguimento por meio de telefonemas quinzenais para familiares ou responsáveis até que o período de 6 meses após o trauma fosse finalizado.

No período de 3 e 6 meses após o trauma, foi preenchida a ficha de acompanhamento das vítimas. As vítimas que ainda se encontravam internadas no Hospital Auxiliar de Suzano/HCFMUSP ou que estavam incapazes de locomoção foram avaliadas na residência ou nesse hospital.

\subsection{PROCESSAMENTO E ANÁLISE DE DADOS}

Todas as informações coletadas foram armazenadas em banco de dados computadorizado construído com uso do software Statistical Package for the Social Sciences (SPSS) versão 17.0. Este programa de computador também foi utilizado para realizar as provas estatísticas, conforme orientação de especialista na área.

\subsubsection{Análise descritiva}

Estatísticas descritivas foram realizadas para todas as variáveis visando à caracterização geral da amostra do estudo. As variáveis categóricas ou ordinais foram descritas por meio de frequências absolutas e relativas. Para as variáveis numéricas contínuas ou discretas, foram apresentadas a média e a mediana como medidas síntese, e o desvio-padrão mínimo e máximo para apontar a variabilidade.

\subsubsection{Análise inferencial}

Nas análises inferenciais foram comparados os resultados da escala de Katz e ERGA entre alta, 3 meses e 6 meses após LAD, a fim de identificar a recuperação da vítima no período. Foram também verificadas as associações entre as variáveis de interesse e os desfechos óbito e dependência aos seis meses do trauma. Ademais, a regressão logística foi 
utilizada para identificar modelos para estimar fatores associados a óbito e à dependência nesse período.

Para comparar os resultados da ERGA e relacionados aos itens da escala de Katz entre as três avaliações, foi utilizado o teste não paramétrico de Friedman, por se tratar de medidas ordinais. Este teste considera em suas comparações a dependência entre os resultados comparados e foi selecionado visto que as avaliações foram relativas a um mesmo paciente.

$\mathrm{Na}$ medida em que houve diferença significante entre os resultados das avaliações, foram feitas comparações múltiplas (comparações dois a dois entre tempos), utilizando o teste de Student-Newman-Keuls adaptado para testes não paramétricos.

Para comparar a média do valor total da escala de Katz entre os três momentos de avaliação, foi utilizada a análise de variância (ANOVA) com medidas repetidas, por se tratar de medidas relativas a um mesmo paciente. Havendo diferença estatisticamente significante entre os tempos, foram feitas comparações múltiplas (comparações dois a dois entre tempos), por meio do teste de Bonferroni.

Para identificar associações entre as variáveis de interesse e os desfechos óbito e dependência aos seis meses do trauma, foram realizadas comparações entre grupos de indivíduos que evoluíram ou não a óbito e, também, entre os que se encontravam dependentes ou independentes aos seis meses após LAD, conforme resultados da ERGA. Nessas comparações, em relação às variáveis categóricas, foram aplicados os testes Qui-Quadrado de Pearson ou Exato de Fisher. O Teste Exato de Fisher foi aplicado nos casos em que a frequência esperada, em pelo menos uma das caselas das tabelas de contingência, foi $\leq 5$. Para a comparação das variáveis numéricas discretas ou contínuas, a técnica estatística utilizada foi o teste t-Student.

Seguindo as análises, com o intuito de verificar se as variáveis associadas aos desfechos retinham sua importância no contexto simultâneo das demais e identificar os fatores de risco para óbito e dependência, foi realizada a análise de Regressão Logística Múltipla. Para esta análise, usouse o método stepwise forward; hora a modelagem foi realizada com ISS e as demais variáveis que apresentaram $p$-value $\leq 0,05$ na comparação entre 
grupos, hora com NISS e essas mesmas variáveis, visto que ISS e NISS estimam gravidade global do trauma e, portanto, apresentam problemas de multicolinearidade. Durante a modelagem, permaneceram no modelo final apenas aquelas que apresentaram significância estatística no modelo de regressão logística, $\mathrm{p} \leq 0,05$.

\subsubsection{Nível de significância e poder do estudo}

Para todas as análises, foi considerado o nível de significância de $5 \%$. Calculou-se o poder do estudo tendo em vista os resultados obtidos em relação ao objetivo principal, isto é, descrever a recuperação da LAD até 6 meses após trauma por meio da diferença nos resultados das avaliações com a ERGA e a escala de Katz na alta, 3 e 6 meses após LAD. À vista disso, o cálculo do poder do estudo pela escala de Katz foi estimado pela comparação da média na pontuação nos três momentos e na ERGA pela comparação da categorização da escala nesses tempos. Foram utilizados nessas análises os mesmos testes descritos anteriormente para comparação dos resultados das escalas entre a alta, 3 e 6 meses. 


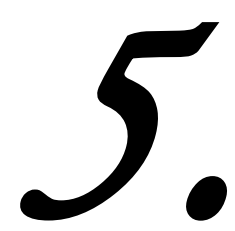

Resultados 


\section{RESULTADOS}

\subsection{CARACTERIZAÇÃO DAS VÍTIMAS COM DIAGNÓSTICO PRINCIPAL DE LAD}

Entre julho de 2013 e fevereiro de 2014, 78 vítimas de LAD admitidas no IC/HCFMUSP atenderam aos critérios de inclusão e exclusão deste estudo e participaram da pesquisa na fase de internação hospitalar. Dessas vítimas, 24 (30,7\%) evoluíram a óbito durante o seguimento de 6 meses, $50(65,1 \%)$ tomaram parte em todas as etapas da pesquisa, 1 paciente $(1,3 \%)$ não compareceu à avaliação após 3 meses da LAD e $3(3,8 \%)$ eximiram-se de participar no estudo após alta hospitalar.

$\mathrm{Na}$ Tabela 5, observa-se que a grande maioria $(89,7 \%)$ dos participantes do estudo era do sexo masculino e encontrava-se inserida no mercado de trabalho na época do trauma. Prevaleceram os jovens entre $18 \mathrm{e}$ 28 anos $(43,6 \%)$ e a baixa escolaridade. A idade e escolaridade média foram de 32 anos $(\mathrm{dp}=11,2)$ e 9,1 anos $(\mathrm{dp}=9,1)$, respectivamente. Participantes com $1^{\circ}$ grau incompleto e completo totalizaram $48,7 \%$ da casuística. A maioria das vítimas era branca $(65,4 \%)$, solteira $(51,3 \%), 73,0 \%$ tinha renda per capita familiar mensal entre 1 e 5 salários mínimos e o valor médio dessa renda foi de $\mathrm{R} \$ 1.290,98(\mathrm{dp}=\mathrm{R} \$ 2.282,64)$.

Tabela 5 - Vítimas de LAD segundo características sociodemográficas na época do trauma. HCFMUSP, 2013-2014.

\begin{tabular}{|c|c|c|}
\hline $\begin{array}{c}\text { CARACTERÍSTICAS } \\
\text { SOCIODEMOGRÁFICAS }\end{array}$ & $\mathbf{N}$ & $\%$ \\
\hline \multicolumn{3}{|l|}{ Gênero } \\
\hline Masculino & 70 & 89,7 \\
\hline Feminino & 8 & 10,3 \\
\hline \multicolumn{3}{|l|}{ Idade (anos) } \\
\hline $18 \vdash 28$ & 34 & 43,6 \\
\hline $28 \vdash 38$ & 20 & 25,6 \\
\hline $38 \vdash 48$ & 15 & 19,2 \\
\hline $48 \vdash 58$ & 9 & 11,6 \\
\hline
\end{tabular}




\section{CARACTERÍSTICAS \\ SOCIODEMOGRÁFICAS}

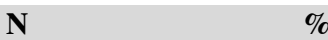

\section{Escolaridade}

$1^{\circ}$ grau incompleto

$1^{\circ}$ grau completo

$2^{\circ}$ grau incompleto

$2^{\circ}$ grau completo

$3^{\circ}$ grau incompleto

$3^{\circ}$ grau completo

Pós-graduação

Vínculo conjugal

Solteiro

Casado

Separado

Raça

Branca

Negra

Situação ocupacional

Inserido no mercado de trabalho

Sem inserção no mercado de trabalho

Renda per capita familiar mensal

(salários mínimos)*

Sem renda

Até 1

$1 \vdash 5$

$5 \vdash-10$

$\geq 10$

* Valor de referência R $\$ 724,00$
30,8

17,9

15,4

19,2

10,3

3,8

2,6

51,3

39,7

9,0

65,4

34,6

$27 \quad 34,6$

$70 \quad 89,7$

$8 \quad 10,3$

De acordo com a Tabela 6, a principal causa de LAD neste estudo foi o acidente de transporte, sendo os motociclistas a mais frequente categoria de traumatizados $(43,6 \%)$ nessas ocorrências, seguidos dos ocupantes de automóvel $(25,6 \%)$. Grande parte das vítimas $(42,3 \%)$ tinha referência de ingestão de bebidas alcoólicas no período próximo ao evento traumático. Todos os participantes da casuística foram removidos por serviços de APH e foi expressiva a frequência do uso de transporte aéreo $(47,4 \%)$ para as vítimas. Indivíduos em coma $(\mathrm{ECGl} \leq 8)$ totalizaram $75,7 \%$ dos traumatizados, sendo $79,5 \%$ dos participantes da pesquisa intubados ainda na cena da ocorrência.

Os valores dos escores da PAS e FC na cena não estavam relatados em 27,0\% dos registros, o valor da $\mathrm{SpO}_{2}$ desta fase do tratamento não constava em $70,0 \%$ dos prontuários e a perda de informações do parâmetro FR na cena foi de $84,6 \%$. Consequentemente, essas variáveis não fizeram parte das análises desta pesquisa. 
Tabela 6 - Vítimas de LAD segundo características relacionadas ao trauma e APH. HCFMUSP, 2013-2014.

\begin{tabular}{|c|c|c|}
\hline $\begin{array}{c}\text { CARACTERÍSTICAS RELACIONADAS AO } \\
\text { TRAUMA E APH }\end{array}$ & $\mathbf{N}$ & $\%$ \\
\hline \multicolumn{3}{|l|}{ Causa externa } \\
\hline \multicolumn{3}{|l|}{ Acidente de transporte } \\
\hline Motociclista & 34 & 43,6 \\
\hline Ocupante de automóvel & 20 & 25,6 \\
\hline Pedestre & 10 & 12,8 \\
\hline Ciclista & 1 & 1,3 \\
\hline Agressão & 3 & 3,8 \\
\hline Queda & 8 & 10,3 \\
\hline Lesões autoprovocadas intencionalmente & 1 & 1,3 \\
\hline Colisão entre duas pessoas - na prática de esporte & 1 & 1,3 \\
\hline \multicolumn{3}{|l|}{ Relato de ingestão de álcool } \\
\hline $\operatorname{Sim}$ & 33 & 42,3 \\
\hline Não & 45 & 57,7 \\
\hline \multicolumn{3}{|l|}{ Tipo de APH } \\
\hline Terrestre & 41 & 52,6 \\
\hline Aéreo & 37 & 47,4 \\
\hline \multicolumn{3}{|l|}{ ECGI na cena } \\
\hline 3 & 21 & 26,9 \\
\hline $4-5$ & 20 & 25,7 \\
\hline $6-8$ & 18 & 23,1 \\
\hline $9-12$ & 6 & 7,7 \\
\hline $13-15$ & 4 & 5,1 \\
\hline Sem informação & 9 & 11,5 \\
\hline \multicolumn{3}{|l|}{ IOT na cena } \\
\hline $\operatorname{Sim}$ & 62 & 79,5 \\
\hline Não & 15 & 19,2 \\
\hline Sem informação & 1 & 1,3 \\
\hline
\end{tabular}

Quanto à gravidade do trauma, o ISS variou de 17 a 75, com média de $35(\mathrm{dp}=11,9)$ e mediana de 33. Na distribuição das vítimas nas três categorias de gravidade, observou-se que nenhum paciente apresentou trauma leve (ISS $<16), 19,2 \%$ tiveram trauma moderado $(\geq 16$ e $<25)$ e predominou o trauma grave (ISS $\geq 25$ ). Nesse último grupo, um paciente alcançou o escore máximo, apontando para extrema gravidade do trauma. Mais de 25,0\% das vítimas apresentaram pontuação superior a 40, valor relacionado com mortalidade de 40,0\% no Major Trauma Outcome Study

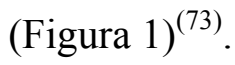


Figura 1 - Vítimas de LAD segundo gravidade do trauma estimada pelo ISS. HCFMUSP, 2013-2014.

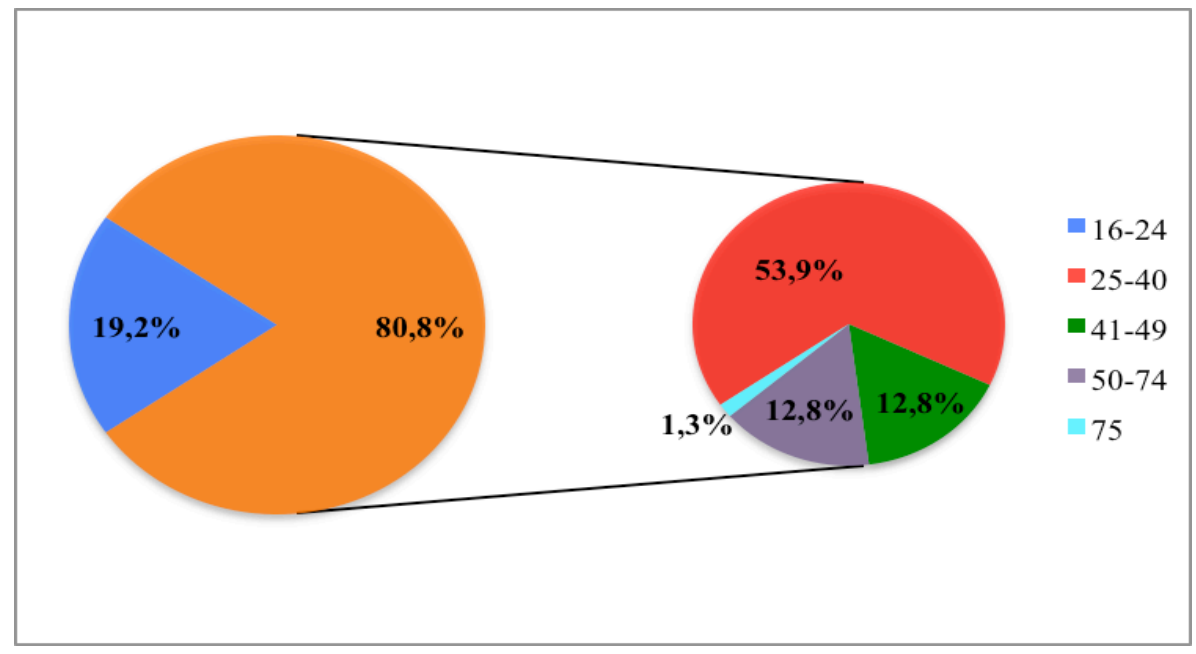

Na Figura 2 observam-se as estimativas de gravidade do trauma pelo NISS. Segundo esse indicador, a quase totalidade das vítimas, 91,0\%, teve trauma grave (NISS $\geq 25)$. Para esse índice, a média foi de 46,2 $(\mathrm{dp}=15,9)$ e mediana de 43, com variação de 18 a 75 . As vítimas com NISS superior a 40 totalizaram $62,8 \%$ da amostra.

Figura 2 - Vítimas de LAD segundo gravidade do trauma estimada pelo NISS. HCFMUSP, 2013-2014.

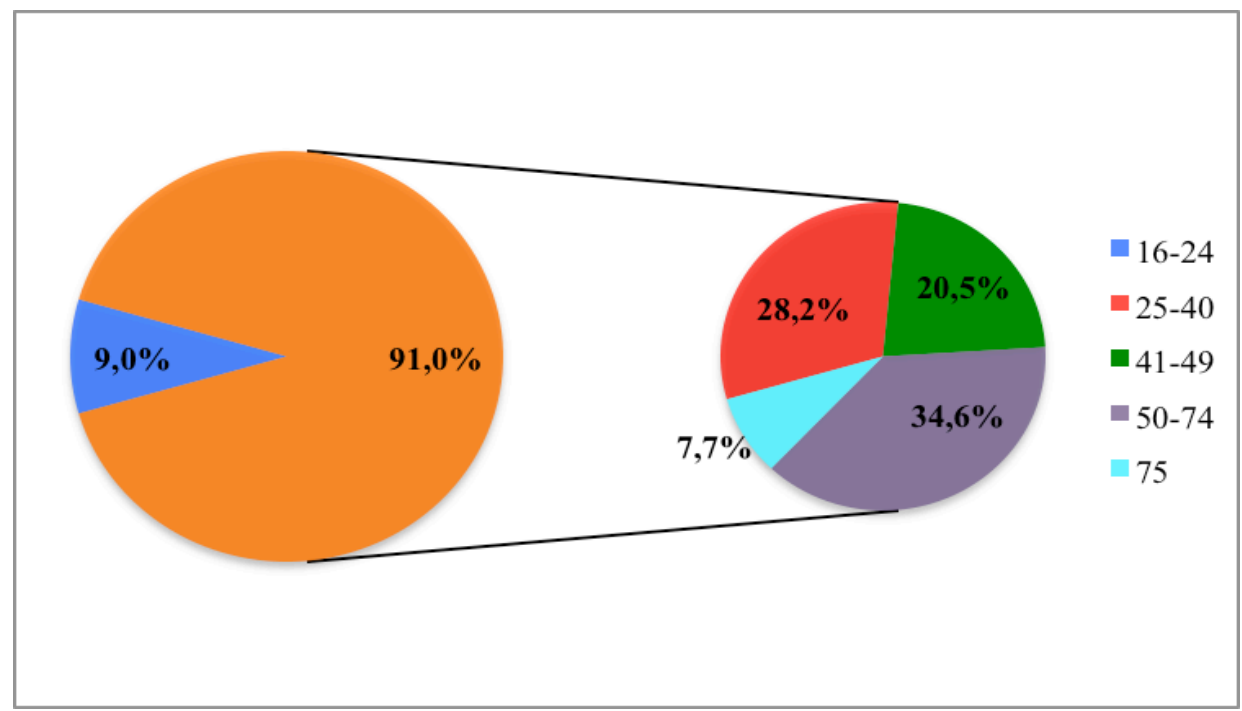

Todas as vítimas de LAD apresentaram MAIS $\geq 4$ na região cabeça, com média de 4,6 $(\mathrm{dp}=0,5)$. Lesões de gravidade crítica, MAIS=5, foram constatadas em 55,1\% da amostra (Figura 3). 
Figura 3 - Vítimas de LAD segundo gravidade do TCE estimada pelo MAIS/cabeça. HCFMUSP, 2013-2014.

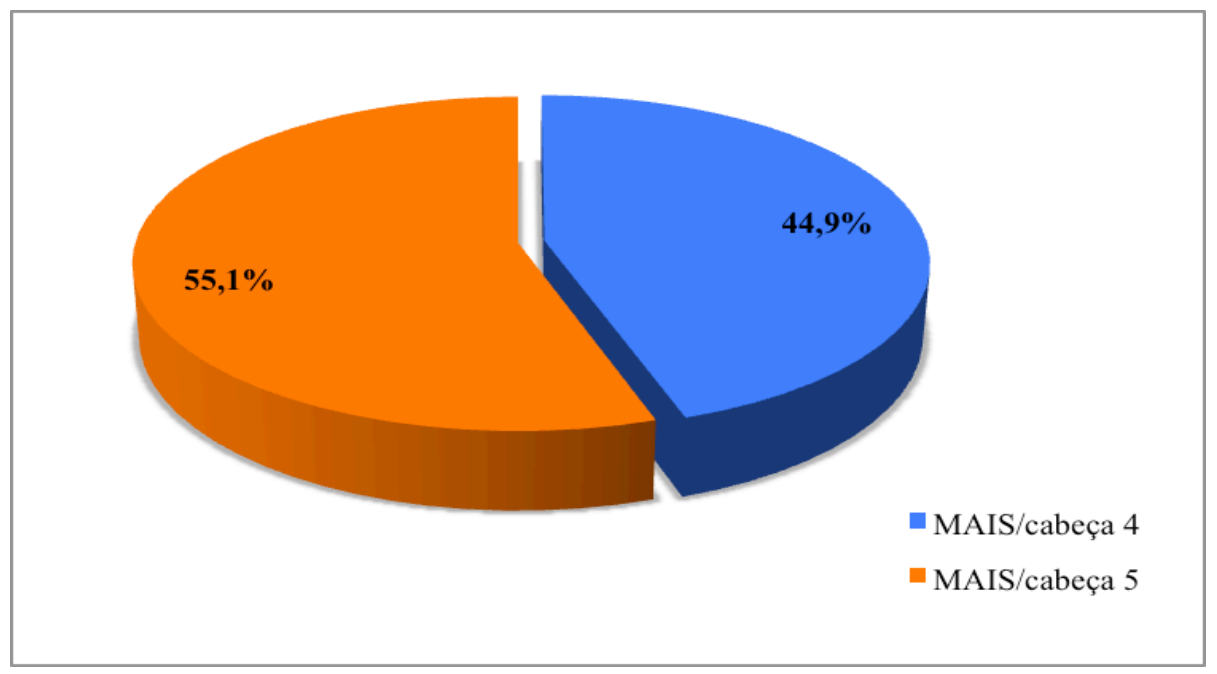

Os dados da Figura 4 mostram que 44,9\% das vítimas apresentaram LAD leve, 19,2\% LAD moderada e 35,9\% LAD grave.

Figura 4 - Vítimas de LAD segundo gravidade dessa lesão. HCFMUSP, 2013-2014.

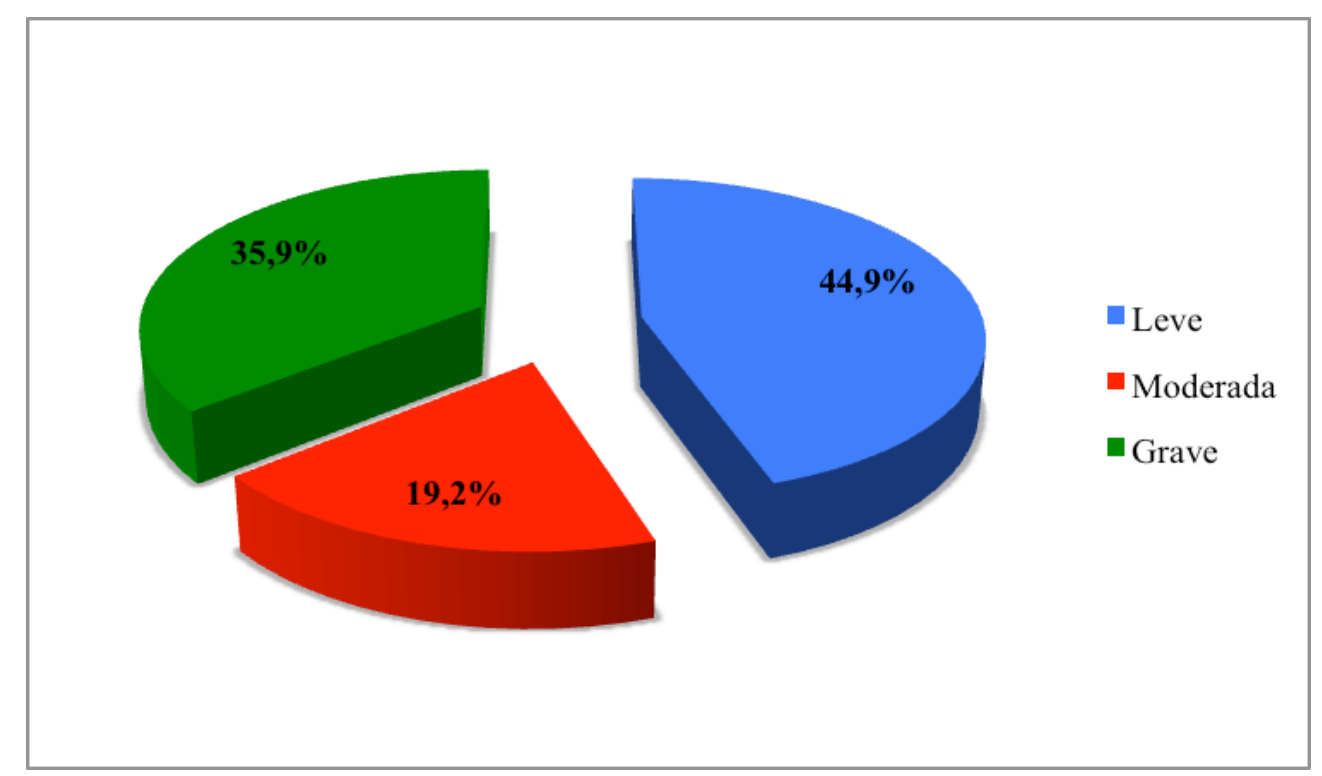

$\mathrm{Na}$ admissão hospitalar, todos os pacientes que não haviam sido intubados na cena do trauma foram submetidos a esse procedimento; por conseguinte, $100,0 \%$ das vítimas de LAD encontravam-se intubadas no período inicial de sua internação hospitalar. A quase totalidade delas $(92,3 \%)$ foi tratada com sedativos nessa fase de atendimento, embora nem sempre mantivessem sedação contínua (Tabela 7). 
Quanto às condições clínicas das vítimas na chegada ao IC/HCFMUSP mostradas na Tabela 7, observa-se FR alterada em 10,3\% da amostra, sendo a taquipneia a alteração mais frequente $(6,4 \%)$. Hipóxia foi detectada pela $\mathrm{SpO}_{2}$ em $15,3 \%\left(\mathrm{SpO}_{2}<90 \%\right)$ e pela $\mathrm{PO}_{2}$ em $14,1 \%\left(\mathrm{PO}_{2}\right.$ $<60 \%$ ) dos traumatizados; $19,2 \%$ dos incluídos neste estudo apresentaram PAS $<90 \mathrm{mmHg} ; 2,5 \%$ tiveram parada cardíaca; taquicardia esteve presente na maioria $(52,5 \%)$ dos selecionados para esta pesquisa nesta fase de tratamento. Alterações glicêmicas foram encontradas em 32,0\% da amostra, sendo a hiperglicemia a mais frequente $(28,2 \%)$. Todos os pacientes tiveram ECGl $\leq 8$, conforme critério de inclusão na amostra, e 60,3\% tiveram alterações pupilares.

Tabela 7 - Vítimas de LAD segundo características clínicas na admissão hospitalar. HCFMUSP, 2013-2014.

\begin{tabular}{|c|c|c|}
\hline $\begin{array}{l}\text { CARACTERÍSTICAS CLÍNICAS NA ADMISSÃO } \\
\text { HOSPITALAR }\end{array}$ & $\mathbf{N}$ & $\%$ \\
\hline \multicolumn{3}{|l|}{ IOT na admissão } \\
\hline Sim & 16 & 20,5 \\
\hline Não (IOT na cena) & 62 & 79,5 \\
\hline \multicolumn{3}{|l|}{ Sedação } \\
\hline Sim & 72 & 92,3 \\
\hline Não & 6 & 7,7 \\
\hline \multicolumn{3}{|l|}{ FR (irmp) } \\
\hline 0 & 2 & 2,6 \\
\hline $1-5$ & 1 & 1,3 \\
\hline $6-9$ & - & - \\
\hline $10-29$ & 64 & 82,0 \\
\hline$>29$ & 5 & 6,4 \\
\hline Sem informação & 6 & 7,7 \\
\hline \multicolumn{3}{|l|}{$\mathrm{SpO}_{2}(\%)$} \\
\hline $0 /$ não mensurável & 2 & 2,5 \\
\hline $1-80$ & 6 & 7,7 \\
\hline $81-89$ & 4 & 5,1 \\
\hline $90-95$ & 9 & 11,6 \\
\hline $96-100$ & 56 & 71,8 \\
\hline Sem informação & 1 & 1,3 \\
\hline \multicolumn{3}{|l|}{$\mathrm{PO}_{2}(\%)$} \\
\hline$<60$ & 11 & 14,1 \\
\hline $60-90$ & 11 & 14,1 \\
\hline$>90$ & 52 & 66,7 \\
\hline Sem informação & 4 & 5,1 \\
\hline \multicolumn{3}{|l|}{ PAS (mmHg) } \\
\hline 0 & 3 & 3,8 \\
\hline $1-49$ & 1 & 1,3 \\
\hline $50-75$ & 8 & 10,3 \\
\hline $76-89$ & 3 & 3,8 \\
\hline$>89$ & 63 & $\begin{array}{l}80,8 \\
\text { (continua) }\end{array}$ \\
\hline
\end{tabular}




\begin{tabular}{|c|c|c|}
\hline $\begin{array}{l}\text { CARACTERÍSTICAS CLÍNICAS NA ADMISSÃO } \\
\text { HOSPITALAR }\end{array}$ & $\mathbf{N}$ & $\begin{array}{l}\text { (continuação) } \\
\text { \% }\end{array}$ \\
\hline \multicolumn{3}{|l|}{ FC (bpm) } \\
\hline 0 & 2 & 2,6 \\
\hline$<50$ & - & - \\
\hline $50-100$ & 35 & 44,9 \\
\hline$>100$ & 41 & 52,5 \\
\hline \multicolumn{3}{|l|}{ Glicemia (mg/dl) } \\
\hline$<70$ & 3 & 3,8 \\
\hline $70-160$ & 46 & 59,0 \\
\hline$>160$ & 22 & 28,2 \\
\hline Sem informação & 7 & 9,0 \\
\hline \multicolumn{3}{|l|}{ ECGI } \\
\hline 3 & 45 & 57,7 \\
\hline $4-5$ & 9 & 11,5 \\
\hline $6-8$ & 24 & 30,8 \\
\hline \multicolumn{3}{|l|}{ Alterações pupilares } \\
\hline Sim & 47 & 60,3 \\
\hline Não & 31 & 39,7 \\
\hline
\end{tabular}

Segundo os dados da Tabela 8, a quase totalidade das vítimas foi internada em UTI (92,3\%), o tempo médio de internação nessa unidade foi de 11,7 dias $(\mathrm{dp}=15,4)$, o valor mediano foi de 7 e a variação de menos de 1 dia a 109 dias. Do total da casuística, 69 pacientes $(88,5 \%)$ usaram sedação contínua, durante um tempo médio de 4,1 dias $(d p=4,3)$, mediana de 3 dias e variação de menos de 1 dia a 18 dias. Os medicamentos mais empregados foram o propofol e o fentanil, utilizados, respectivamente, em 94,2\% e $92,7 \%$ dos sedados. A maioria das vítimas $(61,5 \%)$ fez tratamentos com drogas que atuam no SNC, sem finalidade de sedação. Nesses casos, os medicamentos mais utilizados foram os anticonvulsivantes $(83,3 \%)$, os neurolépticos $(70,8 \%)$ e os benzodiazepínicos $(25,0 \%)$.

Após a admissão hospitalar, as vítimas de LAD demoraram em média 3,7 dias $(\mathrm{dp}=7,2)$ para obter o escore 6 no item MRM da ECGl. O valor mediano desse tempo foi de 1 dia e a variação de menos de 24 horas a 32 dias. Entretanto, no seguimento de 6 meses, 23 vítimas $(29,5 \%)$ não atingiram escore 6 no item MRM da ECGl: 22 morreram antes de alcançar essa pontuação na ECGl e uma encontrava-se em estado vegetativo persistente até o final do período de avaliação (Tabela 8).

Conforme se pode observar na Tabela 8, durante a internação hospitalar, a maioria das vítimas $(53,8 \%)$ foi submetida a cirurgia e 19,2\% 
tiveram reabordagem cirúrgica. Quadros infecciosos foram registrados em $25,6 \%$ dos casos e outras complicações identificadas em 52,6\% dos pacientes. Entre essas outras complicações, as mais observadas foram choque $(27,0 \%)$, insuficiência renal aguda $(20,5 \%)$, rabdomiólise $(15,4 \%)$, distúrbio hidroeletrolítico $(11,5 \%)$, disautonomia simpática $(9,0 \%)$, crise convulsiva $(7,7 \%)$ e pneumonia $(7,7 \%)$.

Tabela 8 - Vítimas de LAD segundo características clínicas na internação hospitalar. HCFMUSP, 2013-2014.

\begin{tabular}{|c|c|c|}
\hline $\begin{array}{c}\text { CARACTERÍSTICAS CLÍNICAS NA } \\
\text { INTERNAÇÃO HOSPITALAR }\end{array}$ & $\mathbf{N}$ & $\%$ \\
\hline \multicolumn{3}{|l|}{ Internação em UTI } \\
\hline Sim & 72 & 92,3 \\
\hline Não & 6 & 7,7 \\
\hline \multicolumn{3}{|l|}{ Uso de sedação contínua } \\
\hline $\operatorname{Sim}$ & 69 & 88,5 \\
\hline Não & 9 & 11,5 \\
\hline \multicolumn{3}{|l|}{ Outros tratamentos com drogas que atuam no SNC } \\
\hline Sim & 48 & 61,5 \\
\hline Não & 30 & 38,5 \\
\hline \multicolumn{3}{|l|}{ Tempo para MRM = 6 (ECGI) } \\
\hline Menos de 24 horas & 16 & 20,5 \\
\hline 1 dia & 23 & 29,5 \\
\hline 2 dias & 5 & 6,4 \\
\hline 3 ou mais dias & 11 & 14,1 \\
\hline Não se aplica & 23 & 29,5 \\
\hline \multicolumn{3}{|l|}{ Tratamento cirúrgico } \\
\hline Sim & 42 & 53,8 \\
\hline Não & 36 & 46,2 \\
\hline \multicolumn{3}{|l|}{ Reabordagem cirúrgica } \\
\hline Sim & 15 & 19,2 \\
\hline Não & 63 & 80,8 \\
\hline \multicolumn{3}{|l|}{ Infecção durante a internação } \\
\hline Sim & 20 & 25,6 \\
\hline Não & 58 & 74,4 \\
\hline \multicolumn{3}{|l|}{ Outras complicações } \\
\hline Sim & 41 & 52,6 \\
\hline Não & 37 & 47,4 \\
\hline \multicolumn{3}{|l|}{ Sinais de LAD precoces na TC } \\
\hline Sim & 55 & 70,5 \\
\hline Não & 23 & 29,5 \\
\hline \multicolumn{3}{|l|}{ Monitorização da PIC } \\
\hline Sim & 3 & 3,8 \\
\hline Não & 75 & 96,2 \\
\hline \multicolumn{3}{|l|}{ HIC } \\
\hline $\operatorname{Sim}$ & 19 & 24,4 \\
\hline Não & 59 & 75,6 \\
\hline
\end{tabular}

Ainda na Tabela 8, pode-se constatar que a maioria das vítimas apresentou sinais precoces de LAD na TC $(70,5 \%)$ e que a HIC após LAD 
foi detectada em $24,2 \%$ das vítimas, ainda que a monitorização da PIC fosse realizada somente em 3 pacientes $(3,8 \%)$.

A Figura 5 apresenta as vítimas segundo resultado da RASS 24 horas antes da retirada da sedação e mostra que 25,6\% tinha escore -5 nessa avaliação. $O$ valor médio da escala foi de $-2,3(\mathrm{dp}=2,6)$ e variação de -5 a 2 com mediana de -3 . Das 15 vítimas $(19,2 \%)$ que foram incluídas na categoria não aplicável, 9 não foram tratadas com sedação contínua e 6 foram a óbito antes da suspensão desse tratamento.

Figura 5 - Vítimas de LAD segundo escores na RASS 24 horas antes da retirada da sedação. HCFMUSP, 2013-2014.

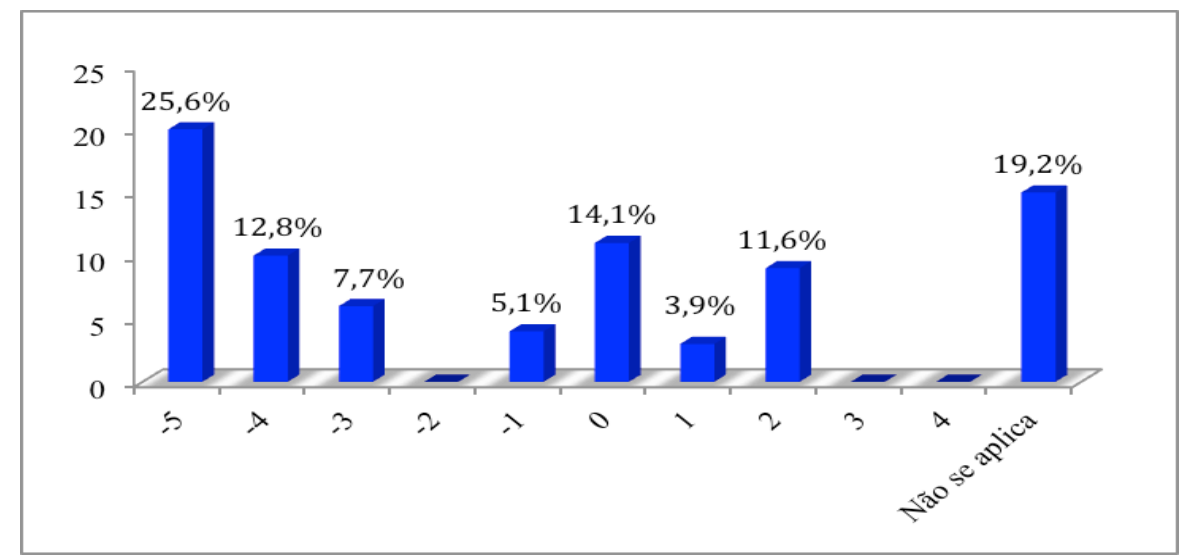

A Figura 6 mostra a evolução da média dos escores da ECGl nos pacientes de LAD a partir da cena do trauma até 48 horas após a retirada da sedação. Inicialmente, houve diminuição da pontuação média da escala (entre cena e admissão). Observou-se melhora acentuada desse parâmetro nas primeiras 24 horas após o término da sedação e discreto aumento da pontuação entre 24 e 48 horas. 
Figura 6 - Evolução do escore médio da ECGl das vítimas de LAD. HCFMUSP, 20132014.

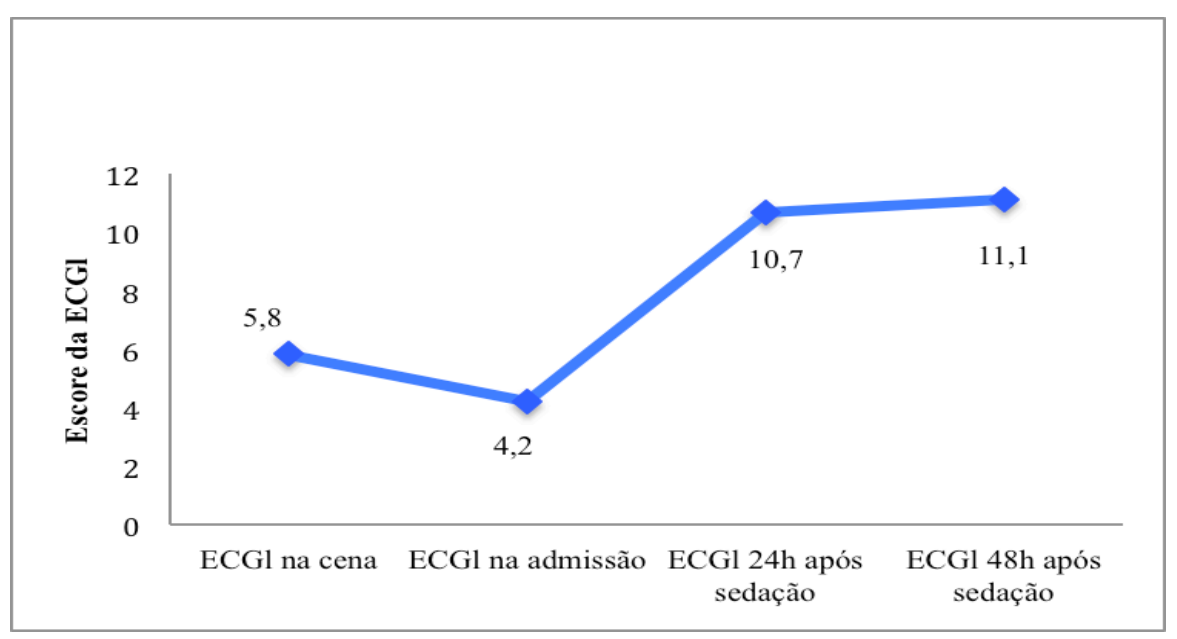

A análise da Figura 7 mostra que, durante a internação hospitalar, cerca de $17,0 \%$ das vítimas apresentaram um ou dois eventos de hipotensão sistêmica. Episódios de hipoglicemia e hipotermia foram mais frequentes e ocorreram em $29,5 \%$ e $59,0 \%$ das vítimas, respectivamente.

Figura 7 - Vítimas de LAD segundo o número de eventos de hipotensão, hipotermia e hipoglicemia durante internação hospitalar. HCFMUSP, 2013-2014.

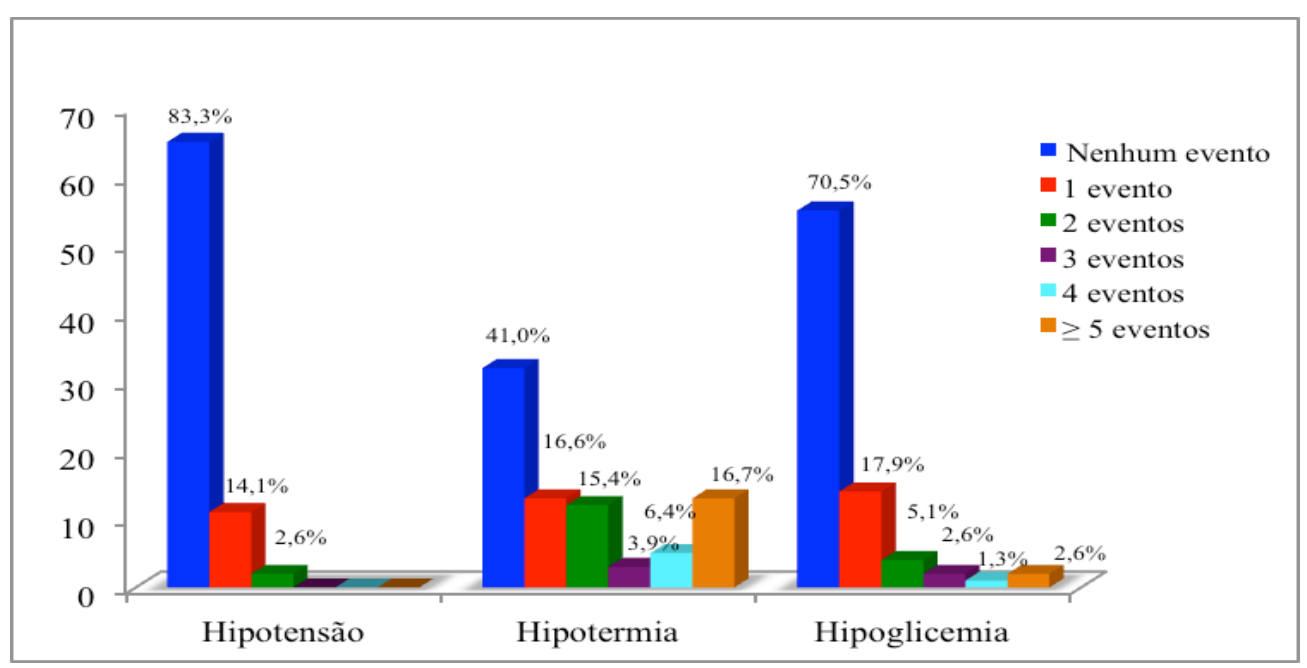

Os dados da Figura 8 evidenciam que a maioria das vítimas de LAD apresentou pelo menos um episódio de hipertensão $(68,0 \%)$, hipertermia $(64,1 \%)$ e hiperglicemia $(64,1 \%)$. Além disso, grande parte teve dois eventos ou mais dessas alterações. 
Figura 8 - Vítimas de LAD segundo o número de eventos de hipertensão, hipertermia e hiperglicemia durante internação hospitalar. HCFMUSP, 2013-2014.

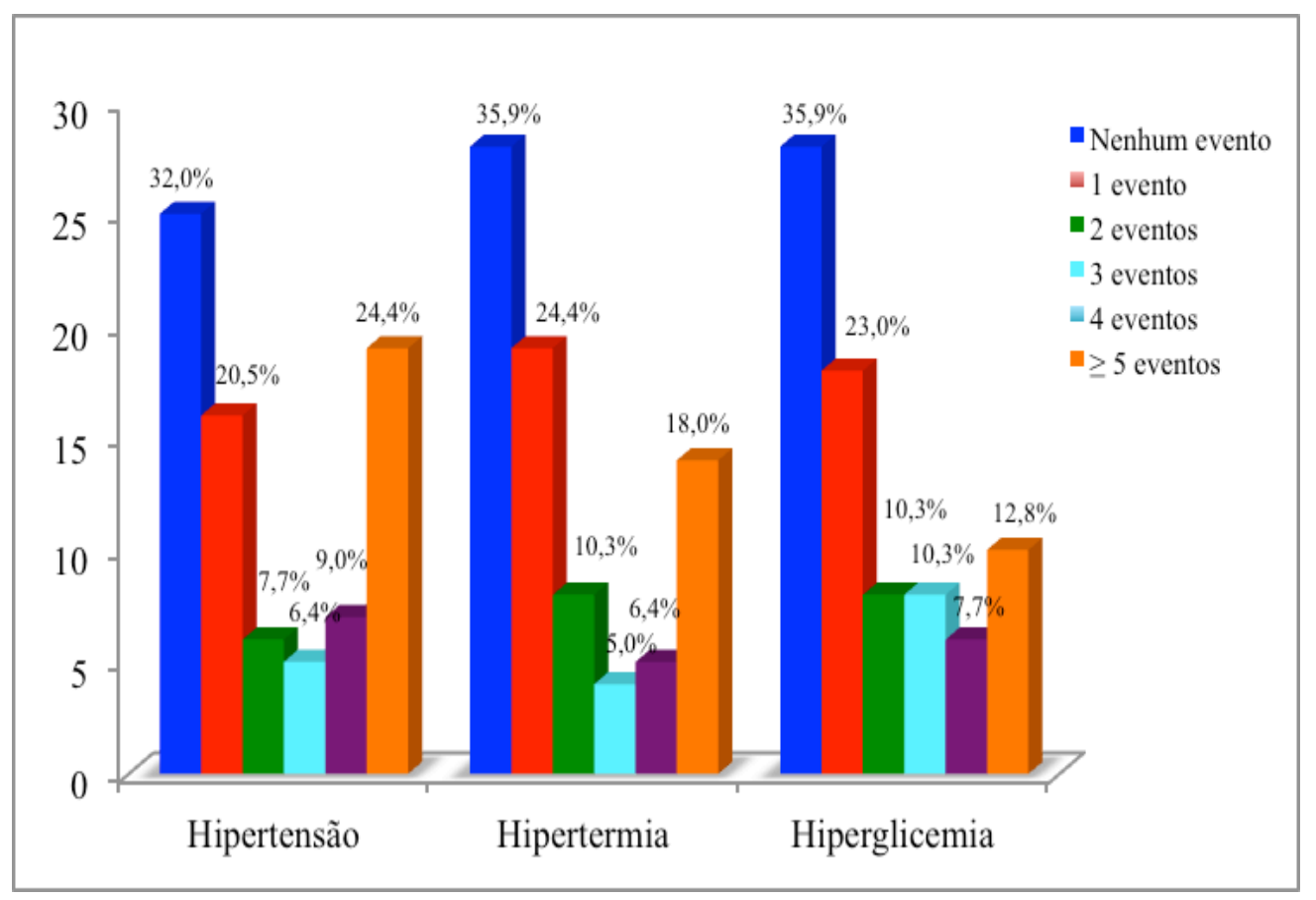

Neste estudo, a média de permanência hospitalar dos pacientes foi de 19,1 dias ( $d p=22,9)$, mediana de 11 dias e o tempo de internação dos doentes teve variação de menos de 1 dia a 111 dias. A Tabela 9 mostra que a mortalidade até 6 meses após LAD dos inseridos neste estudo foi de 30,8\%; entre os que morreram, a média do tempo de sobrevivência foi de 13,5 dias $(d p=24,1)$, a mediana de 4,5 dias e a variação de menos de 1 dia até 110 dias. As mortes após 4 dias foram frequentes; no entanto, é importante ressaltar que fizeram parte deste estudo todas as vítimas internadas pela neurocirurgia. Já as vítimas que chegaram em óbito no hospital, ou que morreram antes da avaliação dessa equipe, não entraram na casuística.

O destino dos pacientes após a alta do IC/HCFMUSP foi a residência, na maioria dos casos $(63,0 \%)$. Os demais requereram internação em outras unidades hospitalares para continuidade do tratamento. 
Tabela 9 - Vítimas de LAD segundo mortalidade e destino após alta do IC/HCFMUSP. HCFMUSP, 2013-2014.

\begin{tabular}{lcc}
\hline VARIÁVEIS & N & \% \\
\hline Óbito em seis meses & 24 & 30,8 \\
Sim & 51 & 65,4 \\
Não & 3 & 3,8 \\
Sem informação & & \\
Tempo de sobrevivência antes do óbito & 2 & 8,3 \\
Até 2 horas após o trauma & 1 & 4,2 \\
1 dia após o trauma & 2 & 8,3 \\
2 dias após o trauma & 2 & 8,3 \\
dias após o trauma & 10 & 41,7 \\
4 a 10 dias após o trauma & 7 & 29,2 \\
Mais de 10 dias após o trauma & & \\
Destino após a alta do IC/HCFMUSP & 34 & 63,0 \\
Residência & 3 & 5,6 \\
Outros hospitais públicos ou privados & 13 & 24,0 \\
Instituto de Ortopedia e Traumatologia/HCFMUSP & 4 & 7,4 \\
Suzano/HCFMUSP & & \\
\hline
\end{tabular}

\subsection{RECUPERAÇÃO DAS VÍTIMAS DE LAD ENTRE A ALTA DO IC/HCFMUSP E 6 MESES APÓS O TRAUMA (ALTA, 3 E 6 MESES)}

Nas avaliações de seguimento após alta do IC/HCFUSP participaram 51 doentes, dos quais 1 não esteve presente na consulta 3 meses após LAD. Desses participantes, $62,7 \%$ realizaram tratamento com especialistas em Fisioterapia, Terapia Ocupacional, Psicologia ou Fonoaudiologia entre a alta hospitalar e seis meses após o trauma. A Figura 9 mostra a distribuição dos pacientes segundo a realização dessas terapias e evidencia que a fisioterapia foi o tratamento mais frequente, realizado em $49,0 \%$ dos casos, seguido pelo de fonoaudiologia e psicologia (ambos com 19,6\% dos participantes).

Figura 9 - Vítimas de LAD segundo realização de tratamentos em especialidades da aérea de saúde entre a alta do IC/HCFMUSP e seis meses após o trauma. HCFMUSP, 2013-2014.

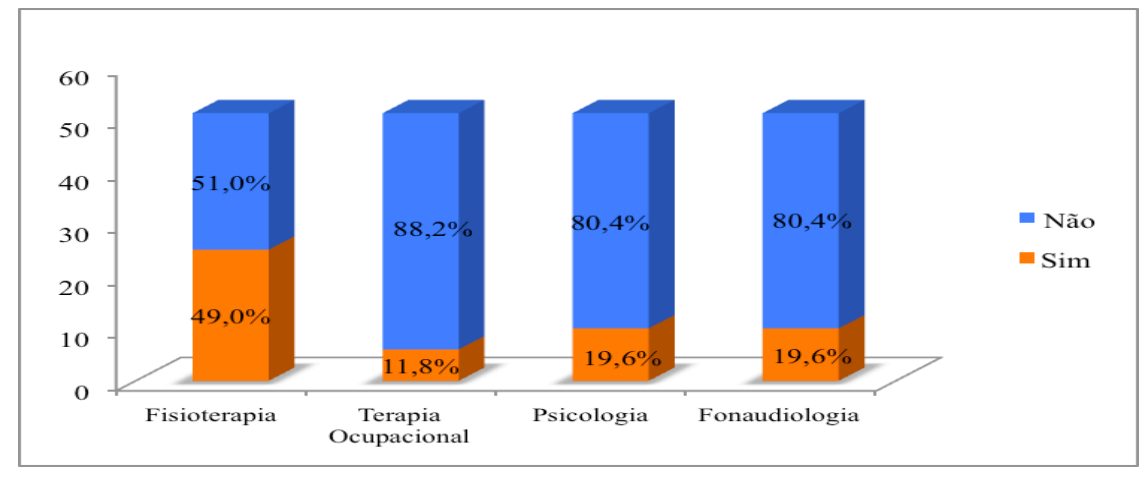


Na Figura 10 pode-se observar a evolução da recuperação das 51 vítimas de LAD entre a alta do IC/HCFMUSP e 6 meses após a LAD, segundo pontuações médias da escala de Katz e ERGA. Os traçados do gráfico evidenciam a tendência de melhora clínica contínua das vítimas no período avaliado, mais acentuada até 3 meses. Na escala de Katz, a pontuação média evoluiu de $8,5(\mathrm{dp}=5,5)$ na alta para $3,2(\mathrm{dp}=5,5)$ aos 3 meses e 1,8 $(\mathrm{dp}=4,5)$ aos 6 meses após LAD. Na ERGA, a evolução foi de $3,8(d p=1,2)$ para $2,1(d p=1,6)$ aos 3 meses e para $1,2(d p=1,6)$ aos 6 meses.

Figura 10 - Médias das pontuações nas escalas de Katz e ERGA entre a alta do IC/HCFMUSP e seis meses após LAD. HCFMUSP, 2013-2014

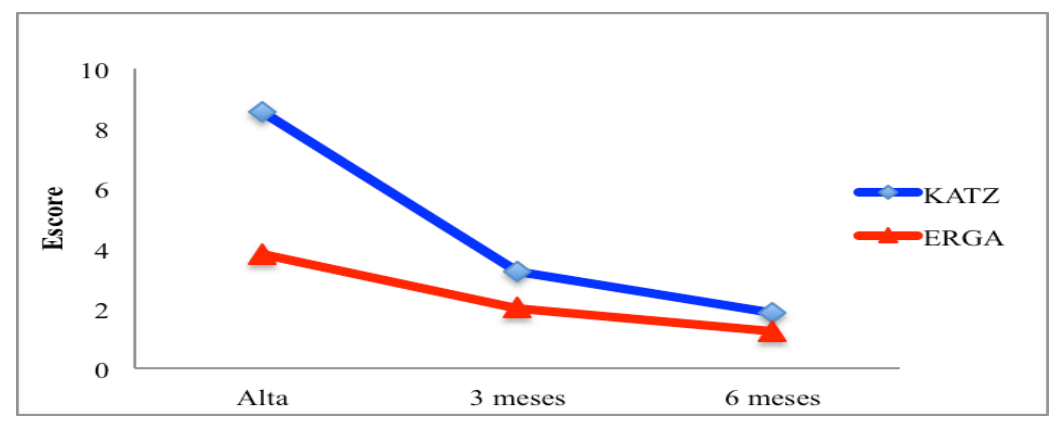

A Tabela 10 mostra a frequência com que os pacientes foram categorizados nas diferentes categorias da ERGA na alta, três e seis meses após o trauma. A frequência de indivíduos incapazes diminuiu expressivamente com o tempo decorrido, ao passo que aumentaram os categorizados em boa e total recuperação. O teste não paramétrico de Friedman indicou diferença nas categorizações da ERGA entre os momentos de avaliação - alta, 3 e 6 meses $-p$-value $<0,001$.

Tabela 10 - Vítimas de LAD segundo categorias da ERGA nos períodos de avaliação. HCFMUSP, 2013-2014.

\begin{tabular}{lcccccc}
\hline CATEGORIAS - ERGA & \multicolumn{2}{c}{ Alta } & \multicolumn{2}{c}{$\mathbf{3}$ meses } & \multicolumn{2}{c}{ 6 meses } \\
\cline { 2 - 7 } & $\mathbf{n}$ & $\mathbf{\%}$ & $\mathbf{n}$ & $\mathbf{\%}$ & $\mathbf{n}$ & $\%$ \\
\hline Recuperação total & - & - & 7 & $14,0 \%$ & 23 & $45,1 \%$ \\
Boa recuperação & 1 & $2,0 \%$ & 16 & $32,0 \%$ & 13 & $25,5 \%$ \\
Incapacidade moderada & 8 & $15,7 \%$ & 10 & $20,0 \%$ & 5 & $9,8 \%$ \\
Incapacidade moderada acentuada & 11 & $21,6 \%$ & 9 & $18,0 \%$ & 4 & $7,8 \%$ \\
Incapacidade grave & 12 & $23,5 \%$ & 4 & $8,0 \%$ & 3 & $5,9 \%$ \\
Incapacidade grave acentuada & 17 & $33,3 \%$ & 2 & $4,0 \%$ & 2 & $3,9 \%$ \\
Estado vegetativo persistente & 2 & $3,9 \%$ & 2 & $4,0 \%$ & 1 & $2,0 \%$ \\
\hline
\end{tabular}

Valor de $\mathrm{p}<0,001$ - teste não paramétrico de Friedman 
De acordo com a Tabela 11, os resultados das comparações múltiplas indicam que a categorização da ERGA diferiu de forma estatisticamente significativa entre todos os tempos analisados (alta, 3 e 6 meses), p-value $<0,001$.

Tabela 11 - Comparações múltiplas dos resultados da ERGA entre a alta do IC/HCFMUSP e seis meses após LAD. HCFMUSP, 2013-2014.

\begin{tabular}{cc}
\hline COMPARAÇÕES - ERGA & Valor de $\mathbf{p}^{*}$ \\
\hline Alta x 3 meses & $<\mathbf{0 , 0 0 1}$ \\
Alta x 6 meses & $<\mathbf{0 , 0 0 1}$ \\
3 meses $\times$ 6 meses & $<\mathbf{0 , 0 0 1}$ \\
\hline Teste de Student-Newman-Keuls adaptado para testes não paramétricos.
\end{tabular}

A Tabela 12 descreve as pontuações da escala de Katz na alta, três e seis meses após o trauma, além de indicar que houve diferença estatisticamente significativa na pontuação da escala entre os tempos, $p$ value $<0,001$. Nessa tabela, a diminuição da pontuação da escala de Katz ao longo do tempo é evidenciada, indicando melhora dos participantes da pesquisa durante o período das avaliações.

Tabela 12 - Estatísticas descritivas e comparação das pontuações na escala de Katz entre a alta do IC/HCFMUSP e seis meses após LAD. HCFMUSP, 2013-2014.

\begin{tabular}{lccccc}
\hline ESCALAS & Média (dp) & Mediana & Mínimo & Máximo & p $^{*}$ \\
\hline Katz alta & $8,5(5,5)$ & 8,00 & 0 & 18 & \\
Katz 3 meses & $3,2(5,5)$ & 0 & 0 & 18 & $<\mathbf{0 , 0 0 1}$ \\
Katz 6 meses & $1,8(4,5)$ & 0 & 0 & 18 & \\
\hline *ANOVA com medidas repetidas. & & & &
\end{tabular}

A Tabela 13 apresenta os resultados das comparações múltiplas realizadas pelo teste de Bonferroni e mostra diferença entre as médias dos valores da escala de Katz em todos os períodos comparados.

Tabela 13 - Comparações múltiplas dos resultados da escala de Katz entre a alta do IC/HCFMUSP e seis meses após LAD. HCFMUSP, 2013-2014.

\begin{tabular}{cc}
\hline COMPARAÇ ÕES - Katz & Valor de $\mathbf{p}^{*}$ \\
\hline Alta x 3 meses & $<\mathbf{0 , 0 0 1}$ \\
Alta x 6 meses & $<\mathbf{0 , 0 0 1}$ \\
3 meses $\times$ 6 meses & $<\mathbf{0 , 0 0 1}$ \\
\hline
\end{tabular}


A Figura 11 mostra a evolução da pontuação média dos seis domínios avaliados pela escala de Katz nos três períodos de estudo. Observa-se que a diminuição da pontuação média ocorreu em todos os itens da escala e nas três avaliações. Nota-se também que os itens "tomar banho" e "vestir-se" apresentaram, inicialmente, a mais acentuada alteração (maior pontuação média) e uma melhora marcante com o passar do tempo (importante diminuição no escore médio). Em contrapartida, "alimentar-se" foi o item que, na alta, estava menos alterado e que, embora tenha tido uma menor diminuição na pontuação média em relação aos demais, alcançou aos seis meses valor médio similar a "necessidades urinárias" e "cuidar da higiene".

Figura 11 - Médias das pontuações nos itens da escala de Katz entre a alta do IC/HCFMUSP e 6 meses após LAD. HCFMUSP, 2013-2014.

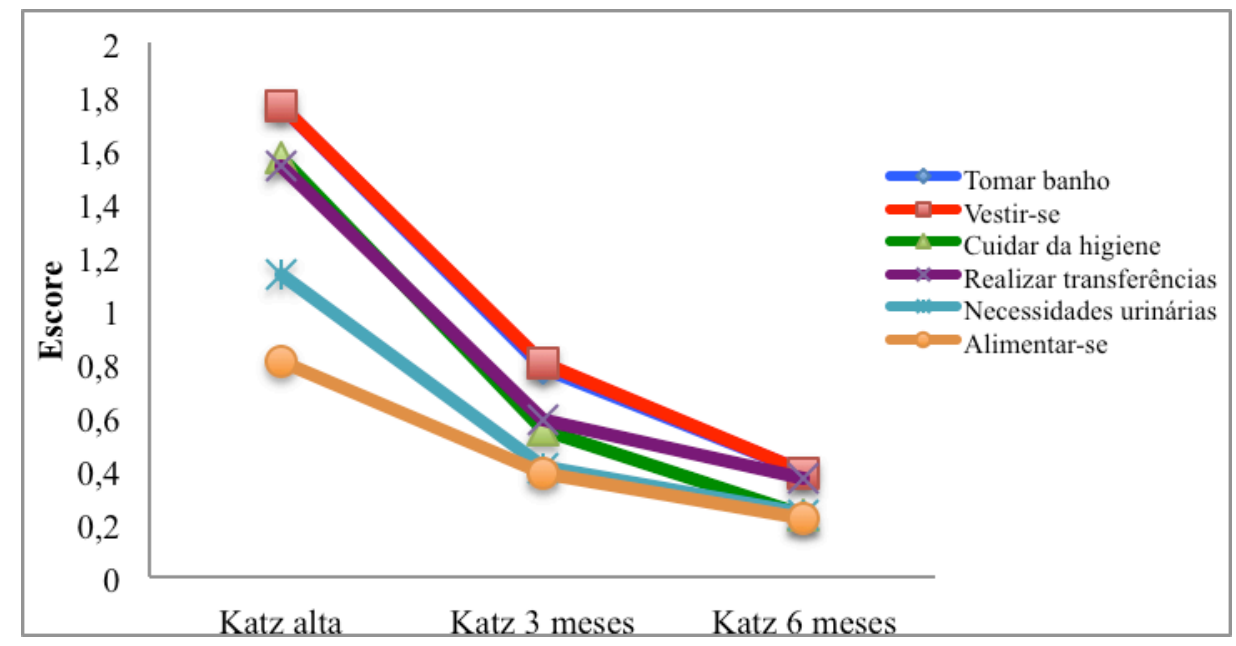

Nas Tabelas 14 e 15 estão apresentados os resultados relacionados ao item "tomar banho" da escala de Katz. A maior independência para essa atividade da vida diária adquirida pelas vítimas de LAD durante os seis meses de seguimento pode ser sumarizada pela independência de $17,6 \%$ dos casos na alta hospitalar ante $80,4 \%$ aos 6 meses e pela redução na necessidade de ajuda humana parcial $(41,2 \%)$ ou total $(25,5 \%)$ para $4,0 \%$ e $7,8 \%$, respectivamente, até o final do seguimento. Diferença na categorização das vítimas nesse domínio com o passar do tempo foi atestada pela estatística não paramétrica de Friedman, que alcançou $p$-value de $<0,001$. As comparações múltiplas indicaram que a pontuação nesse item da 
escala de Katz diferiu de forma estatisticamente significativa entre todos os tempos analisados (alta, 3 e 6 meses); p-value $<0,001$ para comparação entre alta e 3 meses, alta e 6 meses e 0,018 para 3 e 6 meses.

Tabela 14 - Vítimas de LAD segundo categorias do item "tomar banho" da escala de Katz nos períodos de avaliação. HCFMUSP, 2013-2014.

\begin{tabular}{lcccccc}
\hline \multicolumn{1}{c}{\begin{tabular}{c}
\multicolumn{1}{c}{ CATEGORIAS DO ITEM } \\
“TOMAR BANHO" (KATZ)
\end{tabular}} & \multicolumn{2}{c}{ Alta } & \multicolumn{2}{c}{ 3 meses } & \multicolumn{2}{c}{ 6 meses } \\
\cline { 2 - 7 } & $\mathbf{n}$ & $\mathbf{\%}$ & $\mathbf{n}$ & $\mathbf{\%}$ & $\mathbf{n}$ & $\mathbf{\%}$ \\
\hline $\begin{array}{l}\text { Independente para banhar-se, entrar } \\
\text { e sair do banheiro }\end{array}$ & 9 & 17,6 & 32 & 64,0 & 41 & 80,4 \\
$\begin{array}{l}\text { Necessita de ajuda através do uso } \\
\text { órtese ou algum material para } \\
\text { banho }\end{array}$ & 8 & 15,7 & 4 & 8,0 & 4 & 7,8 \\
$\begin{array}{l}\text { Necessidade de ajuda humana para } \\
\text { lavar algumas partes do corpo }\end{array}$ & 21 & 41,2 & 9 & 18,0 & 2 & 4,0 \\
\begin{tabular}{l} 
Dependência total para banhar-se \\
\hline
\end{tabular} & 13 & 25,5 & 5 & 10,0 & 4 & 7,8 \\
\hline
\end{tabular}

Valor de $\mathrm{p}<0,001$ - teste não paramétrico de Friedman

Tabela 15 - Comparações múltiplas das médias do item "tomar banho" da escala de Katz entre a alta do IC/HCFMUSP e 6 meses após LAD. HCFMUSP, 2013-2014.

\begin{tabular}{cc}
\hline COMPARAÇÕES DO ITEM & Valor de $\mathbf{p}^{*}$ \\
"TOMAR BANHO" (KATZ) & $<\mathbf{0 , 0 0 1}$ \\
Alta x 3 meses & $<\mathbf{0 , 0 0 1}$ \\
Alta x 6 meses & $\mathbf{0 , 0 1 8}$ \\
3 meses x 6 meses &
\end{tabular}

Nota-se, na Tabela 16, que o comportamento do item "vestir-se" da escala de Katz teve semelhança ao relacionado a "tomar banho". As comparações múltiplas também indicaram que a categorização das vítimas diferiu de forma estatisticamente significativa entre todos os tempos analisados (alta, 3 e 6 meses); $p$-value $<0,001$ para comparação entre alta e 3 meses, alta e 6 meses e 0,010 para 3 e 6 meses (Tabela 17).

Tabela 16 - Vítimas de LAD segundo categorias do item "vestir-se" da Katz nos períodos de avaliação. HCFMUSP, 2013-2014.

\begin{tabular}{lcccccc}
\hline \multicolumn{1}{c}{$\begin{array}{c}\text { CATEGORIAS DO ITEM } \\
\text { "VESTIR-SE" (KATZ) }\end{array}$} & \multicolumn{2}{c}{ Alta } & \multicolumn{2}{c}{ m meses } & \multicolumn{2}{c}{ 6 meses } \\
\cline { 2 - 7 } & $\mathbf{n}$ & $\mathbf{0}$ & $\mathbf{n}$ & $\mathbf{\%}$ & $\mathbf{n}$ & $\%$ \\
\hline $\begin{array}{l}\text { Independente para pegar roupa e se } \\
\text { vestir }\end{array}$ & 7 & 13,7 & 33 & 66,0 & 41 & 80,4 \\
$\begin{array}{l}\text { Necessidade de apoio em algum } \\
\text { objeto para se vestir }\end{array}$ & 10 & 19,6 & 1 & 2,0 & 3 & 5,9 \\
$\begin{array}{l}\text { Necessidade de ajuda humana no } \\
\text { vestir-se }\end{array}$ & 23 & 45,1 & 11 & 22,0 & 4 & 7,8 \\
Dependência total para vestir-se & 11 & 21,6 & 5 & 10,0 & 3 & 5,9 \\
\hline
\end{tabular}

Valor de $\mathrm{p}<0,001$ - teste não paramétrico de Friedman. 
Tabela 17 - Comparações múltiplas das médias do item "vestir-se" da escala de Katz entre a alta do IC/HCFMUSP e 6 meses após LAD. HCFMUSP, 2013-2014.

\begin{tabular}{cc}
\hline $\begin{array}{c}\text { COMPARAÇÕES DO ITEM } \\
\text { "VESTIR-SE" (KATZ) }\end{array}$ & Valor de p* \\
\hline Alta x 3 meses & $<\mathbf{0 , 0 0 1}$ \\
Alta x 6 meses & $<\mathbf{0 , 0 0 1}$ \\
3 meses x 6 meses & $\mathbf{0 , 0 1 0}$ \\
\hline
\end{tabular}

*Teste de Student-Newman-Keuls adaptado para testes não paramétricos.

$\mathrm{Na}$ apresentação do item "cuidado pessoal" da escala de Katz, Tabelas 18 e 19, nota-se que, no momento da alta, 17,6\% dos participantes deste estudo encontravam-se totalmente independentes para essa AVD; no entanto, após 6 meses da LAD, 90,2\% haviam adquirido esse nível de capacidade para realizar esta tarefa. Assim como nos demais itens, a necessidade de ajuda humana foi bastante reduzida entre alta e 6 meses e a comparação na categorização desse domínio apresentou p-value $<0,001$. Verificou-se que houve diferença estatisticamente significativa entre todos os tempos; $p$-value $<0,001$ ao confrontar resultados de alta e 3 meses, alta e 6 meses e 0,037 para 3 e 6 meses.

Tabela 18 - Vítimas de LAD segundo categorias do item "cuidado pessoal" da escala de Katz nos períodos de avaliação. HCFMUSP, 2013-2014.

\begin{tabular}{lcccccc}
\hline CATEGORIAS DO ITEM & \multicolumn{2}{c}{ Alta } & \multicolumn{2}{c}{ 3 meses } & \multicolumn{2}{c}{ 6 meses } \\
\cline { 2 - 7 } “CUIDADO PESSOAL” (KATZ) & $\mathbf{n}$ & $\mathbf{\%}$ & $\mathbf{n}$ & $\mathbf{\%}$ & $\mathbf{n}$ & $\mathbf{\%}$ \\
\hline $\begin{array}{l}\text { Independente para ir ao banheiro e se } \\
\text { limpar }\end{array}$ & 9 & 17,6 & 39 & 78,0 & 46 & 90,2 \\
$\begin{array}{l}\text { Necessidade de ajuda através do uso de } \\
\text { órtese ou uso regular de papagaios, } \\
\text { comadre ou urinol para higiene }\end{array}$ & 13 & 25,5 & 2 & 4,0 & 1 & 2,0 \\
$\begin{array}{l}\text { Necessidade de ajuda humana para ir } \\
\text { ao banheiro }\end{array}$ & 21 & 41,2 & 4 & 8,0 & 1 & 2,0 \\
$\begin{array}{l}\text { Dependência total para higiene ir ao } \\
\text { banheiro ou se limpar }\end{array}$ & 8 & 15,7 & 5 & 10,0 & 3 & 5,8 \\
\hline Valor de p $<0,001$ - teste não paramétrico de Friedman. & & & &
\end{tabular}

Tabela 19 - Comparações múltiplas das médias do item "cuidado pessoal" da escala de Katz entre a alta do IC/HCFMUSP e 6 meses após LAD. HCFMUSP, 2013-2014.

\begin{tabular}{cc}
\hline COMPARAÇÕES DO "ITEM & Valor de p* \\
CUIDADO PESSOAL" (KATZ) & $<\mathbf{0 , 0 0 1}$ \\
\hline Alta x 3 meses & $<\mathbf{0 , 0 0 1}$ \\
Alta x 6 meses & $\mathbf{0 , 0 3 7}$ \\
3 meses x 6 meses
\end{tabular}

*Teste de Student-Newman-Keuls adaptado para testes não paramétricos. 
Os dados das Tabelas 20 e 21 atestam que houve melhora importante em "realizar transferência" entre alta e 3 meses após LAD. Diferença estatisticamente significativa em relação a este item foi observada entre alta e 6 meses após LAD ( $p$-value $<0,001)$, porém essa diferença foi alcançada no período entre alta e 3 meses ( $p$-value $<0,001$ ), visto que não houve diferença estatisticamente significativa nos resultados desse item da escala entre 3 e 6 meses ( $p$-value 0,186).

Tabela 20 - Vítimas de LAD segundo categorias do item "realizar transferência" da Katz nos períodos de avaliação. HCFMUSP, 2013-2014.

\begin{tabular}{|c|c|c|c|c|c|c|}
\hline \multirow{2}{*}{$\begin{array}{c}\text { CATEGORIAS DO ITEM } \\
\text { "REALIZAR } \\
\text { TRANSFERÊNCIA" (KATZ) }\end{array}$} & \multicolumn{2}{|c|}{ Alta } & \multicolumn{2}{|c|}{3 meses } & \multicolumn{2}{|c|}{6 meses } \\
\hline & n & $\%$ & $\mathbf{n}$ & $\%$ & $\mathbf{n}$ & $\%$ \\
\hline $\begin{array}{l}\text { Independente para entrar ou sair do } \\
\text { leito, sentar e levantar da cadeira }\end{array}$ & 8 & 15,7 & 38 & 76,0 & 42 & 82,4 \\
\hline $\begin{array}{l}\text { Necessita de ajuda através do uso } \\
\text { órtese ou algum apoio material para a } \\
\text { transferência }\end{array}$ & 12 & 23,5 & 3 & 6,0 & 3 & 5,9 \\
\hline $\begin{array}{l}\text { Necessidade de ajuda humana para } \\
\text { entrar e sair do leito, sentar e levantar } \\
\text { da cadeira }\end{array}$ & 27 & 53,0 & 3 & 6,0 & 2 & 3,9 \\
\hline $\begin{array}{l}\text { Dependência total para a } \\
\text { transferência }\end{array}$ & 4 & 7,8 & 6 & 12,0 & 4 & 7,8 \\
\hline
\end{tabular}

Valor de $\mathrm{p}<0,001$ - teste não paramétrico de Friedman.

Tabela 21 - Comparações múltiplas das médias do item "realizar transferência" da escala de Katz entre a alta do IC/HCFMUSP e 6 meses após LAD. HCFMUSP, 2013-2014.

\begin{tabular}{cc}
\hline $\begin{array}{c}\text { COMPARAÇÕES DO ITEM "REALIZAR } \\
\text { TRANSFERÊNCIA" (KATZ) }\end{array}$ & Valor de p* \\
\hline Alta x 3 meses & $<\mathbf{0 , 0 0 1}$ \\
Alta x 6 meses & $<\mathbf{0 , 0 0 1}$ \\
3 meses x 6 meses & 0,186 \\
\hline
\end{tabular}

*Teste de Student-Newman-Keuls adaptado para testes não paramétricos.

$\mathrm{Na}$ análise das Tabelas 22 e 23 relacionadas a "necessidades urinárias" e Tabelas 24 e 25 sobre a capacidade de "alimentar-se", nota-se grande semelhança de resultados. Para essas atividades da vida diária, a maioria dos participantes do estudo já era totalmente independente na alta do IC/HFMUSP (51,0\%) em "necessidades urinárias" e 64,7\% em “alimentar-se"). Além disso, aos 3 meses, eram poucos os pacientes não haviam atingido essa condição (8 em "necessidades urinárias" e 7 em “alimentar-se"). As comparações múltiplas indicaram que a categorização 
das vítimas diferiu de forma estatisticamente significativa entre alta e 3 meses, além de alta e 6 meses ( $p$-value $<0,001)$ em ambos os itens. Não houve diferença estatisticamente significativa nos resultados da escala entre 3 e 6 meses em "necessidades urinárias" e "alimentar-se" ( $p$-value 0,400 e 0,395, respectivamente), indicando que a melhora na capacidade de realizar essas atividades ocorreu nos primeiros 3 meses após LAD.

Tabela 22 - Vítimas de LAD segundo categorias do item "necessidades urinárias" da escala de Katz nos períodos de avaliação. HCFMUSP, 2013-2014.

\begin{tabular}{|c|c|c|c|c|c|c|}
\hline \multirow{2}{*}{$\begin{array}{l}\text { CATEGORIAS DO ITEM } \\
\text { "NECESSIDADES } \\
\text { URINÁRIAS" (KATZ) }\end{array}$} & \multicolumn{2}{|c|}{ Alta } & \multicolumn{2}{|c|}{3 meses } & \multicolumn{2}{|c|}{6 meses } \\
\hline & $\mathbf{n}$ & $\%$ & n & $\%$ & n & $\%$ \\
\hline $\begin{array}{l}\text { Independência para controlar os } \\
\text { movimentos intestinais e a urina }\end{array}$ & 26 & 51,0 & 42 & 84,0 & 45 & 88,3 \\
\hline $\begin{array}{l}\text { Necessidade de ajuda através do uso } \\
\text { regular de urinol, comadre ou papagaio } \\
\text { para controlar micção e defecação }\end{array}$ & 6 & 11,8 & 3 & 6,0 & 2 & 3,9 \\
\hline $\begin{array}{l}\text { Necessidade de ajuda humana para } \\
\text { controlar a micção ou defecação }\end{array}$ & 4 & 7,8 & - & - & 2 & 3,9 \\
\hline $\begin{array}{l}\text { Dependência total através do uso } \\
\text { constante de cateteres, enemas ou } \\
\text { fraldas }\end{array}$ & 15 & 29,4 & 5 & 10,0 & 2 & 3,9 \\
\hline
\end{tabular}

Valor de $\mathrm{p}<0,001$ - teste não paramétrico de Friedman.

Tabela 23 - Comparações múltiplas das médias do item "necessidades urinárias" da escala de Katz entre a alta do IC/HCFMUSP e 6 meses após LAD. HCFMUSP, 2013-2014.

\begin{tabular}{cc}
\hline $\begin{array}{c}\text { COMPARAÇÕES DO ITEM } \\
\text { "NECESSIDADES }\end{array}$ & Valor de $\mathbf{p} *$ \\
URINÁRIAS" (KATZ) & \\
\hline Alta x 3 meses & $<\mathbf{0 , 0 0 1}$ \\
Alta x 6 meses & $<\mathbf{0 , 0 0 1}$ \\
3 meses x 6 meses & 0,400 \\
\hline *Teste de Student-Newman-Keuls adaptado para testes não paramétricos.
\end{tabular}

Tabela 24 - Vítimas de LAD segundo categorias do item "alimentar-se" da escala de Katz nos períodos de avaliação. HCFMUSP, 2013-2014.

\begin{tabular}{lcccccc}
\hline \multicolumn{1}{c}{ CATEGORIAS DO ITEM } & \multicolumn{2}{c}{ Alta } & \multicolumn{2}{c}{ 3 meses } & \multicolumn{2}{c}{ 6 meses } \\
\cline { 2 - 7 } “ALIMENTAR-SE" (KATZ) & $\mathbf{n}$ & $\mathbf{\%}$ & $\mathbf{n}$ & $\mathbf{\%}$ & $\mathbf{n}$ & $\%$ \\
\hline $\begin{array}{l}\text { Independente para pegar o alimento e } \\
\text { levá-lo até a boca }\end{array}$ & 33 & 64,7 & 43 & 86,0 & 46 & 90,2 \\
$\begin{array}{l}\text { Necessidade de ajuda através do uso } \\
\text { de adaptadores para alimentação }\end{array}$ & 2 & 3,9 & - & - & 1 & 2,0 \\
$\begin{array}{l}\text { Necessidade de ajuda humana para } \\
\text { pegar o alimento e levá-lo até a boca }\end{array}$ & 8 & 15,7 & 4 & 8,0 & 2 & 3,9 \\
\begin{tabular}{l} 
Dependência total para alimentação \\
\hline
\end{tabular} & 8 & 15,7 & 3 & 6,0 & 2 & 3,9 \\
\hline
\end{tabular}

Valor de $\mathrm{p}<0,001$ - teste não paramétrico de Friedman. 
Tabela 25 - Comparações múltiplas das médias do item "alimentar-se" da escala de Katz entre a alta do IC/HCFMUSP e 6 meses após LAD. HCFMUSP, 2013-2014.

\begin{tabular}{cc}
\hline COMPARAÇÕES ITEM DO & Valor de $\mathbf{p} *$ \\
“ALIMENTAR-SE" (KATZ) & $<\mathbf{0 , 0 0 1}$ \\
Alta x 3 meses & $<\mathbf{0 , 0 0 1}$ \\
Alta x 6 meses & 0,395 \\
\hline meses x 6 meses & \\
\hline
\end{tabular}

Teste de Student-Newman-Keuls adaptado para testes não paramétricos.

Nas Tabelas 26 e 27 são apresentados os participantes da pesquisa segundo sua evolução na ERGA (Tabela 26) e escala de Katz (Tabela 27) nos três períodos de avaliação. Considerando-se os resultados da ERGA, nenhum paciente apresentou piora de funcionalidade quando comparações dos resultados das avaliações foram realizadas. A melhora entre alta e 6 meses ocorreu na quase totalidade da casuística (96,0\% dos participantes); uma das duas vítimas que não apresentaram alteração na categorização permaneceu em estado vegetativo persistente e outra manteve incapacidade grave acentuada. A melhora entre alta e 3 meses ocorreu em $82,0 \%$ dos casos e entre 3 e 6 meses em 60,0\%; entretanto, é importante considerar nessa análise que $14,0 \%$ dos pacientes alcançaram recuperação total aos 3 meses, portanto não poderiam apresentar melhora entre as duas últimas avaliações (Tabela 26).

Tabela 26 - Vítimas de LAD segundo a evolução pela ERGA após o trauma. HCFMUSP, 2013-2014.

\begin{tabular}{lcccccc}
\hline \multicolumn{1}{c}{ EVOLUÇÃO } & \multicolumn{7}{c}{ Período } \\
\cline { 2 - 7 } PELA ERGA & \multicolumn{2}{c}{ Alta x 3 meses } & 3 meses x 6 meses & \multicolumn{2}{c}{ Alta x 6 meses } \\
\cline { 2 - 7 } & $\mathbf{n}$ & $\mathbf{\%}$ & $\mathbf{n}$ & $\%$ & $\mathbf{n}$ & $\%$ \\
\hline Piora & - & - & - & - & - & - \\
Inalterado & 9 & 18,0 & 20 & 40,0 & 2 & 4,0 \\
Melhora & 41 & 82,0 & 30 & 60,0 & 49 & 96,0 \\
\hline Total & $50^{*}$ & 100,0 & $50^{*}$ & 100,0 & 51 & 100,0 \\
\hline *Exclú́do 1 paciente que não compareceu na avaliação de 3 meses. & & & &
\end{tabular}

Em relação à escala de Katz (Tabela 27), dos 51 pacientes em seguimento, $6(11,8 \%)$ apresentaram pontuação mínima na escala já no período da alta do IC/HCFMUSP (alcançaram independência total para as AVD) e, consequentemente, não participaram desta análise. Na avaliação da 
evolução dos 45 pacientes restantes, observou-se que 2 doentes apresentaram piora de um ponto no escore total da escala entre alta e 6 meses, a quase totalidade apresentou melhora no período $(93,4 \%), 90,2 \%$ melhoraram entre alta e 3 meses e 38,6\% entre 3 e 6 meses. Aos 3 meses após LAD, $25(55,5 \%)$ das 45 vítimas já haviam atingido pontuação zero na escala de Katz e, portanto, alcançaram o mais alto nível de funcionalidade da escala.

Tabela 27 - Vítimas de LAD que não alcançaram pontuação máxima na escala de Katz até alta do IC/HCFMUSP (n=45) segundo evolução após o trauma. HCFMUSP, 2013-2014.

\begin{tabular}{ccccccc}
\hline EVOLUÇÃO & \multicolumn{7}{c}{ Período } \\
\cline { 2 - 7 } PELA KATZ & \multicolumn{7}{c}{ Alta x 3 meses } & 3 meses x 6 meses & \multicolumn{2}{c}{ Alta x 6 meses } \\
\cline { 2 - 7 } & $\mathbf{n}$ & $\mathbf{\%}$ & $\mathbf{n}$ & $\%$ & $\mathbf{n}$ & $\%$ \\
\hline Piora & 1 & 2,3 & 1 & 2,3 & 2 & 4,4 \\
Inalterado & 3 & 6,8 & 26 & 59,1 & 1 & 2,2 \\
Melhora & 40 & 90,9 & 17 & 38,6 & 42 & 93,4 \\
\hline Total & $44 *$ & 100,0 & $44^{*}$ & 100,0 & 45 & 100,0 \\
\hline
\end{tabular}

* Excluído 1 paciente avaliado no período de 3 meses.

\subsection{VÍTIMAS COM DIAGNÓSTICO PRINCIPAL DE LAD AOS 6 MESES APÓS TRAUMA}

Aos 6 meses após LAD, 30,8\% dos pacientes incluídos neste estudo haviam evoluído a óbito em consequência do trauma ou complicações. Nas Figuras 12 e 13 apresentam-se os resultados da escala de Katz e ERGA referentes a 51 sobreviventes que participaram das avaliações até o término do estudo. Aplicando-se a ERGA, grande parte (45,1\%) dessas vítimas alcançaram recuperação total aos 6 meses após trauma e 25,5\% apresentaram boa recuperação. Indivíduos "independentes, mas incapazes" totalizaram $16,6 \%$ da amostra $(9,8 \%$ incapacidade moderada e $7,8 \%$ incapacidade moderada acentuada); incapazes e dependentes perfizeram 6 indivíduos (11,8\%), sendo 3 categorizados em incapacidade grave, 2 em incapacidade grave acentuada e 1 em estado vegetativo persistente (Figura 12). Por conseguinte, observou-se que a grande maioria das vítimas $(88,2 \%)$ alcançou recuperação condizente com vida independente aos 6 meses após 
LAD e as gravemente incapacitadas, dependentes, totalizaram uma pequena proporção $(11,8 \%)$.

Resultados da escala de Katz mostraram distribuição em dependente e independente similar à observada na ERGA. A frequência de indivíduos com independência total segundo essa escala variou de $80,4 \%$ a $90,2 \%$ entre os seis domínios (Figura 13). Na análise global dos resultados dessa escala, sete vítimas $(13,7 \%)$ tiveram indicação de necessidade de ajuda humana parcial ou dependência nas atividades avaliadas pela escala. Dessas vítimas, uma apresentou somente necessidade de ajuda parcial em "vestir-se" e foi categorizada como "independente, mas incapaz" pela ERGA, ao passo que as demais também tiveram indicação de dependência nessa escala. $\mathrm{O}$ perfil similar dos resultados das duas escalas apontou para a realização de uma única análise para identificar os fatores associados ao risco de dependência, sendo a ERGA o instrumento escolhido para identificar o grupo de vítimas dependentes aos 6 meses após LAD.

Figura 12 - Vítimas de LAD aos 6 meses após trauma segundo capacidade funcional pela ERGA. HCFMUSP, 2013-2014.

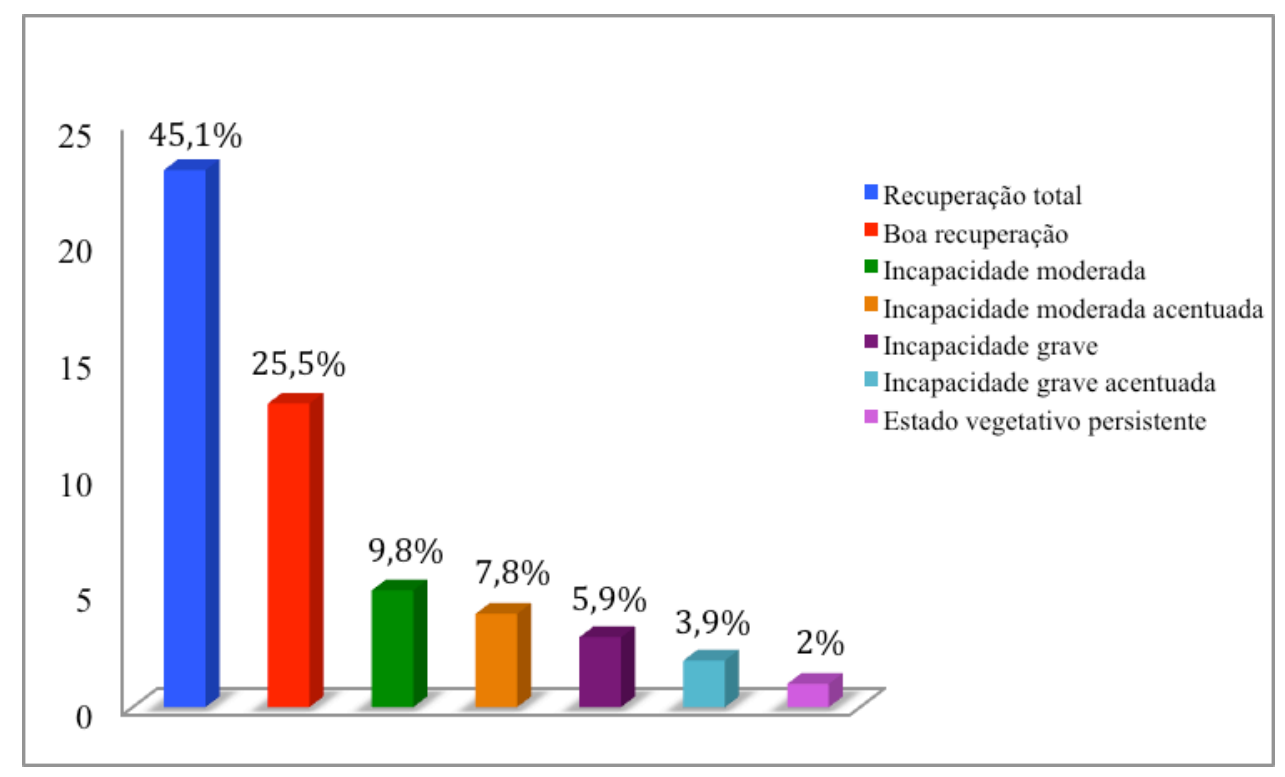


Figura 13 - Vítimas de LAD segundo categorias da escala de Katz aos 6 meses após o trauma por itens da escala. HCFMUSP, 2013-2014

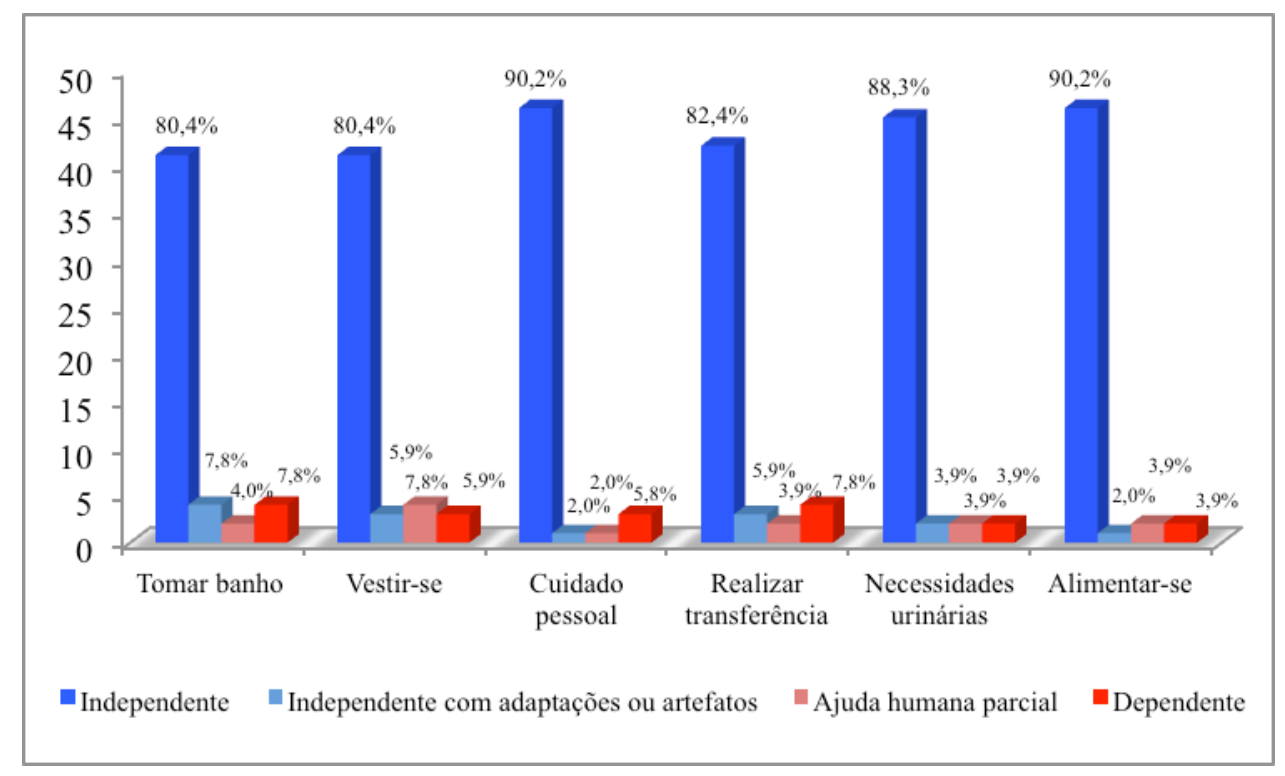

\subsection{FATORES ASSOCIADOS A ÓBITO}

Para identificar os fatores associados ao óbito até 6 meses após LAD, as 78 vítimas de LAD admitidas no IC/HCFMUSP que atenderam aos critérios de inclusão e exclusão deste estudo foram agrupadas segundo seu estado vital nesse período. As Tabelas 28 e 29 apresentam as comparações dos dois grupos formados tendo em vista as características sociodemográficas na época do trauma. Nos dados dessas tabelas verifica-se que não houve diferença estatisticamente significante entre os pacientes que foram ou não a óbito em relação a todas as características sociodemográficas analisadas neste estudo. 
Tabela 28 - Estatísticas descritivas e comparações entre mortos e vivos aos 6 meses após LAD em relação a idade, anos de escolaridade e renda per capita familiar (R\$) na época do trauma. HCFMUSP, 2013-2014.

\begin{tabular}{lccc}
\multicolumn{1}{c}{ CARACTERÍSTICAS } & \multicolumn{2}{c}{ Óbito } & \\
\cline { 2 - 3 } SOCIODEMOGRÁFICAS & Sim & Não & valor de p* \\
\hline Idade & & & \\
Média & 33,8 & 31,2 & 0,359 \\
Desvio padrão & 12,8 & 10,5 & \\
Mediana & 31,5 & 30,5 & \\
Mín-Máx & $18-58$ & $18-57$ & \\
Anos de escolaridade & & & 0,701 \\
Média & 9,3 & 9,0 & \\
Desvio padrão & 4,1 & 3,2 & \\
Mediana & 10,0 & 9,0 & \\
Mín-Máx & $3-19$ & $1-18$ & \\
Renda per capita familiar (R\$) & & & \\
Média & 995,00 & $1.422,50$ & \\
Desvio padrão & $1.975,80$ & $2.548,80$ & \\
Mediana & 500,00 & $1.000,00$ & \\
Mín-Máx & $0,00-10.000,00$ & $0,0-17.500,00$ & \\
\hline
\end{tabular}

* Teste T-Student.

Tabela 29 - Comparações entre mortos e vivos aos 6 meses após LAD em relação a gênero, raça, vínculo conjugal e situação ocupacional na época do trauma. HCFMUSP, 2013-2014.

\begin{tabular}{|c|c|c|c|c|c|}
\hline \multirow{3}{*}{$\begin{array}{c}\text { CARACTERÍSTICAS } \\
\text { SOCIODEMOGRÁFICAS }\end{array}$} & \multicolumn{4}{|c|}{ Óbito } & \multirow{3}{*}{ valor de $p$} \\
\hline & \multicolumn{2}{|c|}{ Sim } & \multicolumn{2}{|c|}{ Não } & \\
\hline & $\mathbf{n}$ & $\%$ & $\mathbf{n}$ & $\%$ & \\
\hline \multicolumn{6}{|l|}{ Gênero } \\
\hline Masculino & 22 & 91,7 & 48 & 88,9 & \multirow{2}{*}{$>0,999 *$} \\
\hline Feminino & 2 & 8,3 & 6 & 11,1 & \\
\hline \multicolumn{6}{|l|}{ Vínculo conjugal } \\
\hline Solteiro & 12 & 50,0 & 28 & 51,9 & \multirow{3}{*}{$0,971 * *$} \\
\hline Casado & 10 & 41,7 & 21 & 38,9 & \\
\hline Separado & 2 & 8,3 & 5 & 9,2 & \\
\hline \multicolumn{6}{|l|}{ Raça } \\
\hline Branca & 16 & 66,7 & 35 & 64,8 & \multirow[t]{2}{*}{$0,874 * *$} \\
\hline Negra & 8 & 33,3 & 19 & 35,2 & \\
\hline \multicolumn{6}{|l|}{ Situação ocupacional } \\
\hline $\begin{array}{l}\text { Inserido no mercado de } \\
\text { trabalho }\end{array}$ & 20 & 83,3 & 50 & 92,6 & \multirow[t]{2}{*}{$0,242 *$} \\
\hline $\begin{array}{l}\text { Sem inserção no mercado de } \\
\text { trabalho }\end{array}$ & 4 & 16,7 & 4 & 7,4 & \\
\hline
\end{tabular}

Os resultados apresentados na Tabela 30 mostram que os grupos comparados não diferiram entre si quando analisadas as variáveis relacionadas ao trauma e ao APH. 
Tabela 30 - Comparações entre mortos e vivos aos 6 meses após LAD em relação a características relacionadas ao trauma e APH. HCFMUSP, 2013-2014.

\begin{tabular}{|c|c|c|c|c|c|}
\hline \multirow{3}{*}{$\begin{array}{c}\text { CARACTERÍSTICAS } \\
\text { RELACIONADAS AO } \\
\text { TRAUMA E APH }\end{array}$} & \multicolumn{4}{|c|}{ Óbito } & \multirow{3}{*}{ valor de $p$} \\
\hline & \multicolumn{2}{|c|}{ Sim } & \multicolumn{2}{|c|}{ Não } & \\
\hline & $\mathbf{n}$ & $\%$ & n & $\%$ & \\
\hline \multicolumn{6}{|l|}{ Acidente de transporte } \\
\hline Sim & 20 & 83,3 & 45 & 83,3 & $>0,999 *$ \\
\hline Não & 4 & 16,7 & 9 & 16,7 & \\
\hline \multicolumn{6}{|l|}{ Tipo de APH } \\
\hline Aéreo & 11 & 45,8 & 26 & 48,1 & $0,850 * *$ \\
\hline Terrestre & 13 & 54,2 & 28 & 51,9 & \\
\hline \multicolumn{6}{|l|}{ IOT na cena $* * *$} \\
\hline Sim & 18 & 75,0 & 44 & 83,0 & $0,535^{*}$ \\
\hline Não & 6 & 25,0 & 9 & 17,0 & \\
\hline \multicolumn{6}{|l|}{ Relato de ingestão de álcool } \\
\hline $\operatorname{Sim}$ & 8 & 33,3 & 25 & 46,3 & $0,285 * *$ \\
\hline Não & 16 & 66,7 & 29 & 53,7 & \\
\hline
\end{tabular}

* Teste exato de Fisher.

** Teste de associação Qui-Quadrado de Pearson.

*** Exclui 1 caso sem informação.

$\mathrm{Na}$ análise das variáveis que retratam a gravidade do trauma e do TCE mensuradas pelo ISS, NISS e MAIS cabeça, observou-se que diferenças estatisticamente significativas ocorreram em relação a todas as variáveis $(p<0,001)$. Os valores das médias dos escores foram maiores no grupo que evoluiu para óbito (Tabela 31).

Tabela 31 - Estatísticas descritivas e comparações entre mortos e vivos aos 6 meses após LAD em relação a gravidade do trauma (ISS, NISS) e TCE (MAIS/cabeça). HCFMUSP, 2013-2014.

\begin{tabular}{|c|c|c|c|}
\hline \multirow{2}{*}{$\begin{array}{c}\text { GRAVIDADE } \\
\text { DO TRAUMA E TCE }\end{array}$} & \multicolumn{2}{|c|}{ Óbito } & \multirow[b]{2}{*}{ valor de $p^{*}$} \\
\hline & Sim & Não & \\
\hline \multicolumn{4}{|l|}{ ISS } \\
\hline $\begin{array}{l}\text { Média } \\
\text { Desvio padrão } \\
\text { Mediana } \\
\text { Mín-Máx }\end{array}$ & $\begin{array}{c}44,4 \\
11,9 \\
40,5 \\
33-75\end{array}$ & $\begin{array}{c}30,9 \\
9,5 \\
29,0 \\
17-59\end{array}$ & $<0,001$ \\
\hline $\begin{array}{l}\text { NISS } \\
\text { Média } \\
\text { Desvio padrão } \\
\text { Mediana } \\
\text { Mín-Máx }\end{array}$ & $\begin{array}{c}61,8 \\
10,9 \\
66,0 \\
41-75\end{array}$ & $\begin{array}{c}39,2 \\
12,5 \\
34,0 \\
18-66\end{array}$ & $<0,001$ \\
\hline $\begin{array}{l}\text { MAIS/cabeça } \\
\text { Média } \\
\text { Desvio padrão } \\
\text { Mediana } \\
\text { Mín-Máx }\end{array}$ & $\begin{array}{l}5,0 \\
0,2 \\
5,0 \\
4-5 \\
\end{array}$ & $\begin{array}{c}4,4 \\
0,5 \\
4,0 \\
4-5\end{array}$ & $<\mathbf{0 , 0 0 1}$ \\
\hline
\end{tabular}


Na Tabela 32, observa-se que houve fortes evidências estatísticas de diferenças entre as vítimas que foram a óbito ou não em relação à gravidade da LAD $(\mathrm{p}<0,001)$. Vítimas de LAD grave foram mais frequentes no grupo dos mortos e as que tiveram esse tipo de lesão categorizada em leve ou moderada predominaram entre os que sobreviveram. É interessante notar que, no total, eram 28 os pacientes com LAD grave, dentre os quais 22 morreram $(78,6 \%)$.

Tabela 32 - Comparação entre mortos e vivos aos 6 meses após trauma em relação à gravidade da LAD. HCFMUSP, 2013-2014.

\begin{tabular}{|c|c|c|c|c|c|}
\hline \multirow{3}{*}{$\begin{array}{c}\text { GRAVIDADE } \\
\text { DA LAD }\end{array}$} & \multicolumn{4}{|c|}{ Óbito } & \multirow{3}{*}{ valor de $\mathbf{p}$} \\
\hline & \multicolumn{2}{|c|}{ Sim } & \multicolumn{2}{|c|}{ Não } & \\
\hline & n & $\%$ & $\mathbf{n}$ & $\%$ & \\
\hline Leve/Moderado & 2 & 8,3 & 48 & 88,9 & \\
\hline Grave & 22 & 91,7 & 6 & 11,1 & $<0,001$ \\
\hline
\end{tabular}

* Teste de associação Qui-Quadrado de Pearson.

$\mathrm{Na}$ análise das variáveis relacionadas à admissão hospitalar, Tabela 33, observou-se que houve diferença estatisticamente significativa entre os grupos analisados (mortos e vivos) em relação à presença de hipotensão ( $p<0,001)$, hipóxia segundo a $\mathrm{SpO}_{2}(\mathrm{p}=0,001)$, hiperglicemia $(\mathrm{p}=0,008)$ e alterações pupilares $(\mathrm{p}=0,001)$. A presença dessas alterações clínicas na admissão hospitalar foi sempre maior entre os que evoluíram a óbito.

Tabela 33 - Comparações entre mortos e vivos aos 6 meses após LAD em relação às características na admissão hospitalar. HCFMUSP, 2013-2014.

\begin{tabular}{|c|c|c|c|c|c|}
\hline \multirow{3}{*}{$\begin{array}{c}\text { CARACTERÍSTICAS } \\
\text { RELACIONADAS À } \\
\text { ADMISSÃO }\end{array}$} & \multicolumn{4}{|c|}{ Óbito } & \multirow{3}{*}{ valor de $\mathrm{F}$} \\
\hline & \multicolumn{2}{|c|}{ Sim } & \multicolumn{2}{|c|}{ Não } & \\
\hline & n & $\%$ & $\mathbf{n}$ & $\%$ & \\
\hline \multicolumn{6}{|l|}{ Sedação } \\
\hline Sim & 22 & 91,7 & 50 & 92,6 & $>0,999 *$ \\
\hline Não & 2 & 8,3 & 4 & 7,4 & \\
\hline \multicolumn{6}{|l|}{$\mathbf{F R} * * *$} \\
\hline Normal & 19 & 82,6 & 45 & 91,8 & $0,257^{*}$ \\
\hline Alterada & 4 & 17,4 & 4 & 8,2 & \\
\hline
\end{tabular}


(continuação)

\section{CARACTERÍSTICAS \\ RELACIONADAS À ADMISSÃO}

\section{Hipotensão}

Sim

Não

Bradicardia

Sim

Não

Taquicardia

Sim

Não

.

Hipóxia pela $\mathrm{SpO}_{2} * * * *$

Sim

Não

9

\begin{tabular}{ccccc}
\multicolumn{4}{c}{ Óbito } \\
\hline \multicolumn{3}{c}{ Sim } & & \multicolumn{2}{c}{ Não } \\
\hline n & $\%$ & n & $\%$ \\
\hline
\end{tabular}

valor de $p$

11

45,8

4

7,4

$13 \quad 54,2 \quad 50 \quad 92,6$

Hipóxia pela $\mathrm{PO}_{2} * * * * *$

$\begin{array}{lccccc}\text { Sim } & 3 & 12,5 & 8 & 16,0 & >0,999^{*} \\ \text { Não } & 21 & 87,5 & 42 & 84,0 & \end{array}$

Hipoglicemia $* * * * * *$

$\begin{array}{lccccc}\text { Sim } & 1 & 4,3 & 2 & 4,2 & >0,999 * \\ \text { Não } & 22 & 95,7 & 46 & 95,8 & \end{array}$

Hiperglicemia $* * * * * *$

$\begin{array}{llllll}\text { Sim } & 12 & 52,2 & 10 & 20,8 & \mathbf{0 , 0 0 8 * *} \\ \text { Não } & 11 & 47,8 & 38 & 79,2 & \end{array}$

Alterações pupilares

$\begin{array}{lccccc}\text { Sim } & 21 & 87,5 & 26 & 48,1 & \mathbf{0 , 0 0 1 *} \\ \text { Não } & 3 & 12,5 & 28 & 51,9 & \end{array}$

* Teste Exato de Fisher.

** Teste de associação Qui-Quadrado de Pearson.

(conclusão)

***Exclui 6 casos sem informação.

****Exclui 1 caso sem informação.

*****Exclui 4 casos sem informação.

******Exclui 7 casos sem informação.

Conforme se observa na Tabela 34, os valores da ECGl atribuídos às vítimas de LAD na admissão hospitalar não diferiram entre os grupos de mortos e vivos $(p<0,137)$.

Tabela 34 - Estatísticas descritivas e comparação entre mortos e vivos aos 6 meses após LAD em relação a ECGl na admissão. HCFMUSP, 2013-2014.

\begin{tabular}{lccc}
\multicolumn{1}{c}{ ECGI NA } & \multicolumn{2}{c}{ Óbito } & \\
\cline { 2 - 3 } \multicolumn{1}{c}{ ADMISSÃO } & Sim & Não & Valor de p* \\
\hline Média & 3,8 & 4,4 & 0,137 \\
Desvio padrão & 1,6 & 1,6 & \\
Mediana & 3,0 & 3,0 & \\
Mín - Máx & $3-8$ & $3-8$ & \\
\hline
\end{tabular}

* Teste T-Student 
Observa-se na Tabela 35 que houve associação estatisticamente significativa entre as vítimas que foram a óbito e as que apresentaram durante a internação hospitalar outras complicações $(p=0,002)$, sinais precoces de LAD na TC $(p=0,006)$ e HIC $(p=0,003)$. O grupo de vítimas que evoluiu a óbito alcançou proporcionalmente maior frequência de indivíduos com presença de outras complicações $(79,2 \%)$, com sinais precoces de LAD na TC $(91,7 \%)$ e HIC $(45,8 \%)$ perante o grupo de sobreviventes que apresentou percentuais de 40,7\%, 61,1\% e 14,8\%, respectivamente.

Tabela 35 - Comparações entre mortos e vivos aos 6 meses após LAD em relação às características relacionadas à internação hospitalar. HCFMUSP, 2013-2014.

\begin{tabular}{|c|c|c|c|c|c|}
\hline \multirow{3}{*}{$\begin{array}{c}\text { CARACTERÍSTICAS } \\
\text { RELACIONADAS À } \\
\text { INTERNAÇÃO }\end{array}$} & \multicolumn{4}{|c|}{ Óbito } & \multirow{3}{*}{ valor de p } \\
\hline & \multicolumn{2}{|c|}{ Sim } & \multicolumn{2}{|c|}{ Não } & \\
\hline & $\mathbf{n}$ & $\%$ & $\mathbf{n}$ & $\%$ & \\
\hline \multicolumn{6}{|l|}{ Internação em UTI } \\
\hline Sim & 22 & 91,7 & 50 & 92,6 & $>0,999 *$ \\
\hline Não & 2 & 8,3 & 4 & 7,4 & \\
\hline \multicolumn{6}{|l|}{ Uso de sedação contínua } \\
\hline Sim & 22 & 91,7 & 47 & 87,0 & $0,713^{*}$ \\
\hline Não & 2 & 8,3 & 7 & 13,0 & \\
\hline \multicolumn{6}{|l|}{$\begin{array}{l}\text { Outros tratamentos com } \\
\text { drogas que atuam no SNC }\end{array}$} \\
\hline Sim & 13 & 54,2 & 35 & 64,8 & $0,372 * *$ \\
\hline Não & 11 & 45,8 & 19 & 35,2 & \\
\hline \multicolumn{6}{|l|}{ Tratamento cirúrgico } \\
\hline $\operatorname{Sim}$ & 13 & 54,2 & 29 & 53,7 & $0,970 * *$ \\
\hline Não & 11 & 45,8 & 25 & 46,3 & \\
\hline \multicolumn{6}{|l|}{ Reabordagem cirúrgica } \\
\hline $\operatorname{Sim}$ & 4 & 16,7 & 11 & 20,4 & $>0,999 *$ \\
\hline Não & 20 & 83,3 & 43 & 79,6 & \\
\hline \multicolumn{6}{|l|}{ Infeccão } \\
\hline Sim & 7 & 29,2 & 13 & 24,1 & $0,634 * *$ \\
\hline Não & 17 & 70,8 & 41 & 75,9 & \\
\hline \multicolumn{6}{|l|}{ Outras complicações } \\
\hline Sim & 19 & 79,2 & 22 & 40,7 & $0,002 * *$ \\
\hline Não & 5 & 20,8 & 32 & 59,3 & \\
\hline \multicolumn{6}{|l|}{$\begin{array}{l}\text { Sinais de LAD precoces na } \\
\text { TC }\end{array}$} \\
\hline $\operatorname{Sim}$ & 22 & 91,7 & 33 & 61,1 & $0,006 * *$ \\
\hline Não & 2 & 8,3 & 21 & 38,9 & \\
\hline
\end{tabular}


(continuação)

\begin{tabular}{|c|c|c|c|c|c|}
\hline \multirow{3}{*}{$\begin{array}{c}\text { CARACTERÍSTICAS } \\
\text { RELACIONADAS À } \\
\text { INTERNAÇÃO }\end{array}$} & \multicolumn{4}{|c|}{ Óbito } & \multirow{3}{*}{ valor de $p$} \\
\hline & \multicolumn{2}{|c|}{ Sim } & \multicolumn{2}{|c|}{ Não } & \\
\hline & $\mathbf{n}$ & $\%$ & $\mathbf{n}$ & $\%$ & \\
\hline \multicolumn{6}{|l|}{ Monitorização da PIC } \\
\hline $\operatorname{Sim}$ & 2 & 8,3 & 1 & 1,9 & \multirow[t]{2}{*}{$0,223^{*}$} \\
\hline Não & 22 & 91,7 & 53 & 98,1 & \\
\hline \multicolumn{6}{|l|}{ HIC } \\
\hline Sim & 11 & 45,8 & 8 & 14,8 & \multirow[t]{2}{*}{$0,003 * *$} \\
\hline Não & 13 & 54,2 & 46 & 85,2 & \\
\hline \multicolumn{6}{|l|}{ Hipotensão } \\
\hline $\operatorname{Sim}$ & 7 & 29,2 & 6 & 11,1 & \multirow[t]{2}{*}{$0,096^{*}$} \\
\hline Não & 17 & 70,8 & 48 & 88,9 & \\
\hline \multicolumn{6}{|l|}{ Hipertensão } \\
\hline $\operatorname{Sim}$ & 15 & 62,5 & 38 & 70,4 & \multirow[t]{2}{*}{$0,601 *$} \\
\hline Não & 9 & 37,5 & 16 & 29,6 & \\
\hline \multicolumn{6}{|l|}{ Hipotermia } \\
\hline Sim & 17 & 70,8 & 29 & 53,7 & \multirow[t]{2}{*}{$0,156^{* *}$} \\
\hline Não & 7 & 29,2 & 25 & 46,3 & \\
\hline \multicolumn{6}{|l|}{ Hipertermia } \\
\hline Sim & 18 & 75,0 & 32 & 59,3 & \multirow[t]{2}{*}{$0,181 * *$} \\
\hline Não & 6 & 25,0 & 22 & 40,7 & \\
\hline \multicolumn{6}{|l|}{ Hipoglicemia } \\
\hline Sim & 7 & 29,2 & 16 & 29,6 & \multirow[t]{2}{*}{$0,967 * *$} \\
\hline Não & 17 & 70,8 & 38 & 70,4 & \\
\hline \multicolumn{6}{|l|}{$\begin{array}{l}\text { Hipoglicemia nos } \\
5 \text { primeiros dias }\end{array}$} \\
\hline Sim & 5 & 20,8 & 7 & 13,0 & \multirow[t]{2}{*}{$0,498 *$} \\
\hline Não & 19 & 79,2 & 47 & 87,0 & \\
\hline \multicolumn{6}{|l|}{ Hiperglicemia } \\
\hline Sim & 19 & 79,2 & 31 & 57,4 & \multirow[t]{2}{*}{$0,064 * *$} \\
\hline Não & 5 & 20,8 & 23 & 42,6 & \\
\hline \multicolumn{6}{|l|}{$\begin{array}{l}\text { Hiperglicemia nos } \\
5 \text { primeiros dias }\end{array}$} \\
\hline Sim & 13 & 54,2 & 25 & 46,3 & \multirow[t]{2}{*}{$0,521 * *$} \\
\hline Não & 11 & 45,8 & 29 & 53,7 & \\
\hline
\end{tabular}

A Tabela 36 mostra as comparações dos valores médios obtidos por mortos e vivos, segundo características clínicas das vítimas durante a internação hospitalar. Observou-se que houve diferença estatisticamente significante entre os grupos em relação à média da ECGl 48 horas após a retirada da sedação $(\mathrm{p}<0,001)$. O valor médio dos indivíduos que evoluíram a óbito foi inferior ao dos sobreviventes. 
Tabela 36 - Estatísticas descritivas e comparações entre mortos e vivos aos 6 meses após LAD em relação a características relacionadas à internação hospitalar. HCFMUSP, 20132014.

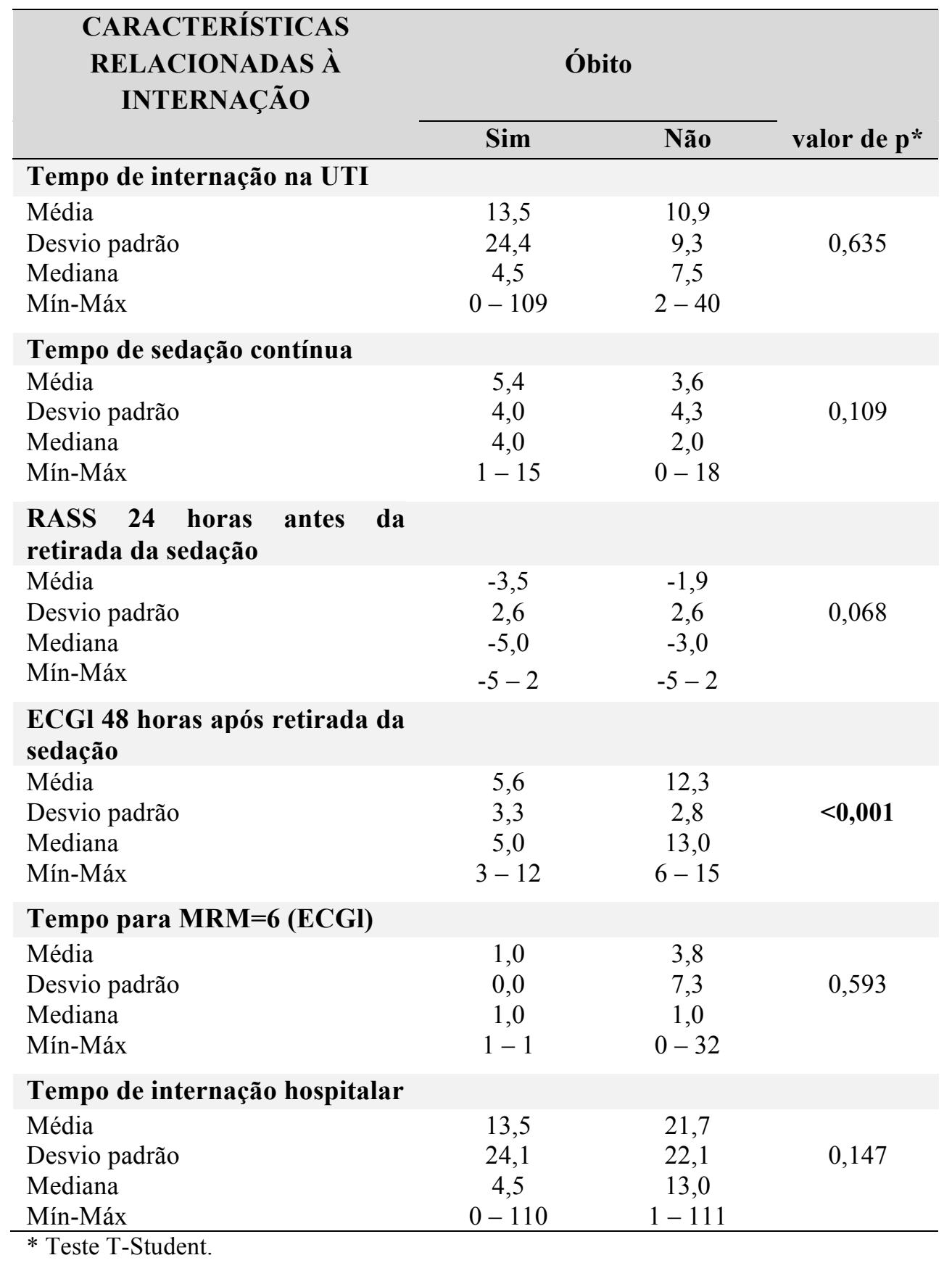

Com o intuito de verificar as variáveis independentemente associadas ao óbito após $\mathrm{LAD}$, as variáveis que tiveram $p$-value $<0,05$ nas análises apresentadas nas Tabelas 28 a 36 foram testadas no modelo de regressão logística múltipla, exceto a variável ECG1 48 horas após a retirada da sedação, tendo em vista que os valores desse parâmetro só estavam presentes em 11 dos pacientes que evoluíram a óbito, pois os demais (13 
participantes) morreram antes da retirada da sedação. Vale ainda lembrar que as variáveis ISS e NISS foram testadas em modelagens distintas, conforme descrito no método.

A Tabela 37 apresenta o modelo de regressão logística múltipla resultante dessa modelagem. Os resultados encontrados apontam a presença de hipóxia pela $\mathrm{SpO}_{2}$ na admissão e a LAD grave como fatores de risco para óbito. Além destas, nenhuma outra variável alcançou nível de significância, quando inseridas conjuntamente durante a modelagem, logo não foram incluídas no modelo. Vítimas com hipóxia na admissão tiveram cerca de 19 vezes mais chances de morrer do que as que não apresentaram essa alteração e a razão de chance das que tiveram LAD grave evoluírem a óbito foi de 125 vezes quando confrontadas com as que apresentaram LAD leve ou moderada.

Tabela 37 - Modelo de regressão logística dos fatores de risco para óbito até seis meses após LAD. HCFMUSP, 2013-2014.

\begin{tabular}{|c|c|c|c|c|}
\hline \multirow[b]{2}{*}{ VARIÁVEL } & \multirow[b]{2}{*}{ valor de $p$} & \multirow[b]{2}{*}{ OR } & \multicolumn{2}{|c|}{ IC para OR $(95 \%)$} \\
\hline & & & $\begin{array}{c}\text { Limite } \\
\text { inferior }\end{array}$ & Limite superior \\
\hline $\begin{array}{l}\text { Hipóxia pela } \mathrm{SpO}_{2} \text { na } \\
\text { admissão (sim) }\end{array}$ & 0,029 & 18,77 & 1,36 & 259,27 \\
\hline LAD grave & $<0,001$ & 125,63 & 14,02 & $1.125,95$ \\
\hline
\end{tabular}

O modelo da Tabela 37 não apresentou um bom ajuste, pois os intervalos de confiança - IC para OR (95\%) - foram grandes. Testou-se o modelo excluindo-se a hipóxia pela $\mathrm{SpO}_{2}$, mas ainda assim o modelo apresentou IC para OR (95\%) entre 13,65 e 395,89.

Ainda que se reconheça a indubitável importância da gravidade da LAD nos resultados dessa lesão, uma nova modelagem foi realizada, excluindo-se esta variável. O modelo resultante está apresentado na Tabela 38 , que mostra que a presença de hipotensão na admissão e o valor do NISS foram independentemente associados ao óbito no final dessa regressão. Os pacientes com hipotensão na admissão tiveram 7,86 vezes mais chances de ir a óbito quando comparados com as vítimas sem esta alteração. Além disso, o acréscimo de um ponto no valor do NISS aumentou em 14,0\% a 
chance do paciente evoluir a óbito nos primeiros seis meses depois de ocorrer a LAD.

Tabela 38 - Modelo de regressão logística dos fatores de risco para óbito até 6 meses após LAD excluindo a gravidade dessa lesão. HCFMUSP, 2013-2014.

\begin{tabular}{|c|c|c|c|c|}
\hline \multirow[b]{2}{*}{ VARIÁVEL } & \multirow[b]{2}{*}{ valor de $p$} & \multirow[b]{2}{*}{ OR } & \multicolumn{2}{|c|}{ IC para OR $(95 \%)$} \\
\hline & & & $\begin{array}{l}\text { Limite } \\
\text { inferior }\end{array}$ & $\begin{array}{l}\text { Limite } \\
\text { superior }\end{array}$ \\
\hline $\begin{array}{l}\text { Hipotensão na admissão } \\
\text { (sim) }\end{array}$ & 0,016 & 7,86 & 1,48 & 41,78 \\
\hline NISS & $<0,001$ & 1,14 & 1,07 & 1,22 \\
\hline
\end{tabular}

\subsection{FATORES ASSOCIADOS À DEPENDÊNCIA AOS SEIS MESES APÓS LAD}

Considerando-se apenas os 51 sobreviventes que participaram até o término do estudo, identificou-se dois grupos de vítimas de LAD, um de dependentes e outro de independentes, no período de seis meses após o trauma. Pelos motivos anteriormente explicitados (p.81), somente a ERGA fundamentou a distribuição das vítimas nas duas categorias; indivíduos incluídos nas categorias incapacidade grave, incapacidade grave acentuada e estado vegetativo persistente dessa escala foram classificados como dependentes, totalizando seis elementos no grupo. Para identificar os fatores associados à dependência aos seis meses após LAD, as mesmas características das vítimas examinadas para estabelecer fatores associados a óbito foram analisadas perante esses dois grupos. As Tabelas 39 a 47 apresentam os resultados dessas análises.

Resultados referentes a características sociodemográficas das vítimas na época do trauma estão apresentados nas Tabelas 39 e 40 e seus dados mostram que não houve diferença estatisticamente significativa entre os grupos quanto a essas variáveis. 
Tabela 39 - Estatísticas descritivas e comparações entre independentes e dependentes aos 6 meses após LAD em relação a idade, anos de escolaridade e renda per capita familiar (R\$) na época do trauma. HCFMUSP, 2013-2014.

\begin{tabular}{lccc}
\multicolumn{1}{c}{ CARACTERÍSTICAS } & Independentes & Dependentes & $\begin{array}{c}\text { valor de } \\
\text { SOCIODEMOGRÁFICAS }\end{array}$ \\
\hline Idade & & & \\
Média & 30,5 & 32,5 & 0,657 \\
Desvio padrão & 10,1 & 11,6 & \\
Mediana & 29,0 & 32,5 & \\
Mín-Máx & $18-58$ & $19-53$ & \\
Anos de escolaridade & & & \\
Média & 8,8 & 10,7 & \\
Desvio padrão & 3,2 & 3,8 & \\
Mediana & 8,0 & 9,5 & \\
Mín-Máx & $1-17$ & $7-18$ & \\
Renda per capita familiar & & & \\
(R\$) & & & \\
Média & $1.201,40$ & $3.598,60$ & \\
Desvio padrão & $1.328,60$ & $6.818,90$ & \\
Mediana & $1.000,00$ & $1.000,00$ & \\
Mín-Máx & $0,00-8.000,00$ & $225,00-$ & \\
& & $17.500,00$ & \\
\hline * Teste T- Student & & &
\end{tabular}

Tabela 40 - Comparações entre independentes e dependentes aos 6 meses após LAD em relação a gênero, raça, vínculo conjugal e situação ocupacional na época do trauma. HCFMUSP, 2013-2014.

\begin{tabular}{|c|c|c|c|c|c|}
\hline \multirow{2}{*}{$\begin{array}{c}\text { CARACTERÍSTICAS } \\
\text { SOCIODEMOGRÁFICAS }\end{array}$} & \multicolumn{2}{|c|}{ Independentes } & \multicolumn{2}{|c|}{ Dependentes } & \multirow[t]{2}{*}{ valor de $p$} \\
\hline & $\mathbf{n}$ & $\%$ & $\mathbf{n}$ & $\%$ & \\
\hline \multicolumn{6}{|l|}{ Gênero } \\
\hline Masculino & 40 & 88,9 & 5 & 83,3 & $0,548 *$ \\
\hline Feminino & 5 & 11,1 & 1 & 16,7 & \\
\hline \multicolumn{6}{|l|}{ Vínculo conjugal } \\
\hline Solteiro & 23 & 51,1 & 4 & 66,7 & $0,659 * *$ \\
\hline Casado & 18 & 40,0 & 2 & 33,3 & \\
\hline Separado & 4 & 8,9 & - & - & \\
\hline \multicolumn{6}{|l|}{ Raça } \\
\hline Branca & 29 & 64,4 & 4 & 66,7 & $>0,999 *$ \\
\hline Negra & 16 & 35,6 & 2 & 33,3 & \\
\hline \multicolumn{6}{|l|}{ Situação ocupacional } \\
\hline $\begin{array}{l}\text { Inserido no mercado de } \\
\text { trabalho }\end{array}$ & 42 & 93,3 & 6 & 100 & $>0,999 *$ \\
\hline $\begin{array}{l}\text { Sem inserção no mercado de } \\
\text { trabalho }\end{array}$ & 3 & 6,7 & - & - & \\
\hline
\end{tabular}


Tabela 41 - Comparações entre independentes e dependentes aos 6 meses após LAD em relação a características relacionadas ao trauma e APH. HCFMUSP, 2013-2014.

\begin{tabular}{|c|c|c|c|c|c|}
\hline \multirow{2}{*}{$\begin{array}{c}\text { CARACTERÍSTICAS } \\
\text { RELACIONADAS AO } \\
\text { TRAUMA E APH }\end{array}$} & \multicolumn{2}{|c|}{ Independentes } & \multicolumn{2}{|c|}{ Dependentes } & \multirow[t]{2}{*}{ valor de $p^{*}$} \\
\hline & $\mathbf{n}$ & $\%$ & $\mathbf{n}$ & $\%$ & \\
\hline \multicolumn{6}{|l|}{ Acidente de transporte } \\
\hline $\begin{array}{l}\text { Sim } \\
\text { Não }\end{array}$ & $\begin{array}{c}36 \\
9\end{array}$ & $\begin{array}{l}80,0 \\
20,0\end{array}$ & $\begin{array}{l}6 \\
-\end{array}$ & 100 & 0,575 \\
\hline \multicolumn{6}{|l|}{ Tipo de APH } \\
\hline $\begin{array}{l}\text { Aéreo } \\
\text { Terrestre }\end{array}$ & $\begin{array}{l}22 \\
23\end{array}$ & $\begin{array}{l}48,9 \\
51,1\end{array}$ & $\begin{array}{l}2 \\
4\end{array}$ & $\begin{array}{l}33,3 \\
66,7\end{array}$ & 0,671 \\
\hline \multicolumn{6}{|l|}{ IOT na cena** } \\
\hline $\begin{array}{l}\text { Sim } \\
\text { Não }\end{array}$ & $\begin{array}{c}38 \\
6\end{array}$ & $\begin{array}{l}86,4 \\
13,6\end{array}$ & $\begin{array}{l}4 \\
2\end{array}$ & $\begin{array}{l}66,7 \\
33,3\end{array}$ & 0,242 \\
\hline \multicolumn{6}{|l|}{ Relato de ingestão de álcool } \\
\hline $\begin{array}{l}\text { Sim } \\
\text { Não }\end{array}$ & $\begin{array}{l}20 \\
25 \\
\end{array}$ & $\begin{array}{l}44,4 \\
55,6\end{array}$ & $\begin{array}{l}2 \\
4 \\
\end{array}$ & $\begin{array}{l}33,3 \\
66,7 \\
\end{array}$ & 0,688 \\
\hline
\end{tabular}

* Teste exato de Fisher.

** Exclui 1 caso sem informação.

Os resultados apresentados na Tabela 41 mostram que os grupos comparados não diferiram entre si quando características relacionadas ao trauma e APH foram analisadas.

$\mathrm{Na}$ análise das variáveis que retratam a gravidade do trauma e TCE mensuradas pelo ISS, NISS e MAIS/cabeça, observou-se que diferenças estatisticamente significativas ocorreram em relação a todos os indicadores de gravidade. Os valores das médias dos escores foram maiores no grupo dos pacientes dependentes (Tabela 42).

Tabela 42 - Estatísticas descritivas e comparações entre dependentes e independentes aos 6 meses após LAD em relação a gravidade do trauma (ISS, NISS) e TCE (MAIS/cabeça). HCFMUSP, 2013-2014.

\begin{tabular}{lccc}
\hline \multicolumn{1}{c}{$\begin{array}{c}\text { GRAVIDADE DO } \\
\text { TRAUMA E TCE }\end{array}$} & Independentes & Dependentes & valor de $\mathbf{p}^{*}$ \\
\hline ISS & & & \\
Média & 30,1 & 41,8 & \\
Desvio padrão & 8,2 & 12,0 & $\mathbf{0 , 0 0 3}$ \\
Mediana & 29,0 & 41,5 & \\
Mín-Máx & $17-57$ & $26-59$ & \\
NISS & & & \\
Média & 37,5 & 55,2 & \\
Desvio padrão & 11,0 & 13,4 & $\mathbf{0 , 0 0 1}$ \\
Mediana & 34,0 & 58,0 & \\
Mín-Máx & $18-66$ & $33-66$ & \\
MAIS/cabeça & & & \\
Média & 4,3 & 5,0 & \\
Desvio padrão & 0,5 & 0,0 & $<0,001$ \\
Mediana & 4,0 & 5,0 & \\
Mín-Máx & $4-5$ & $5-5$ & \\
\hline Teste T-Student. & & & \\
\hline
\end{tabular}

* Teste T-Student. 
Na Tabela 43 observa-se que houve fortes evidências estatísticas de associação entre a capacidade funcional das vítimas aos 6 meses e a gravidade da LAD $(\mathrm{p}<0,001)$. No grupo de dependentes, predominaram as vítimas de LAD grave; entre os independentes, essa lesão foi leve/moderada na quase totalidade dos casos.

Tabela 43 - Comparação entre independentes e dependentes aos 6 meses após trauma em relação à gravidade da LAD. HCFMUSP, 2013-2014.

\begin{tabular}{lcccccc}
\hline GRAVIDADE DA LAD & \multicolumn{3}{c}{ Independentes } & \multicolumn{2}{c}{ Dependentes } & \multirow{2}{*}{ valor de p* } \\
\cline { 2 - 5 } & $\mathbf{n}$ & $\mathbf{\%}$ & $\mathbf{n}$ & $\mathbf{\%}$ & \\
Leve/Moderada & 44 & 97,8 & 1 & 16,7 & \multirow{2}{*0,001}{} \\
Grave & 1 & 2,2 & 5 & 83,3 & \\
\hline * Teste de associação Qui-Quadrado de Pearson. & & & &
\end{tabular}

Todas as variáveis relacionadas à admissão hospitalar e apresentadas nas Tabelas 44 e 45 não mostraram correlação estatisticamente significativa com dependência aos seis meses após LAD.

Tabela 44 - Comparações entre independentes e dependentes aos 6 meses após LAD em relação às características na admissão hospitalar. HCFMUSP, 2013-2014.

\begin{tabular}{|c|c|c|c|c|c|}
\hline \multirow{2}{*}{$\begin{array}{c}\text { CARACTERÍSTICAS } \\
\text { RELACIONADAS À } \\
\text { ADMISSÃO }\end{array}$} & \multicolumn{2}{|c|}{ Independentes } & \multicolumn{2}{|c|}{ Dependentes } & \multirow[t]{2}{*}{ valor de $\mathbf{p}^{*}$} \\
\hline & $\mathbf{n}$ & $\%$ & $\mathrm{n}$ & $\%$ & \\
\hline \multicolumn{6}{|l|}{ Sedação } \\
\hline $\operatorname{Sim}$ & 41 & 91,1 & 6 & 100 & $>0,999$ \\
\hline Não & 4 & 8,9 & - & - & \\
\hline \multicolumn{6}{|l|}{$\mathbf{F R}^{* *}$} \\
\hline Normal & 38 & 92,7 & 5 & 83,3 & 0,432 \\
\hline Alterada & 3 & 7,3 & 1 & 16,7 & \\
\hline \multicolumn{6}{|l|}{ Hipotensão } \\
\hline Sim & 4 & 8,9 & - & - & $>0,999$ \\
\hline Não & 41 & 91,1 & 6 & 100 & \\
\hline \multicolumn{6}{|l|}{ Bradicardia } \\
\hline Sim & - & - & - & - & - \\
\hline Não & 45 & 100,0 & 6 & 100 & \\
\hline \multicolumn{6}{|l|}{ Taquicardia } \\
\hline Sim & 23 & 51,1 & 3 & 50,0 & $>0,999$ \\
\hline \multirow[t]{2}{*}{ Não } & 22 & 48,9 & 3 & 50,0 & \\
\hline & & & & & (continua) \\
\hline
\end{tabular}


(continuação)

\begin{tabular}{lccccc} 
CARACTERÍSTICAS & \multicolumn{2}{c}{ Independentes } & \multicolumn{2}{c}{ Dependentes } & valor de p* \\
RELACIONADAS À & $\mathbf{n}$ & $\%$ & $\mathbf{n}$ & $\%$ & \\
$\begin{array}{l}\text { ADMISSÃO } \\
\text { Hipóxia pela SpO }\end{array}$ N $^{* *}$ & & & & & \\
Sim & 3 & 6,7 & - & - & $>0,999$ \\
Não & 42 & 93,3 & 5 & 100 &
\end{tabular}

Hipóxia pela $\mathrm{PO}_{2} * * * *$

$\begin{array}{lccccc}\text { Sim } & 6 & 14,3 & 2 & 33,3 & 0,258 \\ \text { Não } & 36 & 85,7 & 4 & 66,7 & \\ \text { Hipoglicemia***** } & & & & & \\ \text { Sim } & 2 & 4,9 & - & - & >0,999 \\ \text { Não } & 39 & 95,1 & 6 & 100,0 & \end{array}$

Hiperglicemia $* * * * *$

\begin{tabular}{lccccc} 
Sim & 9 & 22,0 & 1 & 16,7 & $>0,999$ \\
Não & 32 & 78,0 & 5 & 83,3 & \\
Alterações pupilares & & & & & \\
Sim & 21 & 46,7 & 4 & 66,7 & 0,419 \\
Não & 24 & 53,3 & 2 & 33,3 & \\
\hline * Teste exato de Fisher. & & & & (conclusão) \\
**Exclui 4 casos sem informação. & & & & \\
***Exclui 1 caso sem informação. & & & & \\
****Exclui 3 casos sem informação. & & & & \\
$* * * * *$ Exclui 4 casos sem informação. &
\end{tabular}

Tabela 45 - Estatísticas descritivas e comparação entre independentes e dependentes aos 6 meses após LAD em relação a ECG1 na admissão. HCFMUSP, 2013-2014.

\begin{tabular}{lccc}
\hline \multicolumn{1}{c}{ ECGI NA ADMISSÃO } & Independentes & Dependentes & valor de $\mathbf{~}^{*}$ \\
\hline Média & 4,4 & 4,7 & \\
Desvio padrão & 1,6 & 1,9 & 0,706 \\
Mediana & 3,0 & 4,5 & \\
Mín - Máx & $3-8$ & $3-7$ & \\
\hline * Teste T-Student. & &
\end{tabular}

Nos dados da Tabela 46 verifica-se que houve diferença estatisticamente significante entre as vítimas dependentes e independentes em relação à presença durante a internação hospitalar de HIC $(p=0,004)$, infecção $(p=0,022)$ e outras complicações $(p=0,003)$. A frequência relativa de presença dessas condições clínicas foi maior entre os dependentes quando os dois grupos foram comparados. Além disso, todos os indivíduos que tinham dependência aos seis meses após LAD apresentaram complicações durante a internação. 
Tabela 46 - Comparações entre independentes e dependentes aos 6 meses após LAD em relação às características relacionadas à internação hospitalar. HCFMUSP, 2013-2014.

\begin{tabular}{|c|c|c|c|c|c|}
\hline \multirow{2}{*}{$\begin{array}{c}\text { CARACTERÍSTICAS } \\
\text { RELACIONADAS À } \\
\text { INTERNAÇÃO }\end{array}$} & \multicolumn{2}{|c|}{ Independentes } & \multicolumn{2}{|c|}{ Dependentes } & \multirow[t]{2}{*}{ valor de $\mathrm{p}^{*}$} \\
\hline & $\mathbf{n}$ & $\%$ & $\mathbf{n}$ & $\%$ & \\
\hline \multicolumn{6}{|l|}{ Internação em UTI } \\
\hline Sim & 42 & 93,3 & 6 & 100 & $>0,999$ \\
\hline Não & 3 & 6,7 & - & - & \\
\hline \multicolumn{6}{|l|}{ Uso de sedação contínua } \\
\hline $\operatorname{Sim}$ & 39 & 86,7 & 6 & 100,0 & $>0,999$ \\
\hline Não & 6 & 13,3 & - & - & \\
\hline \multicolumn{6}{|l|}{$\begin{array}{l}\text { Outros tratamentos com } \\
\text { drogas que atuam no SNC }\end{array}$} \\
\hline $\operatorname{Sim}$ & 27 & 60,0 & 6 & 100,0 & 0,078 \\
\hline Não & 18 & 40,0 & - & - & \\
\hline \multicolumn{6}{|l|}{ Tratamento cirúrgico } \\
\hline Sim & 23 & 51,1 & 5 & 83,3 & 0,204 \\
\hline Não & 22 & 48,9 & 1 & 16,7 & \\
\hline \multicolumn{6}{|l|}{ Reabordagem cirúrgica } \\
\hline $\operatorname{Sim}$ & 9 & 20,0 & 1 & 16,7 & $>0,999$ \\
\hline Não & 36 & 80,0 & 5 & 83,3 & \\
\hline \multicolumn{6}{|l|}{ Infecção } \\
\hline $\mathrm{Sim}$ & 8 & 17,8 & 4 & 66,7 & 0,022 \\
\hline Não & 37 & 82,2 & 2 & 33,3 & \\
\hline \multicolumn{6}{|l|}{ Outras complicações } \\
\hline $\operatorname{Sim}$ & 15 & 33,3 & 6 & 100,0 & $\mathbf{0 , 0 0 3}$ \\
\hline Não & 30 & 66,7 & - & - & \\
\hline \multicolumn{6}{|l|}{ Sinais de LAD precoce na TC } \\
\hline $\operatorname{Sim}$ & 25 & 55,6 & 6 & 100,0 & 0,070 \\
\hline Não & 20 & 44,4 & - & - & \\
\hline \multicolumn{6}{|l|}{ Monitorização da PIC } \\
\hline Sim & - & - & 1 & 16,7 & 0,118 \\
\hline Não & 45 & 100,0 & 5 & 83,3 & \\
\hline \multicolumn{6}{|l|}{ HIC } \\
\hline $\operatorname{Sim}$ & 4 & 8,9 & 4 & 66,7 & $\mathbf{0 , 0 0 4}$ \\
\hline Não & 41 & 91,1 & 2 & 33,3 & \\
\hline \multicolumn{6}{|l|}{ Hipotensão } \\
\hline $\mathrm{Sim}$ & 5 & 11,1 & 1 & 16,7 & 0,548 \\
\hline Não & 40 & 88,9 & 5 & 83,3 & \\
\hline \multicolumn{6}{|l|}{ Hipertensão } \\
\hline Sim & 31 & 68,9 & 6 & 100,0 & 0,170 \\
\hline Não & 14 & 31,1 & - & - & \\
\hline \multicolumn{6}{|l|}{ Hipotermia } \\
\hline Sim & 23 & 51,1 & 5 & 83,3 & 0,204 \\
\hline Não & 22 & 48,9 & 1 & 16,7 & \\
\hline
\end{tabular}


(continuação)

\begin{tabular}{|c|c|c|c|c|c|}
\hline \multirow{2}{*}{$\begin{array}{c}\text { CARACTERÍSTICAS } \\
\text { RELACIONADAS À } \\
\text { INTERNAÇÃO }\end{array}$} & \multicolumn{2}{|c|}{ Independentes } & \multicolumn{2}{|c|}{ Dependentes } & \multirow[t]{2}{*}{ valor de $p^{*}$} \\
\hline & $\mathbf{n}$ & $\%$ & $\mathbf{n}$ & $\%$ & \\
\hline \multicolumn{6}{|l|}{ Hipertermia } \\
\hline $\operatorname{Sim}$ & 26 & 57,8 & 6 & 100,0 & 0,072 \\
\hline Não & 19 & 42,2 & - & - & \\
\hline \multicolumn{6}{|l|}{ Hipoglicemia } \\
\hline Sim & 13 & 28,9 & 3 & 50,0 & 0,363 \\
\hline Não & 32 & 71,1 & 3 & 50,0 & \\
\hline \multicolumn{6}{|l|}{$\begin{array}{l}\text { Hipoglicemia nos } \\
5 \text { primeiros dias }\end{array}$} \\
\hline Sim & 7 & 15,6 & - & - & 0,578 \\
\hline Não & 38 & 84,4 & 6 & 100,0 & \\
\hline \multicolumn{6}{|l|}{ Hiperglicemia } \\
\hline $\operatorname{Sim}$ & 26 & 57,8 & 4 & 66,7 & $>0,999$ \\
\hline Não & 19 & 42,2 & 2 & 33,3 & \\
\hline \multicolumn{6}{|l|}{$\begin{array}{l}\text { Hiperglicemia nos } \\
5 \text { primeiros dias }\end{array}$} \\
\hline $\operatorname{Sim}$ & 21 & 46,7 & 4 & 66,7 & 0,419 \\
\hline Não & 24 & 53,3 & 2 & 33,3 & \\
\hline
\end{tabular}

$\mathrm{Na}$ Tabela 47 observa-se que houve diferença estatisticamente significativa entre as médias dos grupos em relação aos tempos de internação na UTI $(p<0,001)$, sedação contínua $(p=0,001)$ e internação hospitalar ( $\mathrm{p}=0,037)$. Além do mais, o valor médio da ECGl 48 horas após a retirada da sedação diferiu entre dependentes e independentes $(p<0,001) . \mathrm{Na}$ comparação dos dois grupos, as médias dos tempos foram maiores no grupo de dependentes e o valor médio da ECGl menor.

Tabela 47 - Estatísticas descritivas e comparação entre dependentes e independentes aos 6 meses após LAD em relação a características relacionadas à internação. HCFMUSP, 20132014.

\begin{tabular}{lccc}
\hline \multicolumn{1}{c}{ CARACTERÍSTICAS } & Independentes & Dependentes & valor de p* \\
\multicolumn{1}{c}{$\begin{array}{l}\text { RELACIONADAS À } \\
\text { INTERNAÇÃO }\end{array}$} & & & \\
\hline Tempo de internação na UTI & & & \\
Média & 9,1 & 23,5 & \\
Desvio padrão & 7,7 & 10,5 & $<\mathbf{0 , 0 0 1}$ \\
Mediana & 7,0 & 23,5 & \\
Mín-Máx & $2-40$ & $7-40$ & \\
& & & (continua)
\end{tabular}


(continuação)

CARACTERÍSTICAS RELACIONADAS À INTERNAÇÃO

Tempo de sedação contínua Média

Desvio padrão

Mediana

Mín-Máx

RASS 24 horas antes da retirada da sedação

Média

Desvio padrão

Mediana

Mín-Máx

ECGI 48 horas após retirada da

sedação

Média

Desvio padrão

Mediana

Mín-Máx

Tempo para $M R M=6($ ECGI)

Média

Desvio padrão

Mediana

Mín-Máx

Tempo de internação hospitalar

Média

Desvio padrão

Mediana

Mín-Máx

* Teste T-Student
Independentes Dependentes valor de p*

$\begin{array}{cc}3,0 & 8,8 \\ 3,6 & 6,0 \\ 2,0 & 8,0 \\ 0-14 & 0-18\end{array}$

$\mathbf{0 , 0 0 1}$

8,0
-18

$-2,5$

$2,5 \quad 0,566$

$-3,0$

$-5-1$

$-1,8$

2,6

$-5-2$

$\begin{array}{cr}12,8 & 8,3 \\ 2,6 & 1,9 \\ 14,0 & 9,0 \\ 6-15 & 6-10\end{array}$

$2,6 \quad 16,8$

$5,3 \quad 11,9$

$1,0 \quad 18,0$

$0-23 \quad 4-32$

$17,6 \quad 55,5$

$16,2 \quad 33,0$

$12,0 \quad 47,5$

$2-59$

$23-111$

$\mathbf{0 , 0 3 7}$

(conclusão)

Para identificar os fatores de risco para dependência aos seis meses após $\mathrm{LAD}$, as variáveis que tiveram $p$-value $<0,05$ nas Tabelas 39 a 47 foram inicialmente testadas. Durante a modelagem, a primeira variável que entrou no modelo foi a gravidade da LAD, com a qual nenhuma outra variável alcançou p-value $<0,05$. Assim, no modelo final, permaneceu apenas esta característica das vítimas (Tabela 48). Segundo esse resultado, pacientes com LAD grave tiveram 205 vezes mais chances de serem dependentes aos 6 meses após o trauma, ante as vítimas de LAD leve ou moderada. 
Tabela 48 - Modelo de regressão logística dos fatores de risco para dependência aos 6 meses após LAD. HCFMUSP, 2013-2014.

\begin{tabular}{lcccc}
\hline \multirow{2}{*}{ VARIÁVEL } & valor de $\mathbf{p}$ & OR & \multicolumn{2}{c}{ IC para OR (95\%) } \\
\cline { 4 - 5 } & & & $\begin{array}{c}\text { Limite } \\
\text { inferior }\end{array}$ & Limite superior \\
\hline LAD (grave) & $\mathbf{0 , 0 0 0}$ & 205,00 & 11,02 & $3.813,02$ \\
\hline
\end{tabular}

Da mesma forma que no modelo de óbito, o IC para OR (95\%) foi bastante amplo no resultado da regressão para dependência. Sendo assim, novamente a modelagem foi realizada excluindo a gravidade da LAD e o modelo final desta regressão está apresentado na Tabela 49. Durante a modelagem, apenas o tempo de internação hospitalar apresentou significância estatística no modelo de regressão logística, $p$-value $\leq 0,05$. Este último modelo (Tabela 49) apresentou um melhor ajuste que o anterior e indicou que o acréscimo de um dia de internação hospitalar aumentou em $7 \%$ a chance de uma vítima encontrar-se dependente aos 6 meses após LAD.

Tabela 49 - Modelo de regressão logística dos fatores de risco para dependência aos 6 meses após LAD excluindo a gravidade dessa lesão. HCFMUSP, 2013-2014.

\begin{tabular}{lcccc}
\hline VARIÁVEL & valor de $p$ & OR & \multicolumn{2}{c}{ IC para OR (95\%) } \\
\cline { 4 - 5 } & & $\begin{array}{c}\text { Limite } \\
\text { inferior }\end{array}$ & Limite superior \\
\hline $\begin{array}{l}\text { Tempo de internação } \\
\text { hospitalar (em dias) }\end{array}$ & $\mathbf{0 , 0 0 8}$ & 1,07 & 1,02 & 1,12 \\
\hline
\end{tabular}

\subsection{PODER DO ESTUDO}

O poder do estudo foi de $99,6 \%$, quando calculado considerando a comparação da média na pontuação da escala de Katz na alta, 3 e 6 meses após LAD (Tabela 12) e de 93,7\% quando considerada a diferença nos resultados das avaliações com a ERGA nesses três momentos (Tabela 10). 


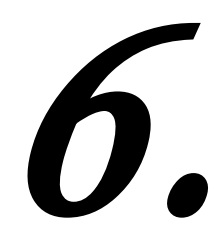

Discussão 


\section{DISCUSSÃO}

A LAD é uma lesão microscópica associada com importante mortalidade e morbidade. Avaliar a recuperação dessas vítimas e os fatores de risco relacionados às suas consequências é de grande relevância para implantação de assistência multidisciplinar adequada e de políticas de saúde que objetivem a prevenção e a reinserção das vítimas de LAD na sociedade.

A maioria das vítimas de LAD admitidas no HCFMUSP eram adultos jovens, brancos, do sexo masculino, com escolaridade média de 9,1 $(d p=3,5)$ anos. Jovens do sexo masculino predominam entre os traumatizados em geral e também entre as vítimas de $\operatorname{LAD}^{(10,22,27-28,51,74)}$. Quanto à raça e à escolaridade, ainda que os resultados sejam similares a outros estudos com vítimas dessa lesão ${ }^{(10,22,27-28,51,74-75)}$, eles aparentam também refletir as características populacionais do local de estudo: o censo demográfico da cidade de São Paulo em 2010 mostra 37,0\% da população de pardos ou pretos e $35,0 \%$ dos recenseados com ensino fundamental incompleto e $17,1 \%$ médio incompleto ${ }^{(76)}$.

Nesta pesquisa, identificou-se que $51,3 \%$ das vítimas eram solteiras, $89,7 \%$ estavam inseridas no mercado de trabalho e a renda per capita média dos participantes foi de $\mathrm{R} \$ 1.290,98(\mathrm{dp}=\mathrm{R} \$ 2.282,64)$. Estas características sociodemográficas das vítimas de LAD, assim como as anteriormente comentadas, podem interferir no processo de recuperação ${ }^{(77-81)}$ e são importantes no planejamento de ações preventivas e estratégias de saúde a fim de diminuir as ocorrências e consequências relacionadas a esse tipo de lesão. Entretanto, as características sociodemográficas da casuística estudada não apresentaram relação com óbito e dependência dos pacientes seis meses após essa lesão.

Os acidentes de transporte foram a causa externa mais frequente da LAD nesta pesquisa, destacando-se as ocorrências com motociclistas $(43,6 \%)$. Nesses eventos, são comuns os impactos em grande velocidade e os movimentos rotacionais encefálicos. A prevalência de internações hospitalares das vítimas de LAD por acidente de transporte nesta e outras 
pesquisas reforça as indicações da literatura de que movimentos rotacionais do encéfalo causam as lesões dos axônios que caracterizam a $\operatorname{LAD}^{(1-}$ $3,10,22,75,82)$

A frequência dos acidentes motociclísticos neste estudo foi impulsionada pelo aumento da frota de motocicletas, que cresce continuamente em todo o país. Segundo dados do Departamento Nacional de Trânsito, a cidade de São Paulo possui mais de um milhão de motocicletas e essa frota duplicou nos últimos nove anos ${ }^{(83)}$. Estudo realizado pela Faculdade de Medicina da Universidade de São Paulo, no ano de 2013 , evidenciou que 55,0\% dos motociclistas que circulam na cidade já sofreram um acidente, 67,0\% aprenderam a pilotar sozinhos, 45,0\% tinham motocicleta há menos de dois anos, 67,0\% das vítimas sem habilitação tiveram lesões graves, $28,0 \%$ dos acidentados ficaram internados, 5,0\% tiveram TCE e 2,0\% dessas vítimas internadas foram a óbito ${ }^{(84)}$.

A ingestão de bebidas alcoólicas no período próximo à ocorrência do trauma foi referida em $42,3 \%$ dos casos analisados, porém esta informação não foi comprovada por dosagens séricas da droga e não foi associada a óbito ou dependência após trauma. O consumo de álcool foi um fator relacionado a uso do serviço pré- hospitalar em vítimas de acidentes de trânsito ${ }^{(85)}$; entretanto, a intoxicação aguda por álcool não foi associada ao tipo e número de LAD e às incapacidades detectadas pela ERGA aos seis meses, em estudo realizado no Japão ${ }^{(86)}$.

Com relação à gravidade global do trauma, aplicando-se o ISS e NISS, observou-se mediana de 33 e 43, escore médio de 35,0 $(\mathrm{dp}=11,9)$ e $46,2(\mathrm{~d} p=15,9)$, respectivamente. A grande maioria das vítimas apresentou valores $\geq 25$ nesses índices, $80,8 \%$ pelo ISS e $91,0 \%$ pelo NISS. Os escores $\geq 25$, tanto no ISS como no NISS, indicam que ocorreram lesões anatômicas graves e essa gravidade tem sido associada com a mortalidade das vítimas de trauma na literatura ${ }^{(87-88)}$.

Estudos que avaliaram a gravidade do trauma em vítimas de LAD por meio do ISS mostraram valores médio e mediano semelhantes aos desta pesquisa: média de $34,0^{(10)}$ e mediana de $30,0^{(22,89)}$ e $29,0^{(41)}$. 
Para todas as vítimas, o MAIS/cabeça foi $\geq 4$ e o valor médio nessa escala foi 4,6 $(d p=0,5)$, embora as vítimas de LAD leve tenham sido as mais frequentes (44,9\%). A LAD, conforme descrita no Manual AIS 2005 update 2008, é uma lesão que recebe pontuação 4 ou 5, sendo portanto considerada grave ou crítica por esse indicador.

Na classificação de Gennarelli ${ }^{(1-2)}$ aplicada neste estudo, a LAD leve é definida clinicamente por coma com duração de 6 a 24 horas, sendo, portanto, a priori, uma lesão importante, mesmo quando de menor gravidade. A LAD é considerada a principal causa de perda de consciência após trauma e a sua definição clínica é de coma prolongado, com duração de mais de 6 horas após o trauma ${ }^{(90)}$.

Os indicadores de gravidade do trauma (ISS e NISS), do TCE (MAIS/cabeça) e da LAD apresentaram associação estatisticamente significante com óbito e dependência. Outros autores ${ }^{(87,91-92)}$ têm mostrado que o MAIS/cabeça e ISS são fatores associados a mortalidade em vítimas de TCE. Em pesquisas com vítimas de LAD também se observou que, quanto maior a gravidade do trauma medida pelo ISS, pior o desfecho e prognóstico $^{(10,22)}$. Em São Paulo, vítimas de TCE que tiveram MAIS/cabeça $\geq 5$ apresentaram 4,89 vezes mais chance de dependência quando comparadas com pacientes que apresentaram escores inferiores ${ }^{(56)}$.

Todos os participantes da casuística foram removidos por serviços de APH, sendo expressiva a frequência do uso de transporte aéreo $(47,4 \%)$. Vítimas de TCE gravemente feridas necessitam de cuidados eficientes e especializados em tempo adequado, e sua sobrevida pode diferir segundo o tipo de serviço pré-hospitalar ${ }^{(93-94)}$. A análise de 209.529 vítimas de TCE nos $\mathrm{EUA}^{(94)}$ evidenciou que o atendimento por transporte pré-hospitalar aéreo está associado com aumento da sobrevida quando comparado com o terrestre, porém este não foi um fato constatado no atual estudo.

Algumas variáveis clínicas das vítimas de TCE avaliadas na cena foram relacionadas com boa recuperação por autores norte-americanos, pontuação mais elevada na ECGl, reatividade bilateral das pupilas e ausência de hipóxia ${ }^{(94)}$. Estudo realizado na Cidade do Cabo - África do Sul, com pacientes atendidos por equipe pré-hospitalar, evidenciou que a 
reatividade bilateral das pupilas, $\mathrm{SpO}_{2} \geq 90,0 \%$ e pontuação na ECGl elevada estão associadas com resultados favoráveis após o TCE grave ${ }^{(15)}$. Nos resultados, a chance de boa recuperação após o TCE grave diferiu entre as variáveis; observou-se que as mais elevadas pontuações na ECGl apresentaram maior sensibilidade para melhor recuperação após TCE grave, seguida da reatividade bilateral das pupilas e $\mathrm{SpO}_{2} \geq 90,0 \%$.

$\mathrm{Na}$ atual investigação, não foram evidenciadas associações entre as variáveis do APH e condições das vítimas aos seis meses após TCE. No entanto, características importantes das vítimas não fizeram parte das análises por falta de informações nos registros hospitalares.

A ECGl foi o único parâmetro físiológico da cena incluído nas análises, ainda que, em 11,5\% dos casos, não houvesse informação. Em relação aos seus resultados, observou-se redução de 1,6 ponto na pontuação média dos participantes entre a cena e admissão hospitalar; 10 pacientes que apresentaram ECGl $>8$ na cena evoluíram para valores inferiores no período.

Pesquisa $^{(95)}$ realizada com vítimas de TCE no APH mostrou que 9,0\% dos doentes apresentaram piora do nível de consciência, com diminuição na média de 5 pontos $(\mathrm{dp}=3,0)$ na ECGl durante o transporte. Essa piora foi associada a maior pontuação no ISS, menor pontuação na ECG1 e maior tempo de internação hospitalar.

$\mathrm{Na}$ admissão hospitalar, a pequena parte das vítimas que não havia sido intubada na cena $(20,5 \%)$ foi submetida a esse procedimento. A quase totalidade dos doentes $(92,3 \%)$ foi sedada, embora nem sempre mantivesse sedação contínua na internação. Nesta fase, conforme critério de inclusão na pesquisa, todos os participantes do estudo apresentaram ECGl $\leq 8$, o valor médio na escala foi de 4,2 e as pupilas estavam alteradas em $60,3 \%$ dos casos. Quanto às demais características clínicas das vítimas, 10,3\% apresentaram FR alterada e a taquipneia foi a alteração mais frequente (6,4\%). A hipóxia pela $\mathrm{SpO}_{2}$ foi detectada em $15,3 \%$ dos doentes e pela $\mathrm{PO}_{2}$ em 14,1\%; 19,2\% apresentaram hipotensão, 2,5\% tiveram parada cardíaca e a taquicardia esteve presente na maioria (52,5\%) dos indivíduos. Alterações glicêmicas foram encontradas em 32,0\% da amostra, sendo a hiperglicemia 
a mais frequente $(28,2 \%)$. As alterações pupilares, a hipotensão, a hipóxia pela $\mathrm{SpO}_{2}$ e a hiperglicemia foram associadas a óbito; no entanto nenhuma alteração dessa fase de tratamento relacionou-se com dependência aos seis meses após LAD.

$\mathrm{Na}$ Tunísia, a análise do prognóstico de 124 vítimas de $\operatorname{LAD}^{(10)}$ mostrou que, na admissão hospitalar, as vítimas estavam em coma com média 6,6 na ECG1 $(\mathrm{dp}=2,05), 50,8 \%$ apresentavam pupilas alteradas, a média da glicemia foi de $8,1 \mathrm{mmol} / \mathrm{L}(\mathrm{dp}=3,4)$ e $\mathrm{PO}_{2} 153 \mathrm{mmHg}(\mathrm{dp}=60)$. Os mais baixos valores na ECGl, a hiperglicemia e anisocoria na admissão, estiveram relacionados com prognósticos desfavoráveis (morte, estado vegetativo persistente e incapacidade grave).

Para alguns autores ${ }^{(96)}$, o estabelecimento de um prognóstico confiável após a lesão cerebral é muito difícil no momento da admissão hospitalar. Talvez por esse motivo, nas vítimas de LAD, são escassos os estudos prognósticos utilizando variáveis fisiológicas dessa fase de tratamento.

A média de permanência hospitalar dos pacientes foi de 19,1 dias $(d p=22,9)$, a quase totalidade das vítimas foi internada em UTI $(92,3 \%)$ e o tempo médio de internação nessa unidade foi de 11,7 dias $(\mathrm{dp}=15,4)$. A duração da internação em UTI e hospitalar esteve relacionada com dependência aos 6 meses após LAD: indivíduos independentes aos 6 meses após LAD tiveram, em média, 9,1 dias de internação em UTI $(d p=7,7)$ e 17,6 $(\mathrm{dp}=16,2)$ dias de permanência hospitalar, ao passo que, para os dependentes, esses valores foram de 23,5 $(d p=10,5)$ e 55,5 $(d p=33)$ dias.

Pesquisas com vítimas de LAD apresentaram, assim como a atual, tempo prolongado de internação hospitalar - mediana de $11^{(31)}$ e valores médios de $13,28(\mathrm{dp}=10,1)^{(45)}, 27,8(\mathrm{dp}=6,6)^{(51)}$ e 38,6 dias $(\mathrm{dp}=32,6)^{(10)}$. A média do tempo de internação em UTI foi de 19,6 dias $(\mathrm{dp}=18,8)$ em estudo que analisou vítimas de LAD na Tunísia. Na Malásia ${ }^{(48)}$, investigação realizada com 72 vítimas de LAD identificou tempo de internação em UTI de acordo com o tipo de tratamento realizado; as vítimas com monitorização de PIC, que utilizaram altas doses de sedativos, permaneceram, em média, 
8,20 dias $(\mathrm{dp}=5,89)$ na UTI. Entretanto, as vítimas sem suporte ventilatório e sem monitorização da PIC tiveram valor médio de 4,79 dias $(\mathrm{dp}=3,45)$.

As longas permanências na UTI e hospitalar observadas nesta e em outras investigações com vítimas de LAD podem estar relacionadas ao tipo de tratamento por elas requerido e à gravidade dessa lesão.

$\mathrm{Na}$ atual pesquisa, a grande maioria dos pacientes $(88,5 \%)$ usou sedação contínua durante um tempo médio de 4,1 dias $(\mathrm{dp}=4,3)$. O valor médio da RASS 24 horas antes da retirada da sedação foi de $-2,3(\mathrm{dp}=2,6)$. A maioria das vítimas $(61,5 \%)$ fez tratamentos com drogas que atuam no SNC; os medicamentos mais utilizados foram os anticonvulsivantes $(83,3 \%)$ e os neurolépticos (70,8\%). O tempo de sedação contínua e o valor da ECG1 48 horas após a retirada da sedação foram fatores relacionados com dependência aos 6 meses após LAD; indivíduos independentes nesse período apresentaram menor tempo de sedação e maior pontuação na ECGl após retirada da sedação ante os que ainda eram dependentes. Além do mais, o escore médio da escala 48 horas após a retirada da sedação dos indivíduos que evoluíram a óbito foi significativamente inferior ao dos sobreviventes $(\mathrm{p}<0,001)$.

É comum a utilização de sedação como protocolo no tratamento das vítimas de TCE grave a fim de evitar hipertensão intracraniana, hipertensão arterial, agitação e retirada acidental de sondas e drenos durante a internação, além de auxiliar no controle da temperatura corporal ${ }^{(60)}$. A duração desse tratamento varia prioritariamente de acordo com a gravidade das vítimas e o risco de aumento da PIC se relaciona com o tempo de internação na $\mathrm{UTI}^{(48)}$.

Além da sedação, é frequente nas vítimas de TCE grave a utilização de outras medicações que atuam no SNC com a finalidade de controle de crises convulsivas $^{(60,97-98)}$. As vítimas de TCE grave estão mais suscetíveis a apresentar essas crises na fase aguda do trauma e estudos mostram que o uso profilático de drogas antiepilépticas é benéfico para evitar esses eventos $^{(60,97-98)}$. 
A investigação da presença de HIC após LAD mostrou que esta lesão secundária do TCE, detectada em 24,2\% das vítimas, apresentou associação com óbito e dependência aos 6 meses após LAD.

A HIC é uma lesão secundária que começa algumas horas após o TCE e é associada a desfechos indesejáveis após esse ferimento. Estudos mostram que a elevação da pressão intracraniana ocasiona redução da perfusão cerebral, causando maior mortalidade e pior recuperação após o TCE $^{(60-61,99-100)}$. Pesquisa ${ }^{(101)}$ realizada com 36 vítimas de LAD na Flórida mostrou que a elevação da pressão intracraniana não está associada com a LAD na mesma intensidade que com o TCE grave; entretanto, a utilização do monitor da PIC nessas vítimas pode desencadear mais elevada.

A monitorização de PIC é utilizada para doentes com TCE grave e alterações na TC. Contudo, nesta pesquisa, poucos pacientes foram submetidos a esse procedimento $(3,8 \%)$. Estudos ${ }^{(61,102-105)}$ mostram que a monitorização da PIC não traz benefícios para o paciente e está associada com aumento da mortalidade, pior recuperação após TCE, maior permanência na UTI e duração do uso de ventilação mecânica.

A LAD é de difícil diagnóstico na fase aguda do trauma. A combinação de sinais clínicos e exames de imagem pode sugerir o diagnóstico dessa lesão, porém sua confirmação só é possível post mortem $^{(106)}$. A utilização da TC na sala de emergência ajuda na identificação, diagnóstico e localização de focos de hemorragia. Apesar da baixa resolução na avaliação de tecidos moles após TCE, a TC é considerada ferramenta útil para identificar sinais precoces de LAD na fase aguda e é amplamente utilizada em vítimas de TCE grave pela curta duração, disponibilidade nos centros de trauma e possibilidade de realização em pacientes instáveis ${ }^{(106)}$.

Estudos $^{(3,10,18,47,69,82)}$ mostram que a frequência de LAD é maior em vítimas de TCE grave, que apresentam sinais indiretos da lesão na TC como hemorragia intraventricular, hemorragia subaracnóidea, além da TC normal. Neste estudo, nas análises de associação com as consequências do trauma, os pacientes que tinham TC normal foram analisados separadamente dos que apresentavam sinais sugestivos de LAD e observou-se que a presença 
desses sinais foi mais frequente entre os casos que evoluíram a óbito $(\mathrm{p}=0,006)$.

A análise de 124 vítimas admitidas com TCE grave em hospital na Tunísia mostrou que esse exame sugeriu diagnóstico de LAD em apenas $25,0 \%{ }^{(10)}$ dos doentes, frequência muito inferior à apresentada nesta investigação $(70,5 \%)$. O predomínio de vítimas com sinais precoces de LAD neste estudo provavelmente está relacionado com o critério de seleção da amostra: indivíduos com ECGl $\leq 8$ na admissão hospitalar que tiveram confirmação de LAD. Para esta confirmação foi considerada a presença de sinais da lesão em $\mathrm{TC}$ ou $\mathrm{RM}$ e casos de $\mathrm{ECGl} \leq 8$ por período superior a 6 horas, sem RM e TC normal.

Após a admissão hospitalar, as vítimas de LAD demoraram em média 3,7 dias $(\mathrm{dp}=7,2)$ para obter o escore 6 no item MRM da ECGl. A maioria das vítimas $(53,8 \%)$ foi submetida a cirurgia e 19,2\% tiveram reabordagem cirúrgica. Quadros infecciosos foram registrados em 25,6\% dos casos e outras complicações identificadas em 52,6\% dos pacientes. Estas últimas complicações tiveram associação com óbito e dependência, ao passo que os quadros de infecção apresentaram frequência mais elevada somente entre os dependentes no período de 6 meses após LAD $(\mathrm{p}=0,022)$.

Complicações durante o tratamento, tais como infecção, choque, IRA, rabdomiólise, distúrbio hidroeletrolítico, disautonomia, crise convulsiva e pneumonia, foram frequentes nesta pesquisa. Estudos ${ }^{(10,107-110)}$ mostraram resultados semelhantes, importante frequência de vítimas com infecção ou outras complicações na internação hospitalar.

Essas alterações podem interferir no tempo de hospitalização do doente e no seu desfecho após o TCE. A análise de fatores relacionados à infecção em vítimas de TCE na Grécia mostrou que a maior frequência de infecções respiratórias e o desenvolvimento da meningite estavam associados à internação prolongada, especialmente em UTI ${ }^{(109)}$.

A disautonomia pós-traumática é caracterizada por alterações da frequência cardíaca, frequência respiratória, pressão arterial, temperatura corporal e tônus muscular. Esta condição clínica é muito comum em vítimas 
de TCE grave internadas em UTI e tem como principais fatores de risco para sua ocorrência a idade mais avançada e o diagnóstico de $\operatorname{LAD}^{(111)}$.

Pesquisa $^{(10)}$ realizada com 124 vítimas de LAD observou que, nas primeiras 24 horas após o trauma, 24,2\% das vítimas apresentaram distúrbios neurovegetativos e 97,6\% desenvolveram pelo menos uma alteração sistêmica secundária, como hipertermia (59,7\%), hipotensão (37,0\%) e hiperglicemia (17,7\%); durante a internação, $51,7 \%$ dos pacientes apresentaram disautonomia. Nas análises de associação, estes achados clínicos foram relacionados com pior prognóstico.

Outros estudos ${ }^{(107-108,112-113)}$ mostram que sepse, pneumonia por aspiração, disautonomia, hiperglicemia, hipotermia e choque hemorrágico estão diretamente relacionados com a mortalidade.

$\mathrm{Na}$ internação hospitalar, $16,7 \%$ das vítimas apresentaram um ou dois eventos de hipotensão sistêmica, 29,5\% apresentaram episódios de hipoglicemia e 59,0\% apresentaram episódios de hipotermia. A maioria das vítimas de LAD apresentou pelo menos um episódio de hipertensão (68,0\%), hipertermia $(64,1 \%)$ e hiperglicemia $(64,1 \%)$. A presença dessas alterações durante a internação hospitalar não apresentou associação com consequências de LAD; no entanto, conforme já comentado, as alterações pupilares, a hipotensão, a hipóxia pela $\mathrm{SpO}_{2}$ e a hiperglicemia observadas na admissão hospitalar foram associadas a óbito.

A hipotensão arterial é frequente em vítimas de TCE grave e sua ocorrência nas primeiras horas está significativamente relacionada com aumento da mortalidade ${ }^{(60-61,114)}$. A hipertensão arterial pode estar relacionada a uma perfusão cerebral reduzida e sua ocorrência pode agravar a HIC e o edema cerebral ${ }^{(61)}$. A análise da ocorrência de hipotensão na fase inicial da ressuscitação em pacientes com TCE na cidade de São Francisco mostrou que, das 107 vítimas estudadas, 26 (24\%) apresentaram hipotensão arterial, com média de 1,5 episódio por doente (duração média 9,1 min). Dessas vítimas com hipotensão, 65,0\% foram a óbito e a frequência de episódios foi diretamente proporcional ao número de óbitos ${ }^{(109)}$.

Alterações nos níveis de glicose são provocadas por distúrbios fisiológicos metabólicos, fisiológicos ou são uma resposta ao estresse que 
reflete a gravidade da lesão, e sua ocorrência está relacionada com desfechos desfavoráveis ${ }^{(63,110,115)}$. Pesquisa ${ }^{(63)}$ realizada com 380 vítimas de TCE nos primeiros 5 dias de internação em UTI evidenciou que os níveis de glicose mais elevados $(\geq 160 \mathrm{mg} / \mathrm{dl})$ nas primeiras 24 horas após a internação estavam associados a mortalidade; além disso, doentes com hipoglicemia $<60 \mathrm{mg} / \mathrm{dl}$ apresentaram maior incidência de mortalidade.

A mortalidade até 6 meses após LAD foi de 30,8\%, a média do tempo de sobrevivência dos que morreram foi de 13,5 dias $(\mathrm{dp}=24,1)$ e $63,0 \%$ dos indivíduos foram para a residência após alta do IC/HCFMUSP.

Em estudos com vítimas de LAD, a frequência de mortes apresentou grandes variações: $8,1 \%{ }^{(116)}, 14,3 \%{ }^{(47)}, 21,4 \%{ }^{(48)}, 21,9 \%{ }^{(117)}, 31,0 \%{ }^{(118)}$, $38,1 \%{ }^{(40)}$ e $42,7 \%{ }^{(10)}$. A diferença das frequências de mortalidade observada nos estudos pode estar relacionada ao período em que foi computada (até alta, 6 meses, 2 anos), aos critérios de elegibilidade da amostra, além de gravidade do trauma e LAD; nesta pesquisa, das 24 vítimas que foram a óbito, 22 (91,7\%) tiveram LAD grave.

A recuperação das vítimas de LAD até 6 meses após trauma foi o foco central desta investigação, tendo em vista as indicações da literatura de que a recuperação funcional após TCE de diferentes gravidades é um processo dinâmico, que se estabiliza aos 6 meses. Além disso, a LAD é um tipo específico de lesão que ocorre nas vítimas de TCE para a qual tem se atribuído importante mortalidade e morbidade.

Há uma contínua preocupação em conhecer as curvas de recuperação que representam a ocorrência de melhora espontânea após TCE. Identificar repetidamente a funcionalidade e a capacidade para realizar AVD das vítimas permite conhecer o padrão de recuperação e até a estabilidade da lesão cerebral. Ademais, informações sobre as perdas, deficiências e alterações presentes nos primeiros 6 meses após trauma são importantes no direcionamento e na avaliação da assistência prestada.

Estudos prévios $^{(13-14)}$ e observações clínicas indicam que, nos primeiros 6 meses após o TCE, ocorrem grandes mudanças na condição do paciente; após esse período, há estabilidade no processo de recuperação. 
Análises realizadas especificamente com vítimas de LAD em uma única avaliação mostraram resultados referentes a alta, 3 meses, 6 meses e 1 ano após trauma. Estudos que tiveram mais de uma avaliação apresentaram variação nos períodos de seguimento; 12 primeiras semanas após lesão ${ }^{(49)}$, entre 2 e 12 semanas $^{(50)}$, alta e 6 meses $^{(48)}, 3$ e 6 meses $^{(51)}$ e 3 meses e 2 $\operatorname{anos}^{(47)}$.

As avaliações em períodos inferiores a 3 meses, assim como entre 3 e 6 meses $^{(51)}$, foram realizadas em ensaios clínicos com drogas. Seus resultados relativos à recuperação não visam descrever a regularidade em readquirir as capacidades, mas sim apresentar o efeito do uso dessas drogas.

Autores que analisaram a evolução das vítimas com uma periodicidade similar a este estudo mostraram resultados favoráveis (total recuperação, boa recuperação ou incapacidade moderada e moderada acentuada) em 40,3\%,79,6\% e 97,8\% das vítimas na alta, 3 e 6 meses, respectivamente ${ }^{(48)}$, frequências próximas a este estudo quando agrupamento similar das categorias da ERGA foi realizado $(39,3 \%, 84,0 \% \mathrm{e}$ $88,2 \%$ ). Nos resultados de ambas as investigações, a frequência de indivíduos com resultados desfavoráveis (estado vegetativo persistente, incapacidade grave e grave acentuada) diminuiu com o tempo decorrido, mais expressivamente nos 3 primeiros meses, enquanto aumentava a frequência dos que apresentaram resultados favoráveis.

Com avaliações mais tardias e esparsas, a frequência de resultados favoráveis na ERG (boa recuperação e incapacidade moderada) foi de $32,1 \%$ aos 3 meses e $60,7 \%$ aos 2 anos, indicando melhora importante no período e que 6 meses pode não ser o ponto de estabilidade da recuperação após $\mathrm{LAD}^{(47)}$. Entretanto, há de se ponderar que medidas tardias podem ser influenciadas por outros eventos após trauma e, principalmente, pelas adaptações das vítimas às suas incapacidades ${ }^{(78,119)}$.

Os testes estatísticos do atual estudo indicaram que, com o passar do tempo, as vítimas alcançaram melhora significativa na capacidade funcional segundo a ERGA, tanto entre alta e 3 meses como entre 3 e 6 meses. Entre a alta do IC/HCFMUSP e 6 meses após a LAD, as análises de recuperação 
mostraram melhora da capacidade funcional pela ERGA em 96,0\% dos avaliados e no desempenho das AVD em 93,4\% dos casos.

Em relação às AVD, houve diminuição na pontuação média da escala de Katz em todos os períodos: de 8,5 $(\mathrm{dp}=5,5)$ na alta para 3,2 $(\mathrm{dp}=$ $5,5)$ aos 3 meses e 1,8 $(\mathrm{dp}=4,5)$ aos 6 meses após LAD. Essas diferenças nas médias de pontuação indicaram que houve melhora estatisticamente significativa nas AVD entre os três intervalos de avaliação das vítimas (entre alta e 3 meses, entre 3 e 6 meses e entre alta e 6 meses). Entretanto, a análise dos domínios mostrou que a diferença entre as três avaliações ocorreu nos domínios tomar banho, vestir-se e cuidado pessoal; no que se refere à capacidade de realizar transferência, necessidades urinárias e alimentar-se, a recuperação ocorreu nos 3 primeiros meses após LAD, havendo tendência de estabilidade na capacidade de realizar essas AVD no período subsequente. Além do mais, pode-se observar, pelas médias da escala de Katz e ERGA, que a melhora na capacidade de realizar AVD e na funcionalidade foi mais acentuada até 3 meses, ainda que permanecesse até 6 meses após LAD.

Estudos com vítimas de LAD não têm utilizado medidas repetidas da capacidade das AVD para caracterizar o curso da remissão espontânea das consequências dessa lesão. Para essa finalidade, tem-se analisado o indivíduo como um todo funcional e integrado à sociedade, utilizando-se escalas de funcionalidade que buscam abranger o resultado geral das incapacidades, assim como a ERG, a ERGA e a DRS. O uso desses instrumentos tem mostrado que a consequência total de um trauma pode não refletir a soma das incapacidades das vítimas, e uma incapacidade, às vezes, pode ser compensada ou interagir com outras e ampliar seus efeitos indesejáveis. Exemplificando, um participante deste estudo que necessitava de ajuda humana parcial para vestir-se e, portanto, era dependente para AVD, foi categorizado em incapacidade moderada na ERGA, condizente com vida independente.

Aos 6 meses após LAD, 24 vítimas (30,8\%) haviam morrido em consequência do trauma ou complicações. Não obstante, entre os sobreviventes avaliados até esse período (51 vítimas), 88,2\% alcançaram 
categorização na ERGA condizente com vida independente e 45,1\% apresentaram total recuperação do trauma; portanto, referiram retorno às condições pré-traumáticas. Nesse período, indivíduos com incapacidades totalizaram $29,4 \%$ e, desses, $11,8 \%$ eram dependentes.

Resultados observados na literatura mostram piores desfechos para as vítimas de LAD aos 6 meses - frequência de incapazes entre 40,0\% e $87,5 \%$ e de dependentes entre $20,0 \%$ e $41,3 \%{ }^{(18,23,31,42-43)}$. Entretanto, a maioria dos participantes desta pesquisa apresentou LAD de gravidade leve (44,9\%) ou moderada (19,2\%), e entre essas vítimas somente uma (2,2\%) encontrava-se dependente no período (Tabela 43-LAD X dependência).

Nas AVD, a grande maioria das vítimas apresentou total independência, variando entre $80,4 \%$ e $90,2 \%$ a frequência nos seis domínios da escala de Katz. Considerando-se todos os domínios dessa escala, sete participantes $(13,7 \%)$ tiveram indicação de necessidades de ajuda humana ou dependência nas atividades avaliadas pela escala. Exceto uma vítima, as demais apresentaram dependência para realizar AVD em diversos domínios.

Pesquisadores que aplicaram o Índice de Barthel para avaliar a capacidade de realizar AVD em 65 vítimas de LAD encontraram, aos 6 meses após LAD, escore médio de 80,7, compatível com independência para essas atividades ${ }^{(27)}$.

Pesquisas que avaliaram AVD em vítimas de TCE encontraram frequências de $69,0 \%{ }^{(120)}$ e $76,1 \%{ }^{(121)}$ de vítimas independentes aos 6 meses após o trauma, valores inferiores aos observados nesta pesquisa $(86,3 \%)$. Somente nas avaliações mais tardias, os grupos de vítimas de TCE grave alcançaram o patamar desta investigação - 2 anos após o trauma, mais de $80,0 \%$ dos pacientes eram independentes no autocuidado; após 5 anos, mais de $90,0 \%$ tornaram-se independentes ${ }^{(78,122)}$.

A investigação do papel da RM no prognóstico de 100 pacientes de TCE moderado e grave revelou que $65,0 \%$ tiveram LAD e $31,0 \%$ encontravam-se dependentes para realizar as AVD após 6 meses do $\mathrm{TCE}^{(120)}$. 
De modo geral, aos 6 meses, as vítimas de LAD estavam independentes tanto na avaliação pela ERGA (88,2\%) quanto pela escala de Katz $(83,3 \%)$, resultados mais favoráveis que os apresentados em publicações sobre o mesmo período de recuperação. Novamente, era provável que pesasse nas diferenças dos resultados a maioria de vítimas com LAD leve ou moderada $(64,1 \%)$ na amostra estudada. Entre os 50 indivíduos que tiveram lesão dessa gravidade, 2 morreram e somente 1 encontrava-se dependente aos 6 meses. Por outro lado, entre as 28 vítimas de LAD grave, 22 evoluíram a óbito e 5 eram dependentes pela ERGA e escala de Katz; portanto, na última avaliação, a quase totalidade dessas vítimas (27) apresentou desfecho desfavorável.

A LAD grave se destacou como fator de risco para óbito e dependência neste estudo, embora as análises de regressão logística multivariada não permitissem bom ajuste no modelo estatístico - IC para OR (95\%) de 13,65 a 395,89 para óbito e 11,2 a 3813,02 para dependência. Ainda que os intervalos de confiança claramente confirmem o importante papel da gravidade da LAD com fator de risco de consequências desfavoráveis dessa lesão, eles foram bastante amplos, em virtude do pequeno número dos eventos morte ( 2 casos) e dependência (1 caso) entre as vítimas de LAD leve e moderada, e atribuíram instabilidade ao modelo.

Várias revisões de literatura têm ressaltado a gravidade das LAD como fator relacionado a desfecho desfavorável após essa lesão ${ }^{(106,123-125,)}$; entretanto, pouco tem se estudado a respeito dessa gravidade estimada por características clínicas, conforme proposto por Gennarelli $(1987,1993)^{(1-2)}$. Nas pesquisas, tem-se valorizado os exames de imagem e os biomarcadores para estimar a gravidade e os prognósticos das vítimas; no entanto, seus achados corroboram com os desta investigação, evidenciando que, quanto maior a gravidade da LAD, pior o desfecho para vítima ${ }^{(82,126-127)}$.

Além da gravidade da LAD, outras variáveis apresentaram associação com óbito: os indicadores de gravidade do trauma (ISS e NISS) e TCE (MAIS/cabeça); alterações pupilares, hipotensão, hipóxia pela $\mathrm{SpO}_{2} \mathrm{e}$ hiperglicemia na admissão hospitalar; durante a internação, o escore da ECGl após retirada da sedação, presença de HIC e complicações, exceto 
infecção, além dos sinais precoces de LAD na TC. Vítimas que morreram apresentaram com maior frequência esses sinais e essas alterações clínicas durante admissão hospitalar e internação do que os sobreviventes, e ainda tiveram pontuações mais elevadas nos índices de gravidade e baixos escores na ECGl após retirada da sedação.

Dessas características das vítimas, destacaram-se nas análises multivariadas a hipóxia pela $\mathrm{SpO}_{2}$ e a hipotensão na admissão hospitalar, além do NISS. Não obstante, o modelo estatístico mais ajustado incluiu somente as duas últimas variáveis e mostrou que os pacientes com hipotensão na admissão tiveram 7,86 vezes mais chances de ir a óbito quando comparados com as vítimas sem esta alteração. Além disso, o acréscimo de um ponto no valor do NISS aumentou em 14,0\% a chance do paciente morrer nos primeiros 6 meses depois de ocorrer a LAD.

Em análise de 78 vítimas com diagnóstico exclusivo de LAD após 12,3 meses em média $(\mathrm{dp}=10,8)$, observou-se que os fatores significativamente associados ao óbito foram hipotensão $(\mathrm{p}=0,047)$, glicemia $>144 \mathrm{mg} / \mathrm{dl}(\mathrm{p}=0,041)$ e baixas pontuações na $\mathrm{ECGl}(\mathrm{p}=0,013)$ na admissão hospitalar; maior número de LAD na TC $(\mathrm{p}=0,004)$ e de lesões secundárias do trauma $(\mathrm{p}=0,002)$; presença de choque $(\mathrm{p}=0,047)$, distúrbios de coagulação ( $p=0,02)$, transfusão $(p=0,017)$ e ausência na recuperação da consciência $(\mathrm{p}<0,001)^{(10)}$. Na análise multivariada, apenas a ausência da recuperação da consciência (OR 116,4) e o maior número de LAD (OR 3,99 ) foram identificados como fatores independentes para mortalidade ${ }^{(10)}$. Esses achados tiveram semelhanças com os observados na atual investigação.

Estudo com vítimas de colisão de veículo a motor e queda de altura com diagnóstico de hemorragia subaracnoide verificou que a ECGl (OR 0,89) e a PAS sistólica (OR 1,02) na cena e o ISS (OR 1,11) foram preditores independentes associados a mortalidade após o trauma ${ }^{(128)}$.

Pesquisas que analisaram a associação das características das vítimas de TCE com a mortalidade identificaram que a classificação de Marshall na $\mathrm{TC}^{(129)}$, gravidade da lesão pela $\mathrm{TC}^{(92)}$, lesões cranianas difusas II, III e $\mathrm{IV}^{(130)}$, menor escore na $\mathrm{ECGl}^{(108,129-131)}$, ECGl $\leq 8^{(92)}$, anormalidades 
pupilares na admissão ${ }^{(132)}$, hipotensão(92,113,130-131), hiperglicemia ${ }^{(113,131)}$, hipotermia ${ }^{(113)}, \operatorname{PAS}^{(87,92,108)}, \mathrm{SpO}_{2}{ }^{(133)}$ e $\operatorname{IOT}^{(87)}$ na cena, hipóxia ${ }^{(130-131,134)}$, choque $^{(108,131)}$, aumento da pressão intracraniana em poucas horas ${ }^{(92)}$, monitorização da $\mathrm{PIC}^{(91)}$, pontuação 5 no MAIS/cabeça ${ }^{(87,91)}$ e maior pontuação no $\operatorname{ISS}^{(87,91-92,108,131)}$ foram fatores independentes associados a mortalidade.

Nesta pesquisa, o NISS foi independentemente associado ao óbito; entretanto, não foram encontradas publicações que aplicassem o NISS em grupos de vítimas de LAD. Apesar da revisão de literatura indicar que o NISS apresenta melhor desempenho que o ISS na previsão de mortalidade ${ }^{(135)}$, a comunidade científica ainda é relutante na substituição do ISS pelo NISS para identificar a gravidade do trauma, e este indicador ainda é pouco utilizado.

A dependência após 6 meses de LAD, além de estar associada à gravidade dessa lesão, esteve relacionada à maior pontuação nos indicadores de gravidade do trauma (ISS e NISS) e TCE (MAIS/cabeça); à maior duração da sedação e internação na UTI e no hospital; presença de HIC, infecção e outras complicações durante a internação hospitalar; e pontuações baixas na ECG1 48 horas após a retirada da sedação.

Excluindo-se a gravidade da LAD na modelagem para dependência, o tempo de internação hospitalar foi a variável que se destacou no modelo de regressão múltipla e mostrou que o acréscimo de 1 dia de internação hospitalar aumentou em 7,0\% a chance de uma vítima encontrar-se dependente aos 6 meses após LAD.

Análise de 41 vítimas de TCE grave em Hong Kong mostrou que a idade avançada (OR 1,1) e a internação hospitalar prolongada (OR 1,16) foram preditores independentes de desfecho desfavorável após, em média, 42 meses do trauma ${ }^{(136)}$.

Em outra pesquisa ${ }^{(137)}$ realizada nos EUA com 60 vítimas de TCE grave, o tempo de permanência hospitalar $(p=0,01)$ e o tempo de internação na UTI $(p=0,002)$ foram estatisticamente associados à recuperação 6 meses após o trauma. 
No Brasil, pesquisa realizada com vítimas de TCE entre 6 meses e 3 anos após trauma identificou que indivíduos internados durante 12 dias ou mais tiveram 5,76 vezes mais chance de dependência em relação àqueles com menor tempo de internação ${ }^{(56)}$.

Os fatores associados à dependência ou óbito nos pacientes de TCE avaliados três meses após o trauma foram: menor escore da ECGl na admissão $(p=0,002)$, maior pontuação no ISS $(p=0,009)$, maior tempo de hospitalização $(p=0,014)$ e maior tempo de internação na UTI $(p<0,001)^{(138)}$.

Em estudo ${ }^{(86)}$ com 30 vítimas de LAD, identificou-se que TCE grave $(p<0,001)$, anormalidades pupilares $(p<0,001)$, maior escore do ISS $(p<0,001)$ e lesões em joelho do corpo caloso $(p=0,0002)$ estavam associados a dependência após 1 ano do trauma. $\mathrm{Na}$ análise multivariada dessas vítimas, apenas as lesões em corpo caloso $(p=0,0051)$ aumentaram a chance das vítimas serem dependentes 1 ano após a LAD.

As vítimas de LAD avaliadas três meses após o trauma no Japão evidenciaram que o menor escore da ECGl $(\mathrm{p}<0,001)$, o número de lesões encefálicas identificadas na $\mathrm{RM}(\mathrm{p}<0,01)$ e o maior valor médio na mensuração da PIC $(\mathrm{p}<0,05)$ foram estatisticamente associados a dependência após o trauma ${ }^{(139)}$. Em estudos com vítimas de LAD e TCE moderado, verificou-se que a maior gravidade das lesões encefálicas identificada pela classificação de Marshall na TC $(\mathrm{OR} 1,82)^{(127)}$ e o maior número de LAD nesse exame (OR 3,33) ${ }^{(10)}$ foram preditores de dependência ou óbito após 6 meses do trauma. Não obstante, a recuperação da consciência $(p<0,001)^{(10)}$ e lesões em corpo caloso $(p=0,041)^{(10)}$ foram preditores de resultados favoráveis após 12 meses, em média $(\mathrm{dp}=10,89)$, da LAD.

A avaliação dos fatores relacionados à dependência após 6 meses do trauma em 102 vítimas de LAD mostrou que idade (OR 1,44), ausência bilateral de reatividade pupilar à luz (OR 11,11), múltiplas lesões evidenciadas no corpo caloso (OR 29,23) e tronco cerebral (OR 9,43) pela RM estavam associadas com a dependência após 6 meses do trauma ${ }^{(126)}$.

Usualmente, as pesquisas que estudaram fatores associados às consequências da LAD utilizaram resultados de exames de imagem em suas 
análises $^{(10,81,86,127,139)}$ e evidenciaram relação entre as alterações nas imagens e consequências da $\mathrm{LAD}$, ainda que tenham apresentado contradições em seus resultados. Nesta investigação, quanto a esses exames, somente a presença de sinais precoces de LAD na TC foi variável independente testada, dificultando o confronto dos achados.

Entre as limitações da atual pesquisa, a ausência de dados sobre exames de RM pode ser computada, visto que a combinação de suas imagens com os achados clínicos permitiria maior segurança no diagnóstico de LAD e propiciaria o confronto dos dados clínicos com as lesões cerebrais detectadas. A falta de disponibilidade de recursos para executar esse exame em todos os participantes - somente 20 pacientes realizaram - e as dificuldades para submeter pacientes graves a essa avaliação foram fatores impeditivos para que os resultados da RM fossem considerados neste estudo.

$\mathrm{Na}$ aplicação dos resultados desta pesquisa, algumas limitações devem ser consideradas: a amostra incluiu pacientes de uma única instituição, centro de referência para atendimento de casos de alta complexidade, trazendo restrições para generalização dos resultados. Ademais, a ausência de registros hospitalares sobre condições clínicas do paciente na cena do trauma e durante seu transporte limita a identificação de fatores da fase pré-hospitalar associados aos desfechos da LAD.

Vale ainda salientar que os tratamentos de reabilitação das vítimas foram elencados, porém não computados, nas análises de associação, ainda que se tenha observado que todas as vítimas dependentes na última avalição (6 pacientes) tiveram atendimento com especialistas de saúde para apoio na sua recuperação.

Deve-se considerar que a alta adesão dos pacientes às consultas de seguimento foi reforçada pelo contato diário com as vítimas e familiares durante a internação no HCFMUSP e pelas ligações frequentes que colaboraram para manter a cumplicidade entre os pacientes e a equipe em relação ao tratamento.

Por fim, os resultados alcançados podem ser condensados nas seguintes informações: após LAD, foi elevada a mortalidade; entretanto, a 
grande maioria dos sobreviventes alcançou condições condizentes com vida independente aos 6 meses. Nesse período, a recuperação das vítimas foi expressiva, ainda que mais acentuada nos 3 primeiros meses. A quase totalidade das vítimas de LAD grave evoluiu para óbito ou dependência. Além disso, a presença de hipóxia pela $\mathrm{SpO}_{2}$ ou hipotensão na admissão hospitalar e o NISS sobressaíram-se para óbito na análise conjunta das características das vítimas. Nessa análise, o tempo de internação hospitalar foi fator de risco para dependência. 


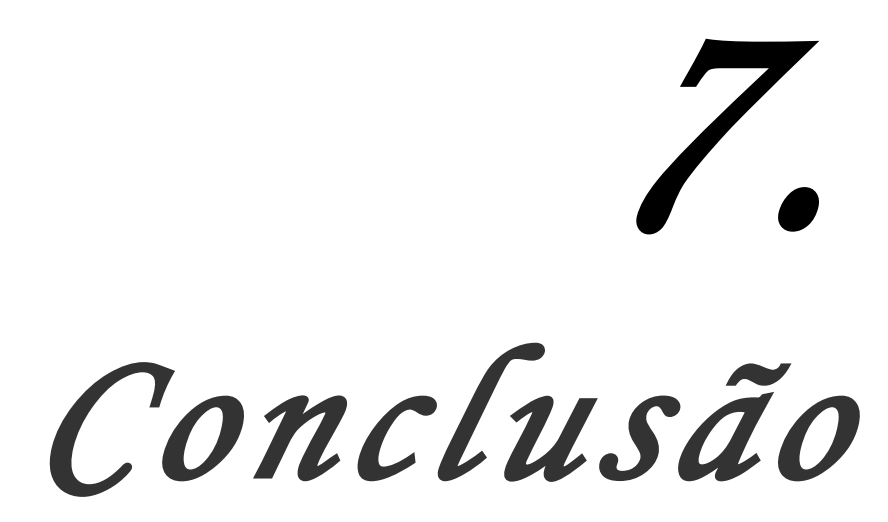




\section{CONCLUSÕES}

A análise de 78 vítimas com diagnóstico principal de LAD, internadas no IC/HCFMUSP entre julho de 2013 e fevereiro de 2014, permitiu as conclusões a seguir apresentadas.

\subsection{QUANTO ÀS CARACTERÍSTICAS CLÍNICAS E SOCIODEMOGRÁFICAS}

As características sociodemográficas mostraram média de 32 anos $(d p=11,2)$ para idade e de 9,1 anos $(d p=9,1)$ para escolaridade. Prevaleceram os jovens entre 18 e 28 anos (43,0\%) e indivíduos com $1^{\circ}$ grau incompleto $(30,8 \%)$. Predominaram pacientes do sexo masculino $(89,7 \%)$, inseridos no mercado de trabalho $(89,7 \%)$, com renda per capita familiar mensal entre 1 e 5 salários mínimos $(73,0 \%)$, brancos $(65,4 \%)$ e solteiros $(51,3 \%)$.

$\mathrm{O}$ acidente de transporte $(83,3 \%)$ foi a causa externa na grande maioria dos eventos traumáticos, sendo os motociclistas as vítimas mais frequentes $(43,6 \%)$. A ingestão de bebidas alcoólicas no período próximo à ocorrência do trauma foi referida em $42,3 \%$ dos casos.

Com relação à gravidade global do trauma, a grande maioria foi de vítimas graves: 80,8\% pelo ISS (média de 35,0; $\mathrm{dp}=11,9$ ) e 91,0\% pelo NISS ( média de 46,2; dp=15,9). O valor médio do índice MAIS/cabeça foi 4,6 $(\mathrm{dp}=0,5)$. Embora as vítimas de LAD leve tenham sido as mais frequentes (44,9\%), a LAD grave foi observada em 35,9\% dos casos.

Todos os participantes da casuística foram removidos por serviços de APH, sendo expressiva a frequência do uso de transporte aéreo $(47,4 \%)$. Na cena, $75,7 \%$ dos traumatizados estavam em coma $(E C G l \leq 8)$ e $79,5 \%$ necessitaram de intubação.

$\mathrm{Na}$ admissão hospitalar, a pequena parte das vítimas que não havia sido intubada na cena $(20,5 \%)$ foi submetida a esse procedimento. A quase totalidade dos doentes $(92,3 \%)$ foi sedada, embora nem sempre mantivesse 
sedação contínua na internação. Nesta fase, todos os participantes do estudo apresentaram ECGl $\leq 8$, conforme critério de inclusão na pesquisa. As pupilas estavam alteradas em $60,3 \%$ dos casos. Quanto às demais características clínicas das vítimas, 10,3\% apresentaram FR alterada e a taquipneia foi a alteração mais frequente $(6,4 \%)$. A hipóxia pela $\mathrm{SpO}_{2}$ foi detectada em 15,3\% dos doentes e pela $\mathrm{PO}_{2}$ em 14,1\%; 19,2\% apresentaram hipotensão, 2,5\% tiveram parada cardíaca e a taquicardia esteve presente na maioria $(52,5 \%)$ dos indivíduos. Alterações glicêmicas foram encontradas em $32,0 \%$ da amostra, sendo a hiperglicemia a mais frequente $(28,2 \%)$.

Durante a internação hospitalar, a quase totalidade das vítimas foi internada em UTI (92,3\%). O tempo médio de internação nessa unidade foi de 11,7 dias $(\mathrm{dp}=15,4)$. A grande maioria dos pacientes $(88,5 \%)$ usou sedação contínua durante um tempo médio de 4,1 dias $(\mathrm{dp}=4,3)$. $\mathrm{O}$ valor médio da RASS 24 horas antes da retirada da sedação foi de $-2,3(d p=2,6)$. A maioria das vítimas $(61,5 \%)$ fez tratamentos com drogas que atuam no SNC. Os medicamentos mais utilizados foram os anticonvulsivantes $(83,3 \%)$ e os neurolépticos $(70,8 \%)$.

Após a admissão hospitalar, as vítimas de LAD demoraram em média 3,7 dias $(\mathrm{dp}=7,2)$ para obter o escore 6 no item MRM da ECGl. A maioria das vítimas $(53,8 \%)$ foi submetida a cirurgia e 19,2\% tiveram reabordagem cirúrgica. Quadros infecciosos foram registrados em 25,6\% dos casos e outras complicações foram identificadas em 52,6\% dos pacientes.

A maioria das vítimas apresentou sinais precoces de LAD na TC (70,5\%). HIC foi detectada em $24,2 \%$ das vítimas e a monitorização da PIC foi realizada em três pacientes $(3,8 \%)$.

$\mathrm{Na}$ internação hospitalar, $16,7 \%$ das vítimas apresentaram um ou dois eventos de hipotensão sistêmica, 29,5 apresentaram episódios de hipoglicemia e 59,0\% de hipotermia. A maioria das vítimas de LAD apresentou pelo menos um episódio de hipertensão $(68,0 \%)$, hipertermia $(64,1 \%)$ e hiperglicemia $(64,1 \%)$.

A média de permanência hospitalar dos pacientes foi de 19,1 dias $(d p=22,9)$. A mortalidade até 6 meses após LAD foi de 30,8\%. A média do 
tempo de sobrevivência dos que morreram foi de 13,5 dias $(\mathrm{dp}=24,1)$ e $63,0 \%$ dos indivíduos foram para a residência após alta do IC/HCFMUSP.

\subsection{RECUPERAÇÃO DAS VÍTIMAS DE LAD ENTRE A ALTA DO IC/HCFMUSP E 6 MESES APÓS O TRAUMA}

A análise da recuperação de 51 vítimas de LAD, sobreviventes a essa lesão, entre a alta do IC/HCFMUSP e 6 meses após a LAD, mostrou melhora da capacidade funcional pela ERGA em 96,0\% dos avaliados e no desempenho nas AVD em 93,4\% dos casos.

Testes estatísticos indicaram que, com o passar do tempo, as vítimas alcançaram melhora significativa na capacidade funcional segundo a ERGA, tanto entre alta e 3 meses como entre 3 e 6 meses (teste não paramétrico de Friedman e teste de Student-Newman-Keuls adaptado para testes não paramétricos). A pontuação média da ERGA evoluiu de 3,8 $(\mathrm{dp}=1,2)$ na alta para 2,1 $(d p=1,6)$ aos 3 meses e 1,2 $(d p=1,6)$ na avaliação final.

Em relação às AVD, houve diminuição na pontuação média da escala de Katz em todos os períodos, de 8,5 $(\mathrm{dp}=5,5)$ na alta para 3,2 $(\mathrm{dp}=$ $5,5)$ aos 3 meses e 1,8 $(\mathrm{dp}=4,5)$ aos 6 meses após LAD. Essas diferenças nas médias de pontuação indicaram que houve melhora estatisticamente significativa nas AVD entre os 3 intervalos de avaliação das vítimas (entre alta e 3 meses, entre 3 e 6 meses e entre alta e 6 meses). Entretanto, a análise dos domínios mostrou que a diferença entre as 3 avaliações ocorreu nos domínios tomar banho, vestir-se e cuidado pessoal; quanto aos itens realizar transferência, necessidades urinárias e alimentar-se, a recuperação da capacidade de realizar essa atividade ocorreu nos 3 primeiros meses após LAD, havendo tendência de estabilidade na capacidade de realizar essas AVD no período subsequente. Além do mais, pode-se observar, com base nas médias da escala de Katz e ERGA, que a melhora na capacidade de realizar AVD e na funcionalidade foi mais acentuada até 3 meses após $\mathrm{LAD}$, ainda que permanecesse até 6 meses. 


\subsection{VÍTIMAS AOS 6 MESES APÓS LAD}

Aos 6 meses após LAD, 24 vítimas (30,8\%) haviam morrido em consequência ao trauma ou complicações. Não obstante, entre os sobreviventes avaliados até esse período (51 vítimas), 88,2\% alcançaram categorização na ERGA condizente com vida independente e 45,1\% apresentaram total recuperação do trauma. Nas AVD, a grande maioria das vítimas apresentou total independência, variando entre $80,4 \%$ e 90,2\% a frequência nos seis domínios da escala de Katz. Considerando-se todos os domínios dessa escala, sete participantes $(13,7 \%)$ tiveram indicação de necessidades de ajuda humana ou dependência nas atividades avaliadas pela escala. Pelas indicações da ERGA, 6 vítimas (11,8\%) eram dependentes nesse período.

\subsection{FATORES ASSOCIADOS A ÓBITO E DEPENDÊNCIA AOS 6 MESES APÓS LAD}

As características sociodemográficas dos participantes deste estudo, relativas ao trauma e $\mathrm{APH}$, não tiveram associação com óbito e dependência. Por outro lado, os indicadores de gravidade do trauma (ISS e NISS), do TCE (MAIS/cabeça) e da LAD apresentaram associação estatisticamente significante com essas consequências. Algumas características clínicas observadas na admissão hospitalar foram associadas a óbito: alterações pupilares, hipotensão, hipóxia pela $\mathrm{SpO}_{2}$ e hiperglicemia. Durante a internação, o escore da ECGl após retirada da sedação, presença de HIC e complicações, exceto infecção, tiveram associação com óbito e dependência. Sinais precoces de LAD associaram-se somente com óbito. Os quadros de infecção, tempo de sedação contínua, duração da internação em UTI e hospitalar foram fatores relacionados com dependência.

A LAD grave se destacou como fator de risco para óbito e dependência nas análises de regressão logística multivariada, ainda que não permitisse bom ajuste no modelo final - grandes IC para OR (95\%). Vítimas de LAD grave (28 casos) na quase totalidade morreram ou encontravam-se 
dependentes aos 6 meses após LAD. Juntamente com a LAD grave, a presença de hipóxia pela $\mathrm{SpO}_{2}$ foi fator de risco para óbito; no entanto, as variáveis hipotensão na admissão e NISS apresentaram o melhor ajuste para esse modelo. Indivíduos que apresentaram hipotensão na admissão tiveram 7,86 vezes mais chances de ir a óbito quando comparados com as vítimas sem esta alteração. A probabilidade de morrer foi $14,0 \%$ maior a cada aumento de um ponto no NISS.

Excluindo-se a gravidade da LAD na modelagem para dependência, o tempo de internação hospitalar foi a variável que se destacou no modelo de regressão múltipla e mostrou que o acréscimo de um dia de internação hospitalar aumentou em 7,0\% a chance de uma vítima encontrar-se dependente aos 6 meses após LAD. 


\section{Referências}




\section{REFERÊNCIAS}

1- Gennarelli TA. Cerebral concussion and diffuse brain injuries. In: Cooper PR (ed). Head Injury. $2^{\text {a }}$ ed. Baltimore; Williams \& Wilkins, 1987. ap. 7, pag.108-24.

2- Gennarelli TA. Cerebral concussion and diffuse brain injuries. In: Cooper PR (ed). Head Injury. $3^{\text {a }}$ ed. Baltimore: Williams \& Wilkins, 1993. p.137-58.

3- Lagares A, Ramos A, Alday R, Ballenilla F, Pérez-Nuñez A, Arrese I, et al. Magnetic resonance in moderate and severe head injury: comparative study of $\mathrm{CT}$ and MR findings. Characteristics related to the presence and location of diffuse axonal injury in MR. Neurocirugia (Astur). 2006;17(2):105-18.

4- $\quad$ Posner JB, Saper CB, Schiff ND, Plum F. Diagnosos of stupor and coma. $4^{\text {th }}$ ed. New York: Oxford University Press, 2007.

5- National Association of Emergency Medical Technicians, PreHospital Trauma Life Support Committee; American College of Surgeons, Committee on Trauma. Atendimento pré-hospitalar ao traumatizado: básico e avançado. Trad. de Renato Sérgio Poggetti. $7^{\text {a }}$ ed. Rio de Janeiro: Elsevier; 2012.

6- Morgado FL, Rossi LA. Correlação entre a escala de coma de Glasgow e os achados de imagem de tomografia computadorizada em pacientes vítimas de traumatismo cranioencefálico. Radiol Bras. 2011;44(1):35-41.

7- Mujica MB, González GT, Larraín CG, Miller PT, Castoldi FL. Resonancia Magnetica cerebral en daño axonal difuso. Rev. chil. radiol. 2003;9(4):182-186.

8- Morais DF, Spotti AR, Tognola WA, Gaia FP, Andrade AFA. Clinical application of magnetic resonance (MR) imaging in acute traumatic brain injury. Arq. Neuro-Psiquiatr. 2008;66(1):58-53. 
9- Morais DF. Aplicação clínica da ressonância magnética em pacientes com traumatismo craniencefálico agudo. Dissertação de Mestrado. São José do Rio Preto: Faculdade de Medicina de São José do Rio Preto, 2006.

10- Chelly H, Chaari A, Daoud E, Dammak H, Medhioub F, Mnif J, et al. Diffuse axonal injury in patients with head injuries: an epidemiologic and prognosis study of 124 cases. J Trauma. 2011;71(4):838-46.

11- Bennet L, Van Den Heuij L, Dean JM, Drury P, Wassink G, Gunn AJ. Neural plasticity and the Kennard principle: does it work for the preterm brain? Clin Exp Pharmacol Physiol. 2013;40(11):774-84.

12- Demertzi A, Schnakers C, Soddu A, Bruno MA, Gosseries O, Vanhaudenhuyse A, et al. Neural plasticity lessons from disorders of consciousness. Front Psychol. 2011;1:245.

13- Jennett B, Bond M. Assessment of outcome after severe brain damage. Lancet. 1975;1(7905):480-4.

14- Sousa RMC, Koizumi MS. Recuperação das vítimas de traumatismo crânio-encefálico no período de 1 ano após o trauma. Rev Esc Enferm USP. 1996;30(3):484-500.

15- Sobuwa S, Hartzenberg HB, Geduld H, Uys C. Predicting outcome in severe traumatic brain injury using a simple prognostic model. S Afr Med J. 2014;104(7):492-4.

16- Steyerberg EW, Mushkudiani N, Perel P, Butcher I, Lu J, McHugh GS, et al. Predicting outcome after traumatic brain injury: development and international validation of prognostic scores based on admission characteristics. PLoS Med. 2008;5(8):e165.

17- Hukkelhoven CW, Steyerberg EW, Habbema JD, Farace E, Marmarou A, Murray GD, et al. Predicting outcome after traumatic brain injury: development and validation of a prognostic score based on admission characteristics. J Neurotrauma. 2005;22(10):1025-1039.

18- Paterakis K, Karantanas AH, Komnos A, Volikas Z. Outcome of 
patients with diffuse axonal injury: the significance and prognostic value of MRI in the acute phase. J Trauma. 2000;49(6):1071-5.

19- Tasaki O, Shiozaki T, Hamasaki T, Kajino K, Nakae H, Tanaka H, et al. Prognostic indicators and outcome prediction model for severe traumatic brain injury. J Trauma. 2009;66(2):304-8.

20- Steyerberg EW, Mushkudiani N, Perel P, Butcher I, Lu J, McHugh GS, et al. Predicting outcome after traumatic brain injury: development and international validation of prognostic scores based on admission characteristics. PLoS Med. 2008;5(8):e165;

21- Ham TE, Sharp DJ. How can investigation of network function inform rehabilitation after traumatic brain injury? Curr Opin Neurol. 2012;25(6):662-9.

22- Moen KG, Skandsen T, Folvik M, Brezova V, Kvistad KA, Rydland $\mathrm{J}$, et al. A longitudinal MRI study of traumatic axonal injury in patients with moderate and severe traumatic brain injury. J Neurol Neurosurg Psychiatry. 2012;83(12):1193-1200.

23- Marquez de la Plata C, Ardelean A, Koovakkattu D, Srinivasan P, Miller A, Phuong V, et al. Magnetic resonance imaging of diffuse axonal injury: quantitative assessment of white matter lesion volume. J Neurotrauma. 2007;24(4):591-8.

24- Schaefer PW, Huisman TA, Sorensen AG, Gonzalez RG, Schwamm LH. Diffusion-weighted MR imaging in closed head injury: high correlation with initial Glasgow coma scale score and score on modified rankin scale at discharge. Radiology. 2004;233(1):58-66.

25- Hall K, Cope N, Rappaport M. Glasgow outcome scale and disability rating scale: comparative usefulness in following recovery in traumatic head injury. Arch Phys Med Rehabil. 1985;66(1):35-7.

26- Sousa RMC. Comparação entre instrumento de mensuração das consequências do trauma cranioencefálico. Rev Esc Enferm USP. 2006; 40(2):203-213. 
27- Jeong JH, Kim YZ, Cho YW, Kim JS. Negative effect of hypopituitarism following brain trauma in patients with diffuse axonal injury. J Neurosurg. 2010;113(3):532-538

28- Chung SW, Park YS, Nam TK, Kwon JT, Min BK, Hwang SN. Locations and clinical significance of non-hemorrhagic brain lesions in diffuse axonal injuries. J Korean Neurosurg Soc. 2012;52(4): 377-83.

29- Rappaport M, Hall KM, Hopkins K, Belleza T, Cope DN. Disability rating scale for severe head trauma: coma to community. Arch Phys Med Rehabil. 1982;63(3):118-23.

30- Maloney-Wilensky E, Gracias V, Itkin A, Hoffman K, Bloom S, Yang $\mathrm{W}$, et al. Brain tissue oxygen and outcome after severe traumatic brain injury: A systematic review. Crit Care Med. 2009;37(6):2057-63.

31- Warner MA, Youn TS, Davis T, Chandra A, Marquez de la, Moore C, et al. Regionally selective atrophy after traumatic axonal injury. Arch Neurol. 2010;67(11):1336-44.

32- Urakami Y. Relationship between sleep spindles and clinical recovery in patients with traumatic brain injury: a simultaneous EEG and MEG study. Clin EEG Neurosci. 2012;43(1):39-47.

33- Bottari C, Dassa C, Rainville C, Dutil B. The factorial validity and internal consistency of the instrumental activities of daily living profile in individuals with a traumatic brain injury. Neuropsychological Rehabilitation: An International Journal. 2009;19(2):177-207.

34- García-Peña M, Sanchez-Chefes A. Perceptive and praxic impairments in traumatic brain injury patients: significance in activities of daily living. Rev Neurol. 2004;38(8):775-784.

35- Katz S, Ford AB, Moskowitz RW, Jackson BA, Jaffe MW. Studies of illness in the aged. the index of ADL: a standardized measure of biological and psychosocial function. JAMA. 1963;185:914-9. 
36- Lino VTS, Pereira SR, Camacho LA, Ribeiro Filho ST, Buksman S. Adaptação transcultural da escala de independência em atividades da vida diária (Escala de Katz). Cad. Saúde Pública. 2008;24(1):103-112.

37- Bottari C, Gosselin N, Guillemette M, Lamoureux J, Ptito A. Independence in managing one's finances after traumatic brain injury. Brain inj. 2011;25(13-14):1306-17.

38- Sulter G, Steen C, De Keyser J. Use of the Barthel index and modified rankin Scale in acute stroke trials. Stroke. 1999;30(8):1538-41.

39- Sohrevardi SM, Ahmadinejad M, Said K, Sarafzadeh F, Zadeh SS, Yousefi M, et al. Evaluation of TGF $\beta 1$, IL-8 and nitric oxide in the serum of diffuse axonal injury patients and its association with clinical status and outcome. Turk Neurosurg. 2013;23(2):151-4.

40- Shakeri M, Boustani MR, Pak N, Panahi F, Salehpour F, Lotfinia I, et al. Effect of progesterone administration on prognosis of patients with diffuse axonal injury due to severe head trauma. Clin Neurol Neurosurg. 2013;115(10):2019-22.

41- Warner MA, Marquez de la Plata C, Spence J, Wang JY, Harper C, Moore $\mathrm{C}$, et al. Assessing spatial relationships between axonal integrity, regional brain volumes, and neuropsychological outcomes after traumatic axonal injury. J Neurotrauma. 2010;27(12):2121-30.

42- Mannion RJ, Cross J, Bradley P, Coles JP, Chatfield D, Carpenter A, et al. Mechanism-based MRI classification of traumatic brainstem injury and its relationship to outcome. J Neurotrauma. 2007;24(1):128-35.

43- Ljungqvist J, Nilsson D, Ljungberg M, Sörbo A, Esbjörnsson E, Eriksson-Ritzén C, et al. Longitudinal study of the diffusion tensor imaging properties of the corpus callosum in acute and chronic diffuse axonal injury. Brain Inj. 2011;25(4):370-8.

44- Wang JY, Bakhadirov K, Devous MD Sr, Abdi H, McColl R, Moore $\mathrm{C}$, et al. Diffusion tensor tractography of traumatic diffuse axonal injury. Arch Neurol. 2008;65(5):619-26. 
45- Marquez de la Plata CD, Garces J, Shokri Kojori E, Grinnan J, Krishnan K, Pidikiti R, et al. Deficits in functional connectivity of hippocampal and frontal lobe circuits after traumatic axonal injury. Arch Neurol. 2011;68(1):74-84.

46- Matsukawa H, Shinoda M, Fujii M, Takahashi O, Yamamoto D, Murakata A, et al. Genu of corpus callosum in diffuse axonal injury induces a worse 1-year outcome in patients with traumatic brain injury. Acta Neurochir (Wien). 2011;153(8):1687-93.

47- Chabok SY, Moghadam AD, Saneei Z, Amlashi FG, Leili EK, Amiri ZM. Neuron-specific enolase and S100BB as outcome predictors in severe diffuse axonal injury. J Trauma Acute Care Surg. 2012;72(6):1654-7.

48- Liew BS, Johari SA, Nasser AW, Abdullah J. Severe traumatic brain injury: outcome in patients with diffuse axonal injury managed conservatively in hospital Sultanah Aminah, Johor Bahru - an observational study. Med J Malaysia. 2009; 64(4):280-8.

49- Meythaler JM, Brunner RC, Johnson A, Novack TA. Amantadine to improve neurorecovery in traumatic brain injury-associated diffuse axonal injury: a pilot double-blind randomized trial. J Head Trauma Rehabil. 2002;17(4):300-13.

50- Moein P, Abbasi Fard S, Asnaashari A, Baratian H, Barekatain M, Tavakoli N, et al. The effect of boswellia serrata on neurorecovery following diffuse axonal injury. Brain Inj. 2013;27(12):1454-60.

51- Aminmansour B, Fard SA, Habibabadi MR, Moein P, Norouzi R, Naderan M. The efficacy of cyclosporine-A on diffuse axonal injury after traumatic brain injury. Adv Biomed Res. 2014;3:35.

52- Association for the Advancement of Automotive Medice- AAAM. The Abbreviated Injury Scale (AIS): 2005, update 2008. Illions: Des Plaines; 2008.

53- Baker SP, O`neill B, Haddon W, Long WB. The injury severity score: a method for describing patients with multiple injuries and evaluating emergency care. J Trauma. 1974;14(3):187-96. 
54- COHEN, J. Statistical power analysis for the behavioral sciences, $2^{\mathrm{a}}$ ed. Hillsdale, NJ: Lawrence Erlbaum, 1988.

55- Osler T, Baker SP, Long W. A modification of the injury severity score that both improves accuracy and simplifies scoring. J Trauma. 1997;43(6):922-5.

56- Sousa RMC. Fatores de risco para dependência após trauma crânioencefálico. Acta Paul Enferm. 2005;18(4):354-60.

57- Teasdele GM, Pettigrew LE, Wilson JT, Murray G, Jennett B. Analyzing outcome of treatment of severe head injury: review and update on advancing the use of the Glasgow outcome scale. J Neurotrauma. 1998;15(8):587-96.

58- Brasil. Ministério da Saúde. Datasus. CID -10 - Classificação estatística internacional de doenças e problemas relacionados à saúde. Causas externas de morbidade e de mortalidade [texto na Internet]. Brasília; 2012 [citado 2012 jan 10]. Disponível em: http://www.datasus.gov.br/cid10/v2008/cid10.htm.

59- Champion HR, Sacco WJ, Copes WS, Gann DS, Gennarelli TA, Flanagan ME. A Revision of the Trauma Score. J Trauma. 1989;29(5):6239.

60- Brain Trauma Foundation, American Association of Neurological Surgeons, Congress of Neurological Surgeons. Guidelines for the management of severe traumatic brain injury. J Neurotrauma. 2007; 24(suppl 1):S1-106.

61- Haddad SH, ArabiCritical YM. Critical care management of severe traumatic brain injury in adults. Scand J Trauma Resusc Emerg Med. 2012; $3 ; 20: 12$.

62- Sociedade Brasileira de Cardiologia. Diretrizes da Sociedade Brasileira de Cardiologia sobre Análise e Emissão de Laudos Eletrocardiográficos. Brasil, 2009.

63- Liu-DeRyke X1, Collingridge DS, Orme J, Roller D, Zurasky J, 
Rhoney DH. Clinical impact of early hyperglycemia during acute phase of traumatic brain injury. Neurocrit Care. 2009;11(2):151-7.

64- Titus DJ, Furones C, Atkins CM, Dietrich WD. Emergence of cognitive deficits after mild traumatic brain injury due to hyperthermia. Exp Neurol. 2015;263:254-62.

65- Sharma HS. Hyperthermia influences excitatory and inhibitory amino acid neurotransmitters in the central nervous system. An experimental study in the rat using behavioural, biochemical, pharmacological, and morphological approaches. J Neural Transm. 2006;113(4):497-519.

66- Sessler CN, Gosnell MS, Grap MJ, Brophy GM, O'Neal PV, Keane KA, et al. The Richmond agitation-sedation scale validity and reliability in adult intensive care unit patients. Am J Respir Crit Care Med, 2002;166(10):1338-1344.

67- Tomei G, Sganzerla E, Spagnoli D, Guerra P, Lucarini C, Gaini SM, et al. Posttraumatic diffuse cerebral lesions. Relationship between clinical course, CT findings and ICP. J Neurosurg Sci. 1991;35(2):61-75.

68- Liu Jun, Kou Zhifeng, Tian Yongquan. Diffuse axonal injury after traumatic cerebral microbleeds: an evaluation of imaging techniques. Neural Regen Res. 2014;15;9(12):1222-30.

69- Mata-Mbemba D, Mugikura S, Nakagawa A, Murata T, Kato Y, Tatewaki $\mathrm{Y}$, et al. Intraventricular hemorrhage on initial computed tomography as marker of diffuse axonal injury after traumatic brain injury. $\mathrm{J}$ Neurotrauma. 2014 Jul 15. [Epub ahead of print].

70- Iwadate Y, Ono J, Okimura Y, Suda S, Isobe K, Yamaura A. Computed tomography in diagnosis of diffuse axonal injury. No Shinkei Geka. 1990;18(10):915-20.

71- Mittl RL, Grossman RI, Hiehle JF, Hurst RW, Kauder DR, Gennarelli TA, et al. Prevalence of MR evidence of diffuse axonal injury in patients with mild head injury and normal head CT findings. AJNR Am J Neuroradiol. 1994;15(8):1583-9 
72- Carlotti Júnior CG, Colli BO, Dias LAA. Hipertensão intracraniana. Medicina, Ribeirão Preto. 1998;31:552-562.

73- Copes WS, Champion HR, Sacco WJ, Lawnick MM, Keast SL, Bain LW. The Injury Severity Score Revisited. J Trauma. 1988;28(1):69-77.

74- $\quad$ Eum RS, Seel RT, Goldstein R, Brown AW, Watanabe TK, Zasler ND, et al. Predicting institutionalization after traumatic brain injury inpatient rehabilitation. Journal of Neurotrauma. 2014 Sep 9. [Epub ahead of print].

75- Zaninotto AL, de Paula Guirado VM, Baldivia B, Núñes MD, Amorim RL, Teixeira MJ, et al. Improvement of verbal fluency in patients with diffuse brain injury over time. Neuropsychiatric Disease and Treatment. 2014;10:1155-1160.

76- Instituto Brasileiro de Geografia e Estatística (IBGE). Censo demográfico 2010 [texto na internet]. Rio de Janeiro 2015. [citado em 2015 janeiro 5] Disponível em: http://cidades.ibge.gov.br/xtras/perfil.php?lang=\&codmun=355030\&search $=\|$ infogr $\%$ E1 ficos:-informa $\% \mathrm{E} 7 \% \mathrm{~F} 5$ es-completas

77- Bonneterre V, Pérennou D, Trovatello V, Mignot N, Segal P, Balducci $\mathrm{F}$, et al. Interest of workplace support for returning to work after a traumatic brain injury: a retrospective study. Ann Phys Rehabil Med. 2013;56(9-10):652-62.

78- Ponsford JL, Downing MG, Olver J, Ponsford M, Acher R, Carty M, et al. Longitudinal follow-up of patients with traumatic brain injury: outcome at two, five, and ten years post-injury. $J$ Neurotrauma. 2014;31(1):64-77.

79- Grauwmeijer E, Heijenbrok-Kal MH, Haitsma IK, Ribbers GM. A prospective study on employment outcome 3 years after moderate to severe traumatic brain injury. Arch Phys Med Rehabil. 2012;93(6):993-9.

80- Jourdan C, Bosserelle V, Azerad S, Ghout I, Bayen E, Aegerter P, et al. Predictive factors for 1-year outcome of a cohort of patients with severe traumatic brain injury (TBI): results from the PariS-TBI study. Brain Inj. 
2013;27(9):1000-7.

81- Forslund MV, Arango-Lasprilla JC, Roe C, Perrin PB, Andelic N. Multilevel modeling of partnered relationship trajectories and relationship stability at 1, 2, and 5 years after traumatic brain injury in Norway. NeuroRehabilitation. 2014;34(4):781-8.

82- SkandSen T, Kvistad KA, Solheim O, Strand IH, Folvik M, Vik A. Prevalence and impact of diffuse axonal injury in patients with moderate and severe head injury: a cohort study of early magnetic resonance imaging findings and 1-year outcome. J Neurosurg, 2010;113(3):556-63.

83- Departamento Nacional de Trânsito (DENATRAN). Ministério das Cidades. Frota de Veículos [texto na internet]. Brasília, 2014. [citado em 2014 novembro 20]. Disponível em: http://www.denatran.gov.br/frota.htm.

84- Instituto de Ortopedia e Traumatologia do Hospital das Clínicas da Faculdade de Medina da Universidade de São Paulo. Notícias [texto na internet]. São Paulo, 2014. [citado em 2014 dezembro 19]. Disponível em: http://www.iothcfmusp.com.br/pt/5236/hc-divulga-a-mais-completapesquisa-sobre-acidentes-com-motos-em-sp/

85- Ladeira RM, Barreto SM. Fatores associados ao uso de serviço de atenção pré-hospitalar por vítimas de acidentes de trânsito. Cad. Saúde Pública, 2008;24(2):287-294.

86- Matsukawa H, Shinoda M, Fujii M, Takahashi O, Murakata A, Yamamoto D. Acute alcohol intoxication, diffuse axonal injury and intraventricular bleeding in patients with isolated blunt traumatic brain injury. Brain Inj. 2013;27(12):1409-14.

87- Wang HE, Peitzman AP, Cassidy LD, Adelson PD, Yealy DM. Outof-hospital endotracheal intubation and outcome after traumatic brain injury. Ann Emerg Med. 2004;44(5):439-50.

88- Gennari TD, Koizumi MS. Determinação do nível de gravidade do trauma. Rev Saúde Pública. 1995;29(5):333-41.

89- Zwahlen RA, Labler L, Trentz O, Grätz KW, Bachmann LM. Lateral 
impact in closed head injury: a substantially increased risk for diffuse axonal injury- a preliminary study. J Craniomaxillofac Surg. 2007;35(3):142-6.

90- Gennarelli TA, Thibault LE, Adams JH, Graham DI, Thompson CJ, Marcincin RP. Diffuse axonal injury and traumatic coma in the primate. Ann Neurol 1982;12(6):564-74.

91- Lane PL, Skoretz TG, Doig G, Girotti MJ. Intracranial pressure monitoring and outcomes after traumatic brain injury. Can J Surg. 2000;43(6):442-8.

92- Ley EJ, Short SS, Liou DZ, Singer MB, Mirocha J, Melo N, et al. Gender impacts mortality after traumatic brain injury in teenagers. J Trauma Acute Care Surg. 2013;75(4):682-6.

93- Whitaker IY, Gutièrrez MGR, Koizumi MS. Gravidade do trauma avaliada na fase pré-hospitalar. Rev Assoc Med Bras. 1998;44(2):111-9.

94- Bekelis K, Missios S, Mackenzie TA. Prehospital helicopter transport and survival of patients with traumatic brain injury. Ann Surg. 2014 Apr 16. [Epub ahead of print].

95- Majidi S, Siddiq F, Qureshi AI. Prehospital neurologic deterioration is independent predictor of outcome in traumatic brain injury: analysis from National Trauma Data Bank. Am J Emerg Med. 2013;31(8):1215-9.

96- Jennett B, Teasdale G, Braakman R, Minderhoud J, Knill-Jones R. Predicting outcome in individual patients after severe head injury. Lancet. 1976;1(7968):1031-1034.

97- Torbic H, Forni AA, Anger KE, Degrado JR, Greenwood BC. Use of antiepileptics for seizure prophylaxis after traumatic brain injury. Am J Health Syst Pharm. 2013;70(9):759-66.

98- Chang BS, Lowenstein DH. Practice parameter: Antiepileptic drug prophylaxis in severe traumatic brain injury. Neurology. 2003;60(1):10-6.

99- Farahvar A, Gerber LM, Chiu YL, Härtl R, Froelich M, Carney N, et al. Response to intracranial hypertension treatment as a predictor of death in 
patients with severe traumatic brain injury. J Neurosurg. 2011;114(5):14718.

100- Unterberg A, Kiening K, Schmiedek P, Lanksch W. Long-term observations of intracranial pressure after severe head injury. The phenomenon of secondary rise of intracranial pressure. Neurosurgery. 1993;32(1):17-23;

101- Lee TT, Galarza M, Villanueva PA. Diffuse axonal injury (DAI) is not associated with elevated intracranial pressure (ICP). Acta Neurochir (Wien). 1998;140(1):41-6.

102- Haddad S, Aldawood AS, Alferayan A, Russell NA, Tamim HM, Arabi YM. Relationship between intracranial pressure monitoring and outcomes in severe traumatic brain injury patients. Anaesth Intensive Care. 2011;39(6):1043-50.

103- Cremer OL, van Dijk GW, van Wensen E, Brekelmans GJ, Moons $\mathrm{KG}$, Leenen LP, et al. Effect of intracranial pressure monitoring and targeted intensive care on functional outcome after severe head injury. Crit Care Med. 2005;33(10):2207-13.

104- Mauritz W, Steltzer H, Bauer P, Dolanski-Aghamanoukjan L, Metnitz P. Monitoring of intracranial pressure in patients with severe traumatic brain injury: an Austrian prospective multicenter study. Intensive Care Med. 2008;34(7):1208-1215.

105- Stocchetti N, Penny KI, Dearden M, Braakman R, Cohadon F, Iannotti F, Lapierre F, et al. Intensive care management of head-injured patients in Europe: a survey from the European brain injury consortium. Intensive Care Med. 2001;27(2):400-406.

106- Li XY, Feng DF. Diffuse axonal injury: novel insights into detection and treatment. J Clin Neurosci. 2009;16(5):614-9.

107- Selassie AW, Fakhry SM, Ford DW. Population-based study of the risk of in-hospital death after traumatic brain injury: the role of sepsis. $\mathrm{J}$ Trauma. 2011;71(5):1226-34. 
108- Di Saverio S, Gambale G, Coccolini F, Catena F, Giorgini E, Ansaloni L, et al. Changes in the outcomes of severe trauma patients from 15-year experience in a Western European trauma ICU of Emilia Romagna region (1996-2010). A population cross-sectional survey study. Langenbecks Arch Surg. 2014; 399(1):109-26.

109- Manley G, Knudson MM, Morabito D, Damron S, Erickson V, Pitts L. Hypotension, hypoxia, and head injury: frequency, duration, and consequences. Arch Surg. 2001;136(10):1118-23.

110- Griesdale DE, Tremblay MH, McEwen J, Chittock DR. Glucose control and mortality in patients with severe traumatic brain injury. Glucose control and mortality in patients with severe traumatic brain injury. Neurocrit Care. 2009;11(3):311-6.

111- Lv LQ, Hou LJ, Yu MK, Qi XQ, Chen HR, HU GH, et al. Risk factors related to dysautonomia after severe traumatic brain injury. J Trauma. 2011;71(3):538-42.

112- Harrison-Felix C, Kreider SE, Arango-Lasprilla JC, Brown AW, Dijkers MP, Hammond FM, et al. Life expectancy following rehabilitation: a NIDRR traumatic brain injury model systems study. J Head Trauma Rehabil. 2012;27(6):E69-80.

113- Jeremitsky E, Omert L, Dunham CM, Protetch J, Rodriguez A. Harbingers of poor outcome the day after severe brain injury: hypothermia, hypoxia, and hypoperfusion. J Trauma. 2003; 54(2):312-9.

114- Brenner M, Stein DM, Hu PF, Aarabi B, Sheth K, Scalea TM. Traditional systolic blood pressure targets underestimate hypotensioninduced secondary brain injury. J Trauma Acute Care Surg. 2012;72(5):1135-9.

115- Bilotta F, Giovannini F, Caramia R, Rosa G. Glycemia management in neurocritical care patients: a review. J. Neurosurg Anesthesiol. 2009;21(1):2-9.

116- Santos MTS, Siqueira MG, Moraes OJS, Zanon N. Análise prospectiva de fatores prognósticos da lesão axonal difusa: aspectos 
radiológicos. J Bras Neurocirurg. 1998;9(1): 5-8.

117- Yoganandan N, Gennarelli TA, Zhang J, Pintar FA, Takhounts E, Ridella SA. Association of contact loading in diffuse axonal injuries from motor vehicle crashes. J Trauma. 2009; 66(2):309-15.

118- Claassen J, Hansen HC. Early recovery after closed traumatic head injury: Somatosensory evoked potentials and clinical findings. Crit Care Med. 2001;29(3):494 -502.

119- Sbordone RJ, Liter JC, Pettler-Jennings P. Recovery of function following severe traumatic brain injury: a retrospective 10-year follow-up. Brain Inj. 1995;9(3):285-99.

120- Lagares A, Ramos A, Pérez-Nuñez A, Ballenilla F, Alday R, Gómez $\mathrm{PA}$, et al. The role of MR imaging in assessing prognosis after severe and moderate head injury. Acta Neurochir (Wien). 2009;151(4):341-56.

121- Walker WC, Marwitz JH, Wilk AR, Ketchum JM, Hoffman JM, Brown AW, et al. Prediction of headache severity (density and functional impact) after traumatic brain injury: a longitudinal multicenter study. Cephalalgia. 2013;33(12):998-1008.

122- Bushnik T, Englander J, Wright J, Kolakowsky-Hayner SA. Traumatic brain injury with and without late posttraumatic seizures: what are the impacts in the post-acute phase: a NIDRR traumatic brain injury model systems study. J Head Trauma Rehabil. 2012;27(6):E36-44.

123- Li J, Li XY, Feng DF, Pan DC. Biomarkers associated with diffuse traumatic axonal injury: exploring pathogenesis, early diagnosis, and prognosis. J Trauma. 2010;69(6):1610-8.

124- Smith DH, Meaney DF, Shull WH. Diffuse axonal injury in head trauma. J Head Trauma Rehabil. 2003;18(4):307-16.

125- Slazinski T, Johnson MC. Severe diffuse axonal injury in adults and children. J Neurosci Nurs. 1994;26(3):151-4.

126- Calvi MR, Beretta L, Dell'Acqua A, Anzalone N, Licini G, Gemma M. Early prognosis after severe traumatic brain injury with minor or absent 
computed tomography scan lesions. J Trauma. 2011;70(2):447-51.

127- Fabbri A, Servadei F, Marchesini G, Stein SC, Vandelli A. Early predictors of unfavourable outcome in subjects with moderate head injury in the emergency department. J Neurol Neurosurg Psychiatry. 2008;79(5):56773.

128- Sánchez-Olmedo JI, Flores-Cordero JM, Rincón-Ferrari MD, PérezAlé M, Muñoz-Sánchez MA, Domínguez-Roldán JM, et al. Brain death after severe traumatic brain injury: the role of systemic secondary brain insults. Transplant Proc. 2005;37(5):1990-2.

129- Lorente L, Martín MM, González-Rivero AF, Ramos L, Argueso M, Cáceres JJ, et al. Serum soluble CD40 ligand levels are associated with severity and mortality of brain trauma injury patients. Thromb Res. 2014;134(4):832-6.

130- Dantas Filho VP, Falção AL, Sardinha LA, Facure JJ, Araújo S, Terzi RG. Fatores que influenciaram a evolução de 206 pacientes com traumatismo craniencefálico grave. Arq. Neuro-Psiquiatr. 2004;62(2A):313318.

131- Sánchez-Olmedo JI, Flores-Cordero JM, Rincón-Ferrari MD, PérezAlé M, Muñoz-Sánchez MA, Domínguez-Roldán JM, et al. Brain death after severe traumatic brain injury: the role of systemic secondary brain insults. Transplant Proc. 2005;37(5):1990-2.

132- Sekhon MS, McBeth P, Zou J, Qiao L, Kolmodin L, Henderson WR, et al. Association between optic nerve sheath diameter and mortality in patients with severe traumatic brain injury. Neurocrit Care. 2014;21(2):24552.

133- Parchani A, El-Menyar A, Al-Thani H, El-Faramawy A, Zarour A, Asim M, et al. Traumatic subarachnoid hemorrhage due to motor vehicle crash versus fall from height: a 4-year epidemiologic study. World Neurosurg. 2014;82(5):e639-e644.

134- Chi JH, Knudson MM, Vassar MJ, McCarthy MC, Shapiro MB, Mallet S, et al. Prehospital hypoxia affects outcome in patients with 
traumatic brain injury: a prospective multicenter study. J Trauma. 2006;61(5):1134-41.

135- Nogueira LS, Domingues CA, Campos MA, Sousa RMC. Dez anos de new injury severity score (NISS): possível mudança?. Rev. Latino-Am. Enfermagem [online]. 2008;16(2):314-319.

136- Taw BB, Lam AC, Ho FL, Hung KN, Lui WM, Leung GK. Functional survival after acute care for severe head injury at a designated trauma center in Hong Kong. Asian J Surg. 2012;35(3):117-22.

137- Stein DM, Hu PF, Brenner M, Sheth KN, Liu KH, Xiong W, Aarabi B, Scalea TM. Brief episodes of intracranial hypertension and cerebral hypoperfusion are associated with poor functional outcome after severe traumatic brain injury. J Trauma. 2011;71(2):364-73.

138- Wang HC, Wang PM, Lin YJ, Kwan AL, Lin WC, Tsai NW, et al. Serum adhesion molecules, outcome and neuro-psychological function in acute traumatic brain injury patients. Clin Chim Acta. 2013; 423:122-9.

139- Yanagawa Y, Sakamoto T, Takasu A, Okada Y. Relationship between maximum intracranial pressure and traumatic lesions detected by T2*-weighted imaging in diffuse axonal injury. J Trauma. 2009;66(1):1625 . 
Apêndices 


\section{APÊNDICES}

\section{APÊNDICE A}

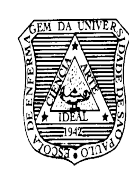

ESCOLA DE ENFERMAGEM DA UNIVERSIDADE DE SÃO PAULO

HOSPITAL DAS CLÍNICAS DA FACULDADE DE MEDICINA DA UNIVERSIDADE DE SÃO PAULO-HCFMUSP

Termo de Consentimento Livre- Esclarecido

DADOS DE IDENTIFICAÇÃO DA VÍTIMA DE LAD OU RESPONSÁVEL LEGAL

1. NOME:

DOCUMENTO DE IDENTIDADE $\mathrm{N}^{\circ}:-\quad$ SEXO : .M $\square$ F $\square$

DATA NASCIMENTO: ___ _ _ _ _

ENDEREÇO:

APTO: _ BAIRRO:_ CIDADE:

CEP: $\quad$ TELEFONE: DDD (

2.FAMILIAR RESPONSÁVEL

NATUREZA (grau de parentesco, tutor, curador etc.): SEXO: $\mathrm{M} \square \mathrm{F} \square$ DATA NASCIMENTO. ENDEREÇO: $\mathrm{N}^{\mathrm{o}}$ :

APTO: BAIRRO:

CIDADE:

CEP: TELEFONE: DDD (

DADOS SOBRE A PESQUISA

1. TÍTULO DO PROTOCOLO DE PESQUISA: RECUPERAÇÃO DAS VÍTIMAS DE LESÃO AXONIAL DIFUSA E FATORES ASSOCIADOS

PESQUISADOR : Rita de Cássia Almeida Vieira

CARGO/FUNÇÃO: Aluna de doutorado da Escola de Enfermagem da Universidade de São Paulo

TELEFONE PARA CONTATO: (11) 964330130 OU (11) $3061-7548$

INSCRIÇÃO CONSELHO REGIONAL Nº: 166680

UNIDADE DO HCFMUSP: Pronto Socorro da Neurocirurgia

3. AVALIAÇÃO DO RISCO DA PESQUISA: RISCO MÍNIMO $\square \mathbf{X} \quad$ RISCO MÉDIO $\square \quad$ RISCO BAIXO $\square$ RISCO MAIOR $\square$

4.DURAÇÃO DA PESQUISA : 1 ano 
Discuti com a enfermeira Rita de Cássia Almeida Vieira sobre minha decisão em participar nesse estudo. Ficam claros para mim quais são os propósitos do estudo, os procedimentos a serem realizados, seus desconfortos e riscos, as garantias de confidencialidade, divulgação dos resultados e de esclarecimentos permanentes. Ficou claro também que minha participação é isenta de despesas e que tenho garantia do acesso a tratamento hospitalar quando necessário. Concordo voluntariamente em participar deste estudo e poderei retirar o meu consentimento a qualquer momento, antes ou durante o mesmo, sem penalidades ou prejuizo ou perda de qualquer beneficio que eu possa ter adquirido, com a participação nesta pesquisa. Estou ciente que 0 documento será elaborado e assinado em duas vias.

Assinatura do paciente ou representante legal Assinatura de testemunha para casos de paciente analfabetos, semianalfabetos, portadores de deficiência visual e auditiva)

Declaro que obtive de forma apropriada e voluntária o Consentimento Livre e Esclarecido deste paciente ou representante legal para a participaç̧ão neste estudo.

Enf Rita de Cássia Almeida Vieira

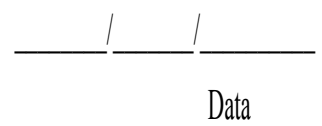




\section{HOSPITAL DAS CLÍNICAS DA FACULDADE DE MEDICINA DA UNIVERSIDADE DE SÃO PAULO - HCFMUSP}

\section{Prezado (a) Senhor (a)}

Você está sendo convidado (a) a participar da pesquisa "RECUPERAÇÃO DAS VÍTIMAS DE LESÃO AXONIAL DIFUSA E FATORES ASSOCIADOS”. Sua colaboração será de muita importância.

Estamos realizando uma pesquisa que tem como objetivo analisar a recuperação de vítimas de trauma com diagnóstico principal de lesão axonial difusa atendidas no Hospital das Clínicas da Universidade de São Paulo.

Para atingirmos nosso objetivo necessitamos que o Senhor (a) responda questões sobre sua capacidade funcional, atividades da vida diária, situação conjugal e retorno a produtividade após o trauma. Sua colaboração será solicitada durante a internação hospitalar e também em duas entrevistas, 3 e 6 meses após o trauma, que poderão ocorrer no ambulatório de trauma do Hospital das Clínicas da Faculdade de Medicina ou em outro local combinado com o pesquisador.

A sua participação é voluntária, sendo garantida a liberdade de não participar ou retirar seu consentimento a qualquer momento, não implicando qualquer prejuízo na continuidade de seu tratamento na Instituição. Você terá o direito de ser mantido atualizado sobre os resultados parciais da pesquisa ou de resultados que sejam de conhecimento dos pesquisadores, caso seja de seu interesse. Todas as informações obtidas serão analisadas em conjunto com as de outros pacientes, sendo garantido que não será divulgada a identificação de nenhum participante. Os pesquisadores firmam o compromisso de divulgar os resultados da pesquisa somente para elaboração de trabalhos científicos

Não haverá despesas pessoais, nem compensação financeira relacionada à sua participação. Neste estudo, você não será submetido a nenhuma intervenção ou procedimento, além daqueles que fazem parte do seu tratamento.

Em qualquer etapa do estudo, o $\operatorname{Sr}(\mathrm{a})$ poderá ter acesso a investigadora para esclarecimentos de dúvidas, a enfermeira Rita de Cássia Almeida Vieira que participará das entrevistas e poderá ser encontrada no endereço Av. Dr. Enéas de Carvalho Aguiar, 419, Departamento ENC, telefone (11) 994330130, email: ritavieira@usp.br ou no Ambulatório de Trauma, às quartas-feiras das 12 as 16 horas.

Acredito ter sido suficientemente esclarecido em relação ao projeto: "Recuperação das vítimas de lesão axonial difusa e fatores associados".

Discuti com a enfermeira Rita de Cássia Almeida Vieira sobre minha decisão em participar nesse estudo. Ficam claros para mim quais são os propósitos do estudo, os procedimentos a serem realizados, seus desconfortos e riscos, as garantias de confidencialidade e de esclarecimentos permanentes. Ficou claro também que minha participação é isenta de despesas e que tenho garantia do acesso a tratamento hospitalar quando necessário. Concordo voluntariamente em participar deste estudo e poderei retirar o meu consentimento a qualquer momento, antes ou durante o mesmo, sem penalidades ou prejuízo ou perda de qualquer benefício que eu possa ter adquirido, com a participação nesta pesquisa. Estou ciente que o documento será elaborado e assinado em duas vias.

DATA:

Assinatura do paciente ou familiar responsável

Declaro que obtive de forma apropriada e voluntária o Consentimento Livre e Esclarecido destes pacientes 


\section{APÊNDICE B}

\section{FICHA DE REGISTRO DE DADOS NA INTERNAÇÃO}

Nome do paciente:

RG HC:

Endereço:

Telefones para contato:

Familiar responsável:

Parentesco:

Idade: Data de Nascimento: Gênero: M( ) F( )

Escolaridade: Data do trauma:

Data da admissão hospitalar: Hora:

Estado conjugal: ( ) solteira ( ) casada （） separada （）viúva Raça: Profissão:

Situação ocupacional: ( ) inserido no mercado de trabalho (empregado ou autônomo)

( ) estudante ( ) do lar

( ) fora do mercado de trabalho (auxílio-doença, aposentado, desempregado, nunca trabalhou)

Renda mensal (familiar): $\mathrm{N}^{\circ}$ de dependentes dessa renda:

Causa Externa:

Acidente de transporte:

( ) pedestre traumatizado ( ) motociclista traumatizado

( ) ocupante de um automóvel traumatizado ( ) ciclista traumatizado

( ) ocupante de uma caminhonete traumatizado

( ) ocupante de um transporte pesado traumatizado

( ) ocupante de um ônibus traumatizado ( ) ocupante de trem traumatizado

\section{Queda}

( ) queda do mesmo nível ( ) queda de outro tipo

( ) Agressão

( ) Lesões autoprovocadas

( Intervenções legais

( ) Eventos cuja intenção é indeterminada

( ) Outros (Especificar) 


\section{CARACTERÍSTICAS RELACIONADAS AO APH}

Atendimento pré-hospitalar: ( ) sim ( ) não qual: $\Delta \mathrm{T}:$

Local do acidente:

ECGl na cena: MRV MRM $\mathrm{AO}$ ( ) S/INF Total:

Intubação (IOT) na cena: ( ) sim ( ) não Sedação: ( ) sim ( ) não ( )S/INF Nome do sedativo:

FR na cena: Pressão na cena: $\mathrm{SpO}_{2}$ na cena:

FC na cena: Pupilas na cena:

Ingestão de álcool: ( ) sim ( ) não ( ) S/inf Outros:

\section{CARACTERÍSTICAS NA ADMISSÃO HOSPITALAR}

ECGl na admissão: MRV MRM $\mathrm{AO}$ ( ) S/INF Total:

Intubação na admissão: ( ) sim ( ) não Sedação na admissão: ( ) sim ( ) não( )S/INF Nome do sedativo:

FR na admissão: PAS na admissão: $\mathrm{SpO}_{2}$ na admissão:

FC na admissão: Pupilas na admissão:

Outros:

Exames na admissão:

$\mathrm{PO} 2$ : Glicemia:

\section{CARACTERÍSTICAS NA INTERNAÇÃO HOSPITALAR}

Internação em UTI: ( ) não ( ) sim Data de internação na UTI:

Data da alta da UTI:

Data de início da sedação: Data da retirada da sedação:

Nome dos sedativos usados na internação:

RASS 24h antes da retirada da sedação:

\section{Escala de Coma de Glasgow (ECGI):}

ECGl após 24h de retirada da sedação: MRV MRM $\mathrm{AO}$ Total:

ECGl após 48h de retirada da sedação: MRV MRM $\mathrm{AO}$ Total:

\section{Duração do coma após a retirada da sedação (dias):}

Definição de Coma: incapacidade de apresentar abertura ocular, pronunciar palavras e obedecer ordens simples (PLUM e POSNER, 1984)

Cirurgia: ( ) $\operatorname{sim}($ ) não Data 


\section{Tipo de Cirurgia:}

Sinais precoces de LAD na TC: ( ) sim ( ) não (TC normal)

Gravidade da LAD: ( ) leve (coma com duração de 6 a 24 horas)

( ) moderada (coma com duração superior a $24 \mathrm{~h}$ com ausência de postura patológica)

( ) grave (coma com duração superior a $24 \mathrm{~h}$ com sinais de comprometimento encefálico- decorticação, decerebração, hipertermia). 
REGISTRO DA DESCRIÇÃO DAS LESÕES E

CÁLCULO DO ISS E NISS

\begin{tabular}{|l|l|l|l|l|l|}
\hline \multicolumn{5}{|c|}{ CÁLCULO DO ISS E NISS } & NISS \\
\hline \multicolumn{1}{|c|}{$\begin{array}{c}\text { Região } \\
\text { Corpórea }\end{array}$} & $\begin{array}{c}\text { Descrição das } \\
\text { lesões }\end{array}$ & $\begin{array}{c}\text { Código } \\
\text { AIS }\end{array}$ & $\begin{array}{c}\text { Gravidade } \\
\text { da lesão }\end{array}$ & ISS & \\
\hline $\begin{array}{l}\text { Cabeça ou } \\
\text { pescoço }\end{array}$ & & & & & \\
\hline Face & & & & & \\
\hline $\begin{array}{l}\text { Total } \\
\text { Extremidades ou } \\
\text { cintura pélvica }\end{array}$ & & & & & \\
\hline $\begin{array}{l}\text { Superfície } \\
\text { externa }\end{array}$ & & & & & \\
\hline conteúdo pélvico & & & & & \\
\end{tabular}




\begin{tabular}{|c|c|c|c|c|c|}
\hline \multicolumn{2}{|c|}{$\begin{array}{l}\text { PACIENTE: } \\
\text { LOCAL DE INTERNAÇÃO: }\end{array}$} & \multicolumn{4}{|c|}{ RGHC: } \\
\hline VARIÁVEIS & Data & Data & Data & Data & Data \\
\hline $\begin{array}{c}\text { Hipotensão } \\
\text { (valores/ PAM) }\end{array}$ & & & & & \\
\hline $\begin{array}{c}\text { Hipertensão } \\
\text { (valores/ PAM) }\end{array}$ & & & & & \\
\hline Hipotermia & & & & & \\
\hline Hipertermia & & & & & \\
\hline Hipoglicemia & & & & & \\
\hline Hiperglicemia & & & & & \\
\hline Crise convulsiva & & & & & \\
\hline $\begin{array}{c}\text { Hipertensão } \\
\text { Intracraniana }\end{array}$ & & & & & \\
\hline Uso da PIC & & & & & \\
\hline $\begin{array}{c}\text { (Total da ECGl) } \\
\text { AO RV RM } \\
\text { Acordou do } \\
\text { coma? }\end{array}$ & & & & & \\
\hline $\begin{array}{c}\text { Medicação do } \\
\text { SNC (S/N) } \\
\text { qual? } \\
\text { 1 Propofol, } \\
2 \text { Fentanil, } \\
3 \text { Midazolan, } \\
4 \text { Precedex, } \\
5 \text { Etomidato, } \\
\text { 6 Succinilcolina } \\
7 \text { Tiopental } \\
8 \text { Diazepan } \\
\text { 9Carbamazepina } \\
\text { 10 Haloperidol } \\
\text { 11 Outra } \\
\end{array}$ & & & & & \\
\hline RASS & & & & & \\
\hline $\begin{array}{l}\text { Cirurgias } \\
\text { Data e Tipo }\end{array}$ & & & & & \\
\hline $\begin{array}{c}\text { Infecção } \\
\text { (sítio/agente } \\
\text { etiológico) }\end{array}$ & & & & & \\
\hline $\begin{array}{c}\text { Outras } \\
\text { complicações: } \\
\text { IRA (diaítica), } \\
\text { rabdomiolise, } \\
\text { sangramento, } \\
\text { Insf Hepática } \\
\text { outas }\end{array}$ & & & & & \\
\hline $\begin{array}{c}\text { Doppler } \\
\text { (Data) }\end{array}$ & & & & & \\
\hline $\begin{array}{c}\text { Óbito }(\mathrm{S} / \mathrm{N}) \\
\text { Data } \\
\text { Causa da morte }\end{array}$ & & & & & \\
\hline
\end{tabular}




\section{APÊNDICE C \\ FICHA DE LEVANTAMENTO DE DADOS NA ALTA HOSPITALAR}

Nome do paciente: RG HC:

Local de internação: Data da alta:

Diagnóstico da lesão:

Destino após alta: ( ) residência própria （ ） residência dos pais

( ) residência de parentes quem?

( ) outro hospital público

( ) hospital privado

( ) outras instituições do HCFMUSP

( ) hospitais de retaguarda e reabilitação

O paciente é capaz de obedecer a comandos simples ou comunicar-se de forma de verbal?

( ) $\operatorname{Sim}$ ( ) Não

Paciente colaborativo e responsivo?

( ) $\operatorname{sim}($ ) não

O senhor (a) é capaz de realizar atividades da vida diária como:

\begin{tabular}{|c|c|}
\hline Tomar banho & $\begin{array}{l}\text { 0- Independente para entrar e sair do banheiro } \\
\text { 1- Necessita de ajuda através do uso órtese ou } \\
\text { algum material para banho } \\
\text { 2- Necessidade de ajuda humana para lavar } \\
\text { algumas partes do corpo } \\
\text { 3- Dependência total para banhar-se }\end{array}$ \\
\hline Vestir-se & $\begin{array}{l}\text { 0- Independente para pegar roupa e se vestir } \\
\text { 1- Necessidade de apoio em algum objeto para se } \\
\text { vestir } \\
\text { 2- Necessidade de ajuda humana no vestir-se } \\
\text { 3- Dependência total para vestir-se }\end{array}$ \\
\hline Cuidar da higiene pessoal & $\begin{array}{l}\text { 0- Independente para ir ao banheiro e se limpar } \\
\text { 1- Necessita de ajuda através do uso órtese ou do } \\
\text { uso regular de papagaio, comadre ou urinol para } \\
\text { higiene } \\
\text { 2- Necessidade de ajuda humana para ir ao } \\
\text { banheiro ou se limpar } \\
\text { 3-Dependência total para higiene }\end{array}$ \\
\hline
\end{tabular}




\begin{tabular}{|c|l|}
\hline Realizar transferência & $\begin{array}{l}0 \text { - Independente para entrar ou sair do leito, sentar } \\
\text { e levantar da cadeira } \\
1-\text { Necessita de ajuda através do uso órtese ou } \\
\text { algum apoio material para a transferência } \\
2-\text { Necessidade de ajuda humana para entrar e sair } \\
\text { do leito, sentar e levantar da cadeira } \\
3-\text { Dependência total para a transferência }\end{array}$ \\
\hline Necessidades urinárias & $\begin{array}{l}0-\text { Independência para controlar os movimentos } \\
\text { intestinais e a urina }\end{array}$ \\
$\begin{array}{l}1-\text { Necessidade de ajuda através do uso regular de } \\
\text { urinol, comadre ou papagaio para controlar micção } \\
\text { e defecação } \\
2-\text { Necessidade de ajuda humana para controlar a } \\
\text { micção ou defecação } \\
3-\text { Dependência total através do uso constante de } \\
\text { cateteres, enemas ou fraldas }\end{array}$ \\
\hline Alimentar-se & $\begin{array}{l}0-\text { Independente para pegar o alimento e levá-lo } \\
\text { até a boca } \\
1-\text { Necessidade de ajuda através do uso de } \\
\text { adaptadores para alimentação } \\
2-\text { Necessidade de ajuda humana para pegar o } \\
\text { alimento e levá-lo até a boca } \\
3-\text { Dependência total para alimentação }\end{array}$ \\
\hline
\end{tabular}

Resultado de Katz:

\section{O Sr (a) consegue realizar as atividades como:}

\begin{tabular}{|l|l|l|l|}
\hline Atividade & $\begin{array}{c}\text { Não necessito de } \\
\text { auxilio }\end{array}$ & $\begin{array}{c}\text { Necessito de algum } \\
\text { auxílio }\end{array}$ & Incapaz \\
\hline 1. Usar o telefone & & & \\
\hline $\begin{array}{l}\text { 2.Caminhar alguma } \\
\text { distância }\end{array}$ & & & \\
\hline $\begin{array}{l}\text { 3.Trabalho } \\
\text { doméstico/manual }\end{array}$ & & & \\
\hline $\begin{array}{l}\text { 4.Tomar a própria } \\
\text { medicação }\end{array}$ & & & \\
\hline $\begin{array}{l}\text { 5. Viajar pequenas } \\
\text { distâncias }\end{array}$ & & & \\
\hline $\begin{array}{l}\text { 6.Dirigir ou utilizar o } \\
\text { transporte público }\end{array}$ & & & \\
\hline
\end{tabular}

Antes de sofrer o acidente o senhor necessitada de auxilio de outra pessoa para realizar as atividades de vida diária?

( ) $\operatorname{Sim}$ ( ) Não 
Antes de sofrer o acidente o senhor necessitada de auxilio de outra pessoa para realizar compras ou cuidar do dinheiro?

( ) $\operatorname{Sim}($ ) Não

Antes de sofrer o acidente o senhor necessitada de auxilio de outra pessoa para realizar pequenas viagens, dirigir ou utilizar o transporte público?

( ) $\operatorname{Sim}($ ) Não

Resultado da ERGA: 


\section{APÊNDICE D \\ FICHA DE LEVANTAMENTO DE DADOS AOS 3 E 6 MESES APÓS A LAD}

Nome do paciente: RG HC:

Local:

Data:

O paciente é capaz de obedecer a comandos simples ou comunicar-se de forma de verbal?

( ) $\operatorname{Sim}($ ) Não

O senhor (a) é capaz de realizar atividades da vida diária como:

\begin{tabular}{|c|c|}
\hline Tomar banho & $\begin{array}{l}\text { 0- Independente para entrar e sair do banheiro } \\
\text { 1- Necessita de ajuda através do uso órtese ou algum material para banho } \\
\text { 2- Necessidade de ajuda humana para lavar algumas partes do corpo } \\
\text { 3- Dependência total para banhar-se }\end{array}$ \\
\hline Vestir-se & $\begin{array}{l}\text { 0- Independente para pegar roupa e se vestir } \\
\text { 1- Necessidade de apoio em algum objeto para se vestir } \\
\text { 2- Necessidade de ajuda humana no vestir-se } \\
\text { 3- Dependência total para vestir-se }\end{array}$ \\
\hline $\begin{array}{c}\text { Cuidar da higiene } \\
\text { pessoal }\end{array}$ & $\begin{array}{l}\text { 0- Independente para ir ao banheiro e se limpar } \\
\text { 1- Necessita de ajuda através do uso órtese ou do uso regular de papagaio, } \\
\text { comadre ou urinol para higiene } \\
\text { 2- Necessidade de ajuda humana para ir ao banheiro ou se limpar } \\
\text { 3- Dependência total para higiene }\end{array}$ \\
\hline $\begin{array}{c}\text { Realizar } \\
\text { transferência }\end{array}$ & $\begin{array}{l}\text { 0- Independente para entrar ou sair do leito, sentar e levantar da cadeira } \\
\text { 1- Necessita de ajuda através do uso órtese ou algum apoio material para a } \\
\text { transferência } \\
\text { 2- Necessidade de ajuda humana para entrar e sair do leito, sentar e levantar } \\
\text { da cadeira } \\
\text { 3- Dependência total para a transferência }\end{array}$ \\
\hline $\begin{array}{l}\text { Necessidades } \\
\text { urinárias }\end{array}$ & $\begin{array}{l}\text { 0- Independência para controlar os movimentos intestinais e a urina } \\
\text { 1- Necessidade de ajuda através do uso regular de urinol, comadre ou } \\
\text { papagaio para controlar micção e defecação } \\
\text { 2- Necessidade de ajuda humana para controlar a micção ou defecação } \\
\text { 3- Dependência total através do uso constante de cateteres, enemas ou fraldas }\end{array}$ \\
\hline Alimentar-se & $\begin{array}{l}\text { 0- Independente para pegar o alimento e levá-lo até a boca } \\
\text { 1- Necessidade de ajuda através do uso de adaptadores para alimentação } \\
\text { 2- Necessidade de ajuda humana para pegar o alimento e levá-lo até a boca } \\
\text { 3- Dependência total para alimentação }\end{array}$ \\
\hline
\end{tabular}

\section{Resultado de Katz:}


O Sr (a) consegue realizar as atividades da vida diária como:

\begin{tabular}{|l|l|l|l|}
\hline Atividade & $\begin{array}{c}\text { Não necessito de } \\
\text { auxilio }\end{array}$ & $\begin{array}{c}\text { Necessito de algum } \\
\text { auxílio }\end{array}$ & Incapaz \\
\hline 1. Usar o telefone & & & \\
\hline $\begin{array}{l}\text { 2.Caminhar alguma } \\
\text { distância }\end{array}$ & & & \\
\hline $\begin{array}{l}\text { 3.Trabalho } \\
\text { doméstico/manual }\end{array}$ & & & \\
\hline $\begin{array}{l}\text { 4.Tomar a própria } \\
\text { medicação }\end{array}$ & & & \\
\hline $\begin{array}{l}\text { 5. Viajar pequenas } \\
\text { distâncias }\end{array}$ & & & \\
\hline $\begin{array}{l}\text { 6.Dirigir ou utilizar o } \\
\text { transporte público }\end{array}$ & & & \\
\hline
\end{tabular}

Antes de sofrer o acidente o senhor necessitada de auxilio de outra pessoa para realizar as atividades de vida diária?

( ) $\operatorname{Sim}$ ( ) Não

Antes de sofrer o acidente o senhor necessitada de auxilio de outra pessoa para realizar compras ou cuidar do dinheiro?

( ) $\operatorname{Sim}($ ) Não

$\mathrm{O} \mathrm{Sr}$ (a) consegue viajar por pequenas distâncias, dirigir ou utilizar transporte público sem assistência de outra pessoa?

( ) $\operatorname{Sim}$ ( ) Não

Antes de sofrer o acidente o senhor necessitada de auxilio de outra pessoa para realizar pequenas viagens, dirigir ou utilizar o transporte público?

( ) $\operatorname{Sim}$ ( ) Não

Você conseguiu retomar as atividades sociais e de lazer regulares fora de casa?

( ) Sim, participo completamente

( ) Sim, participo um pouco menos - metade do tempo

( ) Sim, participo muito menos tempo - menos da metade do tempo

( ) Raramente participo ( ) Não participo

Antes da lesão você costumava a participar de atividades sociais e de lazer regulares fora de casa?

( ) $\operatorname{Sim} \quad(\quad)$ Não 
Resultado da ERGA:

Realização de tratamento com:

( ) Fisioterapia ( ) Terapeuta ocupacional ( ) Psiquiatra ( ) Psicóloga

( ) outra especialidade 


\section{Anexo}




\title{
ANEXO
}

\section{PARECER DE AUTORIZAÇÃO DO COMITÊ DE ÉTICA}

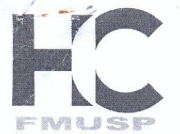

\author{
Hospital das Clínicas da FMUSP
}

Comissão de Ética para Análise de Projetos de Pesquisa - CAPPesq

\section{DADOS DO PROJETO DE PESQUISA}

Título: Recuperação das vítimas de lesão axonial difusa e fatores de risco associados Pesquisador: Rita de Cássia Almeida Vieira Versão: 2

Instituição Proponente: Escola de Enfermagem da Universidade de São Paulo-EEUSP CAAE: 14115513.1 .0000 .5392

Patrocinador Principal: Financiamento Próprio

\section{PARECER CONSUBSTANCIADO DO CEP}

Elaborado pela Instituição Coparticipante

Número do Parecer: 311.774

Data da Relatoria: 19/06/2013

Apresentação do Projeto:. Trata-se de pesquisa de doutorado vinculada ao Programa de Pós Graduação em Saúde do Adulto da EEUSP, sobre a Lesão Axonial Difusa (LAD). Este agravo é uma lesão microscópica dos axônios nos tratos dos hemisférios cerebrais, corpo caloso e tronco cerebral que causa o rompimento do axônio do corpo celular e interrupção do impulso da célula nervosa. A LAD caracterizase por coma durante de seis horas ou mais após o trauma craniencefálico (TCE), excluindo-se os casos de lesões expansivas ou isquêmicas encefálicas. Será realizado um estudo observacional, correlacional, do tipo coorte prospectivo, com abordagem quantitativa. O local da coleta de dados será o Hospital das Clínicas da Faculdade de Medicina da Universidade de São Paulo (HCFMUSP). Para sujeito incluído serão feitas quatro abordagens: durante a internação hospitalar, alta do paciente do hospital, 3 meses e 6 meses após o trauma. São critérios de inclusão: pacientes com diagnóstico de LAD, internados no HCFMUSP no período da coleta de dados; idade maior ou igual a 18 anos; admissão no Hospital até 48 horas após o trauma. Como os familiares relatam mudança de comportamento na recuperação deste tipo de lesão, estes também serão sujeitos do estudo. $O$ familiar poderá ser um membro da família ou alguém que vive junto com a vítima, ou seja, o critério de inclusão é que haja um compromisso ou vínculo familiar próximo entre eles. Durante a internação, serão levantados dados da internação hospitalar, especialmente os relativos à descrição das lesões, índice de religiosidade de Duke, variáveis clínicas e sócio demográficas. No período da alta hospitalar, será preenchida a ficha de levantamento de dados da alta com avaliação da funcionalidade e atividades da vida diária. Nos seguimentos aos três e seis meses após o trauma, será aplicada a ficha de acompanhamento das vítimas, as escalas de funcionalidade, atividades da vida diária e atividades instrumentais da vida diária e índice de religiosidade Duke. Os dados serão analisados com pacotes estatísticos. As perguntas de pesquisa são: 0 padrão de recuperação das vítimas de LAD é similar ao observado nas demais vítimas de TCE? A recuperação das vítimas de LAD está relacionada com as variáveis clínicas e sócio-demográficas? Quais os fatores se associam com a recuperação do doente? Espera-se contribuir para a acumulação de conhecimento sobre a temática, já que há poucos estudos que avaliam a reabilitação das vítimas de LAD. A construção de novos conhecimentos sobre este tipo de lesão e a recuperação dos pacientes poderá contribuir para uma assistência adequada, uma prática clínica baseada em evidências que facilite a reintegração das vítimas de trauma.

Objetivo da Pesquisa:. Descrever a recuperação das vítimas com diagnóstico principal de LAD até seis meses após trauma e identificar fatores clínicos e sócios demográficos associados a essa recuperação, Caracterizar as vítimas com diagnóstico principal de LAD atendidas no Hospital das Clínicas da Universidade de São Paulo, segundo dados clínicos e sócios demográficos; Descrever, na alta hospitalar dessas vítimas, a capacidade funcional pela ERGA e DRS, a AVD por meio das escala de Katz; Relatar a capacidade funcional e a AVD dessas vitimas, após três e seis meses do trauma, utilizando as mesmas

Rua Dr. Ovídio Pires de Campos, 225 - Prédio da Administração - 5o andar CEP 05403-010 - São Paulo - SP.

5511 2661-7585 - 5511 2661-6442 ramais: 16, 17, 18 | marcia.carvalho@hc.fm.usp.br 


\section{Hospital das Clínicas da FMUSP}

Comissão de Ética para Análise de Projetos de Pesquisa - CAPPesq

escalas da alta hospitalar, além de descrever AIVD por meio da escala de Lawton. Comparar os escores da ERGA, DRS, de Katz dos três períodos da recuperação pós-traumática: alta hospitalar, após três e seis meses do trauma e cotejar os escores da escala de Lawton do período de três e seis meses após trauma, Descrever as mudanças comportamentais das vítimas após LAD segundo informações familiares, no período de três e seis meses após o trauma, Identificar os fatores clínicos e sócios demográficos associados à capacidade funcional e atividades da vida diária das vítimas com LAD após seis meses do trauma.

Avaliação dos Riscos e Benefícios: A pesquisa não prevê coleta de material biológico. Serão aplicados instrumentos e escalas com coleta de dados junto aos sujeitos, pacientes e familiares, e no prontuário. 0 risco maior será o desconforto de responder a vários instrumentos, por repetidas vezes, o que pode ser amenizado pelo preparo da equipe em aplicar tais instrumentos com destreza e respeito às peculiaridades de cada momento.

Comentários e Considerações sobre a Pesquisa: A pesquisa é relevante para a enfermagem na saúde do adulto. 0 projeto de pesquisa já foi aprovado pelo CEP da EEUSP.

Considerações sobre os Termos de apresentação obrigatória: Os termos estão adequados e também foram aprovados pelo CEP da EEUSP.

Recomendações: Nenhuma

Conclusões ou Pendências e Lista de Inadequações: Não há pendências

Situação do Parecer: APROVADO

Necessita Apreciação da CONEP: NÃO

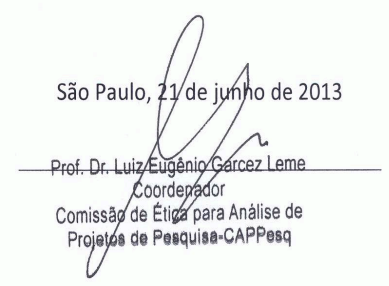

Rua Dr. Ovídio Pires de Campos, 225 - Prédio da Administração - 5 andar CEP 05403-010 - São Paulo - SP.

5511 2661-7585 - 5511 2661-6442 ramais: 16, 17, 18 | marcia.carvalho@hc.fm.usp.br 